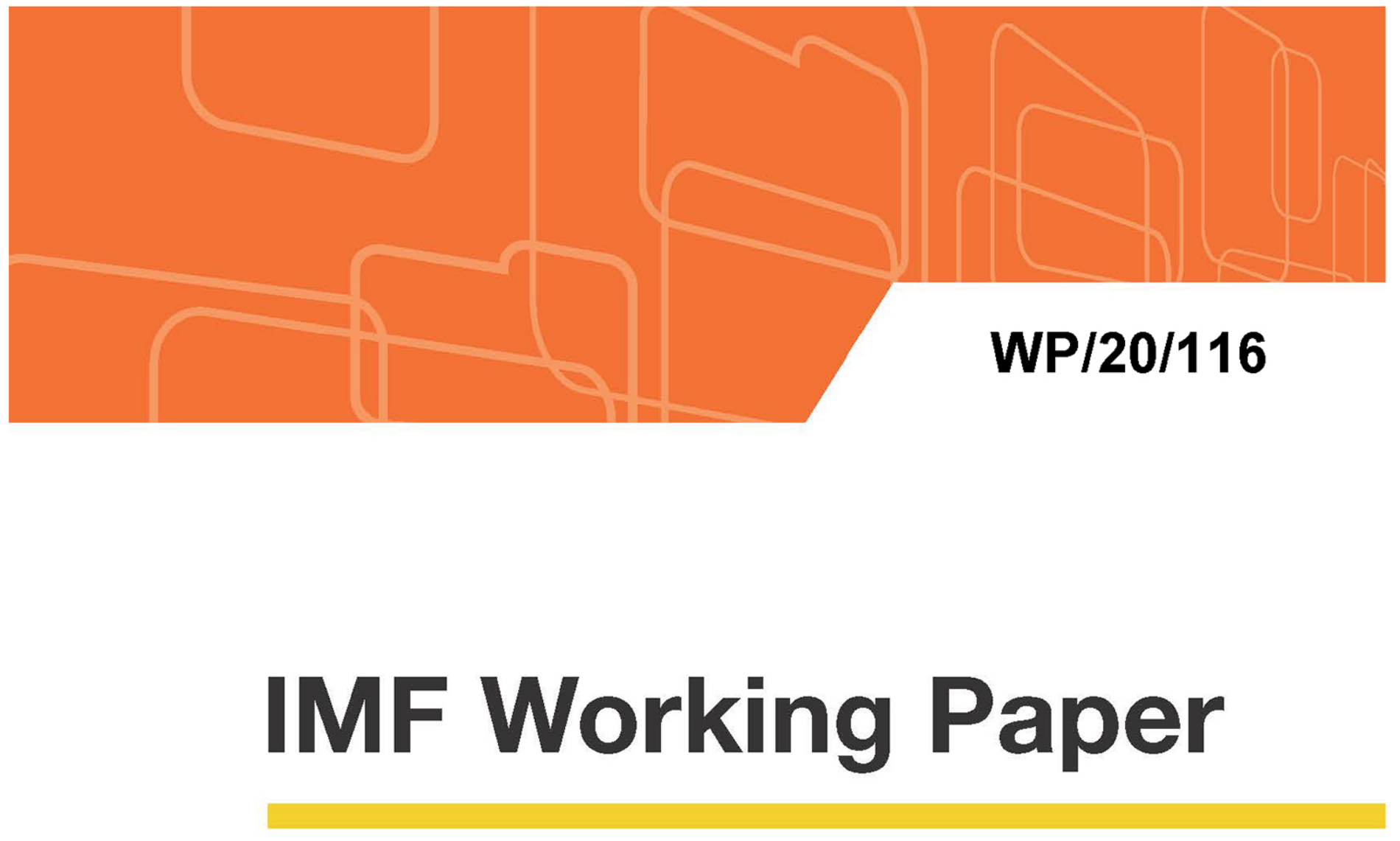

\title{
It is Only Natural: Europe's Low Interest Rates (Trajectory and Drivers)
}

by Marco Arena, Gabriel Di Bella, Alfredo Cuevas, Borja Gracia, Vina Nguyen, and Alex Pienkowski

IMF Working Papers describe research in progress by the author(s) and are published to elicit comments and to encourage debate. The views expressed in IMF Working Papers are those of the author(s) and do not necessarily represent the views of the IMF, its Executive Board, or IMF management. 




\section{It is Only Natural: Europe's Low Interest Rates (Trajectory and Drivers)}

by Marco Arena, Gabriel Di Bella, Alfredo Cuevas, Borja Gracia, Vina Nguyen, and Alex Pienkowski

IMF Working Papers describe research in progress by the author(s) and are published to elicit comments and to encourage debate. The views expressed in IMF Working Papers are those of the author(s) and do not necessarily represent the views of the IMF, its Executive Board, or IMF management. 


\title{
IMF Working Paper
}

\section{European Department}

It Is Only Natural: Europe’s Low Interest Rates (Trajectory and Drivers)

\section{Prepared by Marco Arena, Gabriel Di Bella, Alfredo Cuevas, Borja Gracia, Vina Nguyen, and Alex Pienkowski}

Authorized for distribution by Jörg Decressin

June 2020

Disclaimer: This document was prepared before COVID-19 became a global pandemic and resulted in unprecedented economic strains. It, therefore, does not reflect the implications of these developments and related policy priorities. We direct you to the IMF Covid-19 page that includes staff recommendations with regard to the COVID-19 global outbreak.

\section{IMF Working Papers describe research in progress by the author(s) and are published to} elicit comments and to encourage debate. The views expressed in IMF Working Papers are those of the author(s) and do not necessarily represent the views of the IMF, its Executive Board, or IMF management.

\begin{abstract}
Estimates of the natural interest rate are often useful in the analysis of monetary and other macroeconomic policies. The topic gathered much attention following the great financial crisis and the Euro Area debt crisis due to the uncertainty regarding the timing of monetary policy normalization and the future path of interest rates. Using a sample of European countries (including several members of the Euro Area), this paper provides estimates of country-specific natural interest rates and some of their drivers between 2000 and 2019. In line with the literature, our findings suggest that natural interest rates declined during this period, and despite a rebound in the last few years of it, they have not recovered to their precrisis levels. The paper also discusses the implications of the decline in natural interest rates for monetary conditions and debt sustainability.
\end{abstract}

JEL Classification Numbers: E4, E5, H6, C1

Keywords: Natural interest rate, Neutral interest rate, monetary policy, debt sustainability, Bayesian estimation

Authors’ E-Mail Addresses: MArena@imf.org; GDiBella@imf.org; ACuevas@imf.org; BGracia@imf.org; HNguyen3@imf.org; APienkowski@imf.org; 


\section{Content}

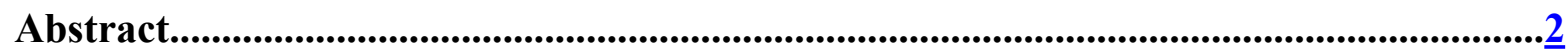

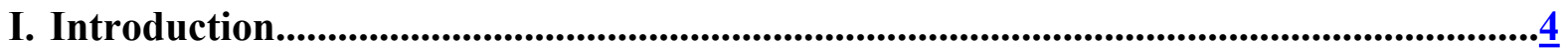

II. The Natural Rate............................................................................................................................... 5

III. Estimation Methodologies and Results.................................................................

IV. Policy Implications....................................................................................................................... 20

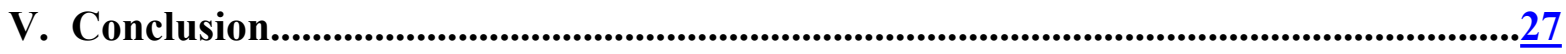

\section{Figures:}

1. Natural Interest Rates with Z Modelled as a Random Walk.................................................10

2. Natural Interest Rates with Z Modelled as a Function of Other Variables..........................13

3. Natural Interest Rate Trend (z) Decomposition...........................................................................14

4. Natural Interest Rates Using Factor Models...........................................................................117

5. Co-movements in $\mathrm{r}^{*}$ and $\mathrm{g}$ in the Euro Area.................................................................18

6. Market Expectations of the Real Rate..................................................................................19

7. Monetary Conditions...............................................................................................................23

8. Monetary Conditions and Fiscal Policy................................................................................25

\section{Annexes:}

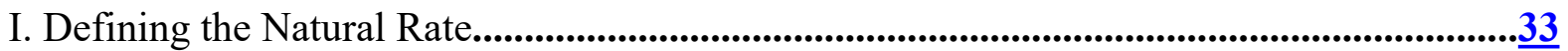

II. Technical Details on the L-W Model....................................................................................36

III. Model Priors: Review of the Literature..........................................................................39

IV. Prior and Posterior Distributions of Parameter and Shock Estimates................................42

V. Technical Details on Factor Models...................................................................................47

VI. Background Figures and Tables....................................................................................52






\section{INTRODUCTION ${ }^{1}$}

The last decade saw a revival in the interest, at both the academic and policy level, in the real natural interest rate, $\mathrm{r}^{*}$. This revival can be explained by the desire to assess the effectiveness of monetary policy in an environment of very low interest rates since the global financial crisis (GFC). And to form a view about the future path of interest rates, including because of their role in shaping public debt dynamics.

The very upheaval in the global economy that stimulated interest in this topic, however, complicates the empirical estimation of $\mathrm{r}^{*}$ and its drivers. The GFC left a legacy of historically low observed real interest rates; but separating cycle from trend in this environment is especially difficult. This adds to the intrinsic statistical uncertainty related to estimating, and even defining, a non-observable variable. This suggests the need to use a variety of analytical approaches (even if this implies subtly different underlying concepts of $\mathrm{r}^{*}$ ) and handling any results with caution. The focus of this paper is on applying a few different approaches to the estimation of $r^{*}$ over the last two decades in a diverse group of European countries (France, Germany, Italy, Lithuania, the Netherlands, Poland, Portugal, Romania, Russia, and Spain). The estimates of $r^{*}$ use easily replicable models, which are flexible enough to be applied to economies with different structures and fundamentals.

The heterogeneity of our sample provides an opportunity to explore some questions related to the determinants of $r^{*}$, such as the role of membership in a currency union, the influence of (often volatile) capital flows, or the different impact of a similar shock on advanced vis-à-vis emerging economies. Our results also help us characterize the stance of monetary policy during periods of interest, such as the run-up to, and the aftermath of the GFC. While the period covered in this study is prior to the COVID-19 crisis, our conclusions on $\mathrm{r}^{*}$ (their country specific level and their determinants) allow us to discuss some factors that may have a bearing on the future level of interest rates, as well as their broad policy implications, including for fiscal sustainability.

All methodologies applied in this paper find a generalized decline in $\mathrm{r}^{*}$ over the last 20 years, particularly in advanced economies. That said, estimates based on economic models that explicitly link $r^{*}$ to developments in the real economy show some partial recovery in recent years, as growth resumed following the crisis. In contrast, statistical models that focus more narrowly on the time series behavior of interest rates show a continuing decline in the natural rate since the end of the crisis. This divergence underscores the uncertainty about the current value of the natural rate and its future path - although none of our estimates points to clear prospects for natural rates increasing.

\footnotetext{
${ }^{1}$ Excellent research assistance by Yuanchen Cai and Boyang Sun is gratefully acknowledged. We also thank Andrea Pescatori, Carolina Osorio Buitron, Vassili Bazinas, and Etienne Vaccaro-Grange for their help with various model codes. We benefited greatly from discussions with, or specific comments from Marco Casiraghi, Mai Dao, Jorg Decressin, Enrica Detragiache, Lucyna Gornicka, Rishi Goyal, Lucy Liu, Meera Louis, Jean Marc Natal, Natalia Novikova, Ara Stepanyan, Marzie Taheri, Sebastian Weber, Jing Zhou, and participants in seminars in IMF European Department and the 2019 IMF Annual Meetings.
} 
Empirical estimates of the difference between the (real) policy rate and $\mathrm{r}^{*}$ (an unobservable variable) can be used to assess the stance of monetary policy in different places and at different times. We find that differences in $\mathrm{r}^{*}$ across countries lead to significant heterogeneity in monetary conditions within the Euro Area during the last two decades, even though these countries operate under a single monetary policy aimed at the Euro Area as a whole. ${ }^{2}$ By the end of our sample, though, monetary conditions were highly accommodative in all Euro Area countries. In emerging Europe, there has been a propensity to pursue procyclical polices (particularly in Russia), largely due to the complicated role of the risk premium. More generally, a persistently low $\mathrm{r}^{*}$ across Europe, and notably in the Euro Area, suggested that unconventional monetary policies (UMPs) may become much more conventional in the future. In terms of fiscal policy, a lower $r^{*}$ does provide some fiscal space on public sector balance sheets - some of which was already being used by several countries by the end of our sample period. But declining potential growth towards the end of this period and already high debt in many countries suggested that country authorities needed to be cautious about accumulating more debt.

The remainder of this paper is organized as follows. Section II discusses common definitions of the natural interest rate, issues related with its measurement, and elements to consider in advanced and emerging economies. Section III presents the methodologies we use to estimate natural rates, and our results. Section IV discusses policy implications, and Section $\mathrm{V}$ concludes.

\section{The Natural Rate}

The natural (or neutral, as it is also often called) rate of interest, $\mathrm{r}^{*}$, like potential output or the non-accelerating inflation rate of unemployment (NAIRU), is an unobservable variable. There are many definitions of $r^{*}$ beginning with Wicksell's in the late XIX century. These definitions typically refer to some idea of equilibrium. But they may differ in important details such as the specific equilibrium conditions one has in mind (including, importantly, for the behavior of prices or inflation), the stability of such an equilibrium, the emphasis placed on dynamics outside equilibrium, the weight placed on supply- or demand-side factors, and the time horizon under consideration. These differences make it easy for two economists to use the same term, "natural rate," while referring to subtly different ideas (see Annex I).

In this paper, $\mathrm{r}^{*}$ is defined as the rate that maintains an economy in equilibrium if it starts there and does not interfere with the autonomous return to equilibrium of an economy initially in disequilibrium. This notion includes the common definition of $r^{*}$ as the real interest rate that would prevail if the output gap were closed and inflation stable. Our view of

\footnotetext{
${ }^{2}$ Among the Euro Area countries in our sample, Lithuania was not a founding member of the EMU, which it joined on January 1, 2015. However, since February 2002, Lithuania pegged its currency to the euro in the context of the ERM II, operating a currency board framework and allowing the use of the euro in settlement of transactions in its territory. For this reason, it is treated as a Euro Area country in this paper.
} 
the natural rate admits variation in the near term in response to changing conditions in the real economy, but also can be expected to settle around some central value (or trajectory) in the longer term - a value that will be related to the steady state rate of growth of the economy. This will become clearer in the following section, as we present the models used in estimation.

\section{Estimating $r *$ Empirically}

We assume that $\mathrm{r}^{*}$ is a short-run interest rate, such as the overnight rate or the 3-month government bill rate. This is consistent with a large part of the literature, which typically looks for the "natural" level r* of some real short-term rate $r$, such as the (properly deflated) rate on short term government debt instruments or the inter-bank overnight interest rate. In some papers, especially those focusing on reserve currency issuers (the U.S., U.K., Japan and the Euro Area), $\mathrm{r}^{*}$ is associated to the idea of a risk-free rate, often that of government bill or the central bank policy rate. Importantly, in such contexts, $r^{*}$ cannot be viewed as the average return on capital in an economy, which typically includes credit and duration risk. As noted by Brand et al (2018), while the real return on capital has been stable or rising in the Euro Area, most measures of $r^{*}$ have been declining. They attribute this divergence to rising risk aversion or higher profit margins, among other factors.

\section{Capital Account and Other Considerations}

In an economy with an open capital account, $\mathrm{r}^{*}$ should also ensure the no-arbitrage condition between real returns on domestic and foreign assets (real uncovered interest parity). Thus, this concept also includes equilibrium in the capital account. In fact, the view of $r^{*}$ as riskfree is less plausible when considering non-reserve currency issuers with an open capital account. In such cases, domestic currency-denominated securities are typically subject to significant exchange rate risk, as resident and non-resident economic agents change their portfolio composition as a response to news signaling, for instance, a more likely appreciation (or depreciation) of the real exchange rate. Indeed, an open capital account in a small economy gives rise to new problems in defining an equilibrium interest rate. ${ }^{3}$ In such a context, lower policy rates may not be available to stimulate a weak economy if economic agents are re-pricing domestic risk. In fact, this is a trade-off faced frequently by policymakers in emerging markets (Rey, 2015). If policy rates are permanently high because of these considerations, then the corresponding $r^{*}$ should be also permanently elevated. This means that real exchange rate uncertainty and country risk premia can push the natural rate upwards in emerging economies, as capital mobility ensures that risk-adjusted real returns are arbitraged. This trade-off is explored empirically in Section III, where we discuss emerging market countries with currencies of their own.

\footnotetext{
${ }^{3}$ Different real exchange rate levels may also bring about the possibility of default and currency inconvertibility, among other factors, which further complicates the definition of equilibrium interest rates in emerging economies.
} 


\section{Natural Rates in a Currency Union}

Considering $r^{*}$ in a currency union also raises interesting conceptual issues. A general assumption in theoretical models is that in the long-term monetary variables should not affect real variables such as potential growth or $\mathrm{r}^{*}$. Thus, in principle, $\mathrm{r}^{*}$ could differ among the members of a currency union if they are subject to asymmetric (domestic and external) shocks, even though they are subjected to a single monetary policy aimed at attaining a given inflation target in the union as a whole. Similarly, a monetary union should not necessarily accelerate convergence, except to the extent that it pushes factors of production to become more homogenous, substitutable and mobile. Again, there need not be a common equilibrium $r^{*}$ within a currency union. In the face of heterogeneous $r^{*}$ rates, a common monetary policy will result in different monetary conditions in each member state, possibly during long periods of time. That said, it is possible to expect some $\mathrm{r}^{*}$ co-movements in countries that belong to monetary union; such co-movements could change over time, an issue that we explore later in the paper.

\section{ESTIMATION METHODOLOGIES AND RESUltS}

A consensus exists that there was a global decline in $\mathrm{r}^{*}$ over the last two decades (Summers, 2014; Holston et al, 2017; Brand et al, 2018 and Del Negro et al, 2019). Rachel and Smith (2015) document a decline in the global long-term r* of around $450 \mathrm{bps}$ since $1980 .{ }^{4}$ They argue that this decline is difficult to explain only by changes in global growth (to which changes in $\mathrm{r}^{*}$ are usually thought to be related), and that shifts in saving and investment preferences have played an important role. In their view, negative demographic forces, higher inequality within countries, and increased desired savings by emerging market governments have increased desired saving. And a decline in the relative price of capital, lower public investment projects, and the increasing spread between the rate of return on capital and the risk-free rate, have reduced desired investment. In this section we apply a variety of methodologies to produce specific estimates for a sample of European countries, both inside and outside the Euro Area, that speak to these issues.

\section{The Laubach-Williams Model and its Variants}

The seminal Laubach and Williams (2003) model (L-W model) is the benchmark framework to estimate $\mathrm{r}^{*}$. In this model, $\mathrm{r}^{*}$ is allowed to vary from one period to the next in response to shocks that take place at short term frequencies. The resulting estimates reflect a tension between demand and supply side considerations, represented by equations that capture demand behavior and the fundamental linkage between $r^{*}$ and potential growth, as well as a Phillips curve, allowing the simultaneous estimation of $\mathrm{r}^{*}$ and potential growth ( $\mathrm{g}$ ) from observable data using a Kalman filter. This framework is often viewed as producing a

\footnotetext{
${ }^{4}$ Magud and Tsounta (2012) find that the natural rate of interest has declined in many Latin American countries over the last decade.
} 
medium-term equilibrium estimates, because $\mathrm{r}^{*}$ is modeled as influenced by factors that change relatively slowly. The original L-W model was calibrated to fit the US economic data; a more recent version can be found in Holston et al. (2016), which covers more countries. What follows is a summary of the model (more details in Annex II).

The model has a backward-looking IS-Curve that relates the current value of the output gap $\left(\tilde{y}_{t}\right)$ to its own lags, and to the difference between the prevailing real interest rates and the natural level $\left(r_{t}-r_{t}^{*}\right)$ :

$\tilde{y}_{t}=\alpha_{1} \tilde{y}_{t-1}-\alpha_{2}\left(r_{t}-r_{t}^{*}\right)+\varepsilon_{t}^{y}$

In expression (1), the prevailing real rate $\left(r_{t}\right)$ is assumed to be exogenous to the framework in the short run. In other words, $r_{t}$ is assumed as policy determined, without explicitly modeling a policy reaction function, and to be equal to the difference between the nominal policy rate $\left(i_{t}\right)$ and one-year ahead (country specific) inflation expectations $\left(\pi_{t+1}^{e}\right)$, while $\varepsilon_{t}^{y}$ is a random shock. Expression (1) suggests that the estimated evolution of the output gap over time, together with the observed path of the real interest rates, can be used to infer something about the trajectory of the natural rate $r_{t}^{*} .^{5}$

As usual, the output gap is equal to the difference between $(\log )$ realized real output $\left(y_{t}\right)$ and its potential $\left(y_{t}^{N}\right)$, with the change in the latter assumed to be driven by trend growth $\left(g_{t}\right)$ and a random i.i.d. shock $\left(\varepsilon_{t}^{N}\right)$ :

$y_{t}^{N}=y_{t-1}^{N}+g_{t}+\varepsilon_{t}^{N}$,

In turn, $g_{t}$ is modeled as a random walk with innovations $\varepsilon_{t}^{g}$ :

$g_{t}=g_{t-1}+\varepsilon_{t}^{g}$

The model also includes an open-economy backward looking Phillips Curve relating inflation $\left(\pi_{t}\right)$ to its own lag, to $\tilde{y}_{t}$ and to import price inflation $\pi_{t}^{m}$ :

$\pi_{t}=\beta_{1} \pi_{t-1}+\beta_{2} \tilde{y}_{t-1}+\beta_{3} \pi_{t-1}^{m}+\varepsilon_{t}^{\pi}$

where $\pi_{t}^{m}$ is assumed to be exogenous and $\varepsilon_{t}^{\pi}$ is an i.i.d. shock.

\footnotetext{
${ }^{5}$ As $r_{t}^{*}$ is proxied by a short-term interest rate, the estimation using expression (1) (IS curve) assumes that equilibrium in the goods market can be achieved by changing, say, the three-month interest rate. However, this may not be the case, as in protracted financial crisis where lower interest rates may be needed along the yield curve.
} 
The model imposes a linear relationship between natural rates and potential output growth, capturing the theoretical idea that they share some of their main drivers; that is, $\mathrm{r}^{*}$ is allowed to reflect supply side developments. But the specification permits the paths of trend growth and $\mathrm{r}^{*}$ to diverge. In this simple setting, the determinants of $r_{t}^{*}$ are trend growth, $g_{t}$, and an exogenous process, $z_{t}$, capturing other possible determinants of $r^{*}$ which may create a wedge over time between $\mathrm{r}^{*}$ and $\mathrm{g}$. Trend growth and $\mathrm{r}^{*}$ are linked by a constant, $c>0$.

$r_{t}^{*}=c g_{t}+z_{t}$

In the simplest version of this model, $z_{t}$ follows a random walk with iid shocks $\left(\varepsilon_{t}^{Z}\right) \cdot{ }^{6}$ As it follows from expressions $1-5$, this framework does not directly allow monetary policy to explain the behavior of the natural interest rate.

We follow Pescatori and Turunen (2015) and estimate the model parameters using Bayesian techniques. This choice allows to circumvent the "pile-up" problem in classical inference and gives the analyst some additional control over the estimation procedure. ${ }^{7}$ In particular, the prior assumptions on the variance of the error terms on $\varepsilon_{t}^{N}, \varepsilon_{t}^{y}$ and $\varepsilon_{t}^{g}$ are important, as they influence how the variance of $\mathrm{r}^{*}$ responds to (the level and trend) shocks to potential growth and to the unexplained component, $z_{t}$. In other words, they influence how closely the estimated $r^{*}$ follows estimates of g. ${ }^{8}$ In addition, we will try different variations of the specification for the term $z_{t}$ in expression (5), starting with a random walk and moving to more complex but potentially more economically interesting specifications. Others in the literature have followed similar approaches (Laubach and Williams (2003) and (2016); Lewis and Vazquez-Grande (2017), Holston et al (2017), among others), facilitating the comparison between their results and ours. ${ }^{9}$

Figure 1 shows our first set of estimates (specifying $z_{t}$ as a random walk) for both Euro Area countries and emerging Europe. Our results suggest that $r^{*}$ declined over the last two decades

\footnotetext{
${ }^{6}$ As part of the estimation process, the output gap found in expressions (1) and (4) would typically be estimated with the rest of the unobserved variables in the model. An alternative is to consider as "data" a measure of the output gap estimated outside the L-W framework, treating it as a noisy signal of the endogenously determined output gap. When estimating $\mathrm{r}^{*}$ below, we will use output gaps estimated by IMF desk economists and reported in the World Economic Outlook (WEO) as an additional signal to estimate our own output gap in the Laubach and Williams framework. See Annex II.

${ }^{7}$ The "pile-up" problem affects inference around unit roots. In the L-W framework, the "pile-up" problem arises in the estimation of trend growth and exogenous factor variances, because the variation of the trend component is much smaller than that of the cyclical component, making the trend variance estimate to be biased towards zero. With Bayesian methods, the pile-up problem of inference around unit roots is not as severe. However, the role of the priors and the assumed covariance structure of the exogenous shocks is magnified in the presence of unit roots (see Stock (1991)).

${ }^{8}$ Annex III describe the implications of these priors for the level and volatility of $\mathrm{r}^{*}$ estimates.

${ }^{9}$ Beyer and Wieland (2017) or Mésonnier and Renne (2007) highlight that the random walk assumption for $z_{t}$ leads to very unstable results. Like Pescatori and Turunen (2015) and Hakkio and Smith (2017), we include some economic drivers of $z_{t}$ in a stationary process.
} 
in virtually all countries in our sample, both in the Euro Area and outside, with some modest recovery post-Euro Area Debt Crisis (2012). As the Figure 1 (and those in Annex VI) suggests, both natural rates and potential growth rates have fallen relative to the early $2000 \mathrm{~s}$ in most places, despite some recovery in the last several years (Germany seems an exception, with a remarkably stable estimated potential growth). But $r *$ typically fell more markedly than potential growth in the course of the last two decades, particularly after the GFC. For Euro Area countries, the average decline in $\mathrm{r}^{*}$ was 2 percentage points since 2000, with $\mathrm{r}^{*}$ estimated at a value of around zero in 2019:Q1. For emerging Europe there is also a decline in $\mathrm{r}^{*}$, which is larger in Russia (around 4 percentage points) compared to that in Romania and Poland (around 1 percentage point) since the early 2000s. The part of the decline in $\mathrm{r}^{*}$ that seems to be explained by the fall in $g$ is generally smaller in Euro Area countries than in emerging economies; in this regard, Russia stands out for having the largest decline in $r^{*}$ combined with the closest linkage to a change in $\mathrm{g}$.




These estimates suggest that the decline in natural rates cannot be attributed to the slowdown in trend growth alone, especially post-GFC. ${ }^{10}$ Annex VI shows the decomposition of $r^{*}$ between trend growth and $z_{t}$ for all countries in our sample, and Figure 1 above includes one advanced economy and one emerging market for illustration purposes. The decline in $r^{*}$ in most Euro Area countries in our sample before the GFC seems to have been driven by weakening trend growth to a large extent, but not fully. After the GFC, however, trend growth picks up somewhat, but $r *$ continues to fall, at least for a while, opening a wide wedge between $\mathrm{r}^{*}$ and $\mathrm{g} .{ }^{11}$ This points to an increasing role of other factors in determining $\mathrm{r}^{*}$ (summarized by $z_{t}$ ). Indeed, for most Euro Area countries in our sample, around half of the overall estimated decline in $\mathrm{r}^{*}$ since the GFC can be attributed to the behavior of the unexplained component, $z_{t}$. In Portugal and Spain, the importance of this $\mathrm{z}$ component is the largest, with the wedge between $r^{*}$ and $g$ rising to 3-4 percentage points around the time of the Euro Area Debt Crisis. ${ }^{12}$ In recent years, $\mathrm{r}^{*}$ has picked up somewhat, seemingly spurred by the recovery in potential growth.

For emerging Europe, the association between $r^{*}$ and $g$ seems stronger than in the Euro Area, although there is a moderately increasing wedge between $r^{*}$ and $g$ after the GFC in Poland and Romania. In the case of Russia, we estimate a value for $r^{*}$ of around 2 percent in early 2019 , broadly similar to our estimate for trend growth. These estimates are not far from those in Kreptsev et al. (2016) and are also broadly similar to those estimated by the Central Bank of Russia's (CBR) (2-3 percent). In the case of Poland, $z_{t}$ contributes negatively to $\mathrm{r}^{*}$ with its value increasing from about zero in the early 2000s to about 1 percentage point (in absolute terms) by early 2019, with most of that increase occurring during and after the GFC.

But what could account for the wedge between $\mathrm{r}^{*}$ and $\mathrm{g}$ ? What economic factors might be behind the estimated trajectories of $z_{t}$ ? To explore this unexplained component, we model $z_{t}$ as a function of some economic variables and autoregressive terms which seem justified by the rather persistent behavior of $z_{t}$ in our initial estimates. As the economies in our sample are open, the explanatory variables that we add aim to reflect external factors. Concretely, for the Euro Area we assume a process for $z_{t}$ of the following form:

\footnotetext{
${ }^{10}$ Our results refer to the median estimates for $\mathrm{r}^{*}$ at each point. The distribution around the median for all countries are available upon request.

11 The estimate of the coefficient $c$ in the expression for $r^{*}$ is around unity, which makes it possible to loosely refer to $z_{t}$ as wedge the between $\mathrm{r}^{*}$ and $\mathrm{g}$.

${ }^{12}$ Spain's $r^{*}$ in Figure 1 shows a somewhat atypical behavior, especially in the two years before the GFC, when it rises. This might reflect the positive and increasing output gap estimated in the WEO, which would have called for tighter monetary conditions at the time. The dip following the euro area is pronounced, but not atypical. In contrast with our results, Brand et al. (2018) showed that Spain's r* declined from about 2.0-2.5 percent before the crisis to about -0.2 percent during the European debt crisis. Fries et a. (2017) found that the $\mathrm{r}^{*}$ for Spain dropped to about -1.5 percent during the crises.
} 
$z_{t}=\delta_{1} z_{t-1}+\delta_{2} z_{t-2}+\delta_{c} \Delta R E E R_{t}+\delta_{p} E D_{t}+\delta_{e} \Delta$ spread $_{t}+\varepsilon_{t}^{Z}$

where $\triangle R E E R_{t}$ is the difference between the actual level of the REER and its trend, $E D_{t}$ is trading partner growth representing external demand, and spread $_{t}$ is the difference between the 10-year country's government yield relative to Germany's 10-year government yield (for Germany we use Credit Default Swaps, CDS). ${ }^{13}$ While the first two are designed to reflect the influence of the current account, the spreads can be seen both as a measure of risk and as a proxy for the influence of the capital account on domestic conditions.

For emerging Europe, we use the following specification:

$z_{t}=\delta_{1} z_{t-1}+\delta_{2} z_{t-2}+\delta_{c} \Delta U S_{t}+\delta_{p} \Delta \mathrm{EMBI}_{t}+\delta_{e} \Delta$ polunc $_{t}+\varepsilon_{t}^{z}$

where $\Delta U S_{t}$ refers to 10 -year Treasury Bond yield at constant maturity deflated by the expected inflation rate, $\triangle E M B I_{t}$ is the Emerging Market Bond Index spread (EMBI, which is usually understood to represent country risk), and $\Delta$ polunc $_{t}$ refers to the news-based index of economic policy uncertainty developed in Baker, Bloom, and Davis (2016). In emerging Europe, short-term REER fluctuations should be associated with both changes in economic policy uncertainty, which affect international financial flows, and with changes in the terms of trade, which affect the current account. ${ }^{14}$

The inclusion of these additional factors increases the volatility of our $\mathrm{r}^{*}$ estimates for Euro Area countries (Figure 2 and Annex VI.2). In particular, the drops in r* in 2009 and 2012 are steeper, and the subsequent recoveries are also more pronounced. However, the estimated overall decrease in $\mathrm{r}^{*}$ over the last two decades is broadly similar regardless of how we model $z_{t}$ (See Annex VI), and large residuals remain in some cases. The fact that the latest estimates of $\mathrm{r}^{*}$ are broadly similar no matter whether $z_{t}$ is modelled as in equation (6) or not may suggest that domestic conditions (possibly related to factors that had a lasting impact in the second decade of this century, such as dealing with debt overhangs in the private and public sectors) play a strong role.

Broadly speaking, these results are also consistent with other estimates in the literature. Brand el al (2018) bring together several estimates of $r^{*}$ for the entire Euro Area. These estimates are concentrated between 0 and -1percent, which encompasses our estimate of individual Euro Area countries (except Lithuania). Fries et al (2017) jointly estimate r* for

\footnotetext{
${ }^{13}$ Pescatori and Turunen (2015) use similar specifications to model $z_{t}$.

${ }^{14}$ Since the country-specific policy uncertainty index is not available for Poland and Romania, we use the European policy-related economic uncertainty for these countries. In addition, we have also run an alternative specification that replaces such index with the REER. To gain intuition how the REER or policy uncertainty may change the level of the natural rate, consider an economy that is subject to persistent shocks to its terms of trade, resulting in domestic consumption volatility and potentially affecting sovereign payments (i.e., affecting policy uncertainty). In such a case, the covariance between consumption and the REER would be negative, prompting a positive wedge between expected real returns of domestic-denominated instruments and those of foreign interest rates, which covariate much less with domestic consumption.
} 
Spain, Italy, France, and Germany. Their estimates show much closer co-movement between the economies, but they also find a similar magnitude in the decline of $r^{*}$ over the last two decades, and find $\mathrm{r}^{*}$ to be close to zero as of end-2017.

Figure 2. Natural Interest Rates with Z Modelled as a Function of Other Variables ${ }^{1 /}$
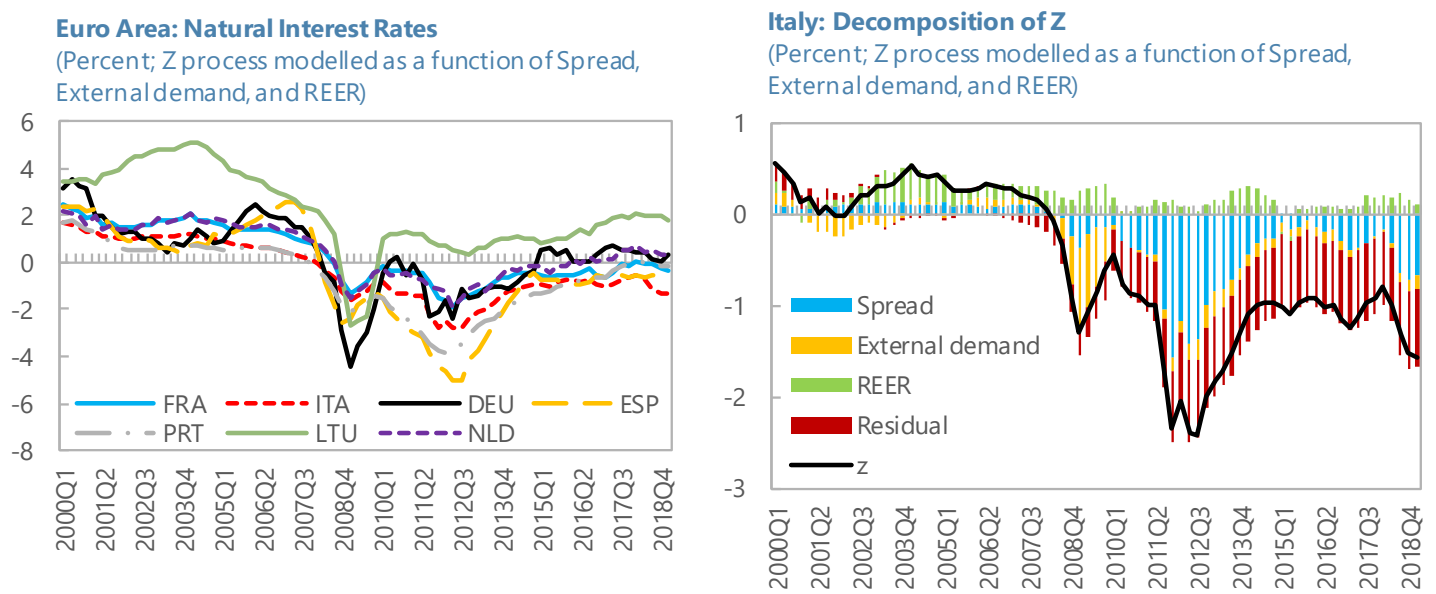

Emerging Europe: Natural Interest Rates

(Percent; Z process modelled as a function of EMBI, US rate, and Policy uncertainty)

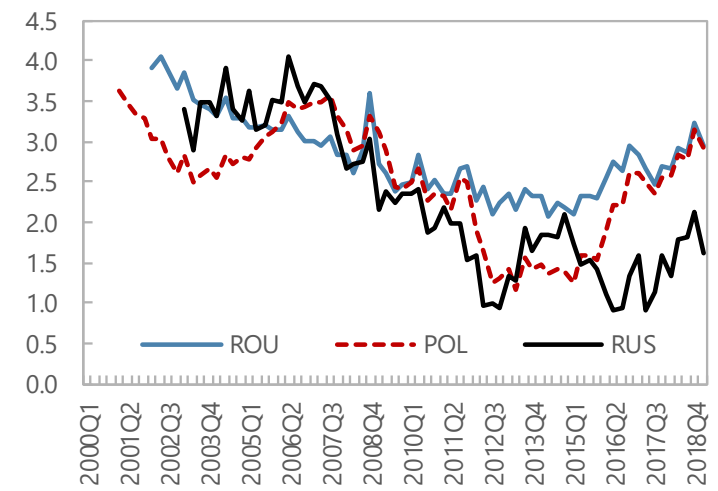

Russia: Decomposition of Z

(Percent; Z process modelled as a function of EMBI, US rate, and Policy uncertainty)

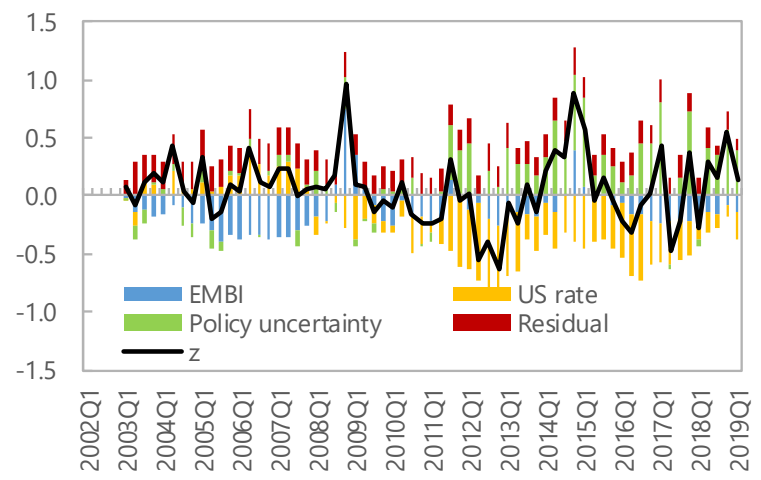

Sources: Authors' calculations.

$1 /$ The contribution of the explanatory variables shows the cumulative contribution over three quarters as each variable and the $z$ process are assumed to follow an AR(2) process. The residual includes the shock to $z$ this period and the lagged residual from the past two quarters.

Looking more closely, our results also suggest that variations in spreads have been at times responsible for large movements in $r^{*}$ in some Euro Area countries. Take Lithuania and Italy for example (Figure 3). In 2009 at the lowest point in Lithuania's recession, the credit crunch (as proxied by the sharp rise in spreads), contributed to a fall in $r^{*}$ of 2 percentage points. 
That is, a much lower real interest rate would have been needed to achieve a closed output gap and stable inflation in those stressed circumstances. The improvement in fundamentals that followed this period allowed Lithuania to avoid significant spillovers from the Euro Area debt crisis and resulted in a dramatic improvement in credit conditions. In turn, Italy saw a deep fall in $\mathrm{r}^{*}$ associated with worsening spreads, driven by heightened uncertainty around debt sustainability at the height of the Euro Area Debt Crisis, as well as a smaller deterioration in recent quarters. Annex VI shows similar developments in Portugal and Spain. Moreover, Figure 3 (and Annex VI) show that while REER changes do not explain much of $z_{t}$ in most Euro Area countries, external demand changes appear to result in sharp declines in $\mathrm{r}^{*}$ during the GFC, especially for export-oriented economies like Germany or the Netherlands. In these countries, the collapse in external demand in 2009 resulted in a 3 percentage point decline in $\mathrm{r}^{*}$, later reversed as external demand rebounded, illustrating the volatility of $\mathrm{r}^{*}$ and its sensitivity to external shocks.

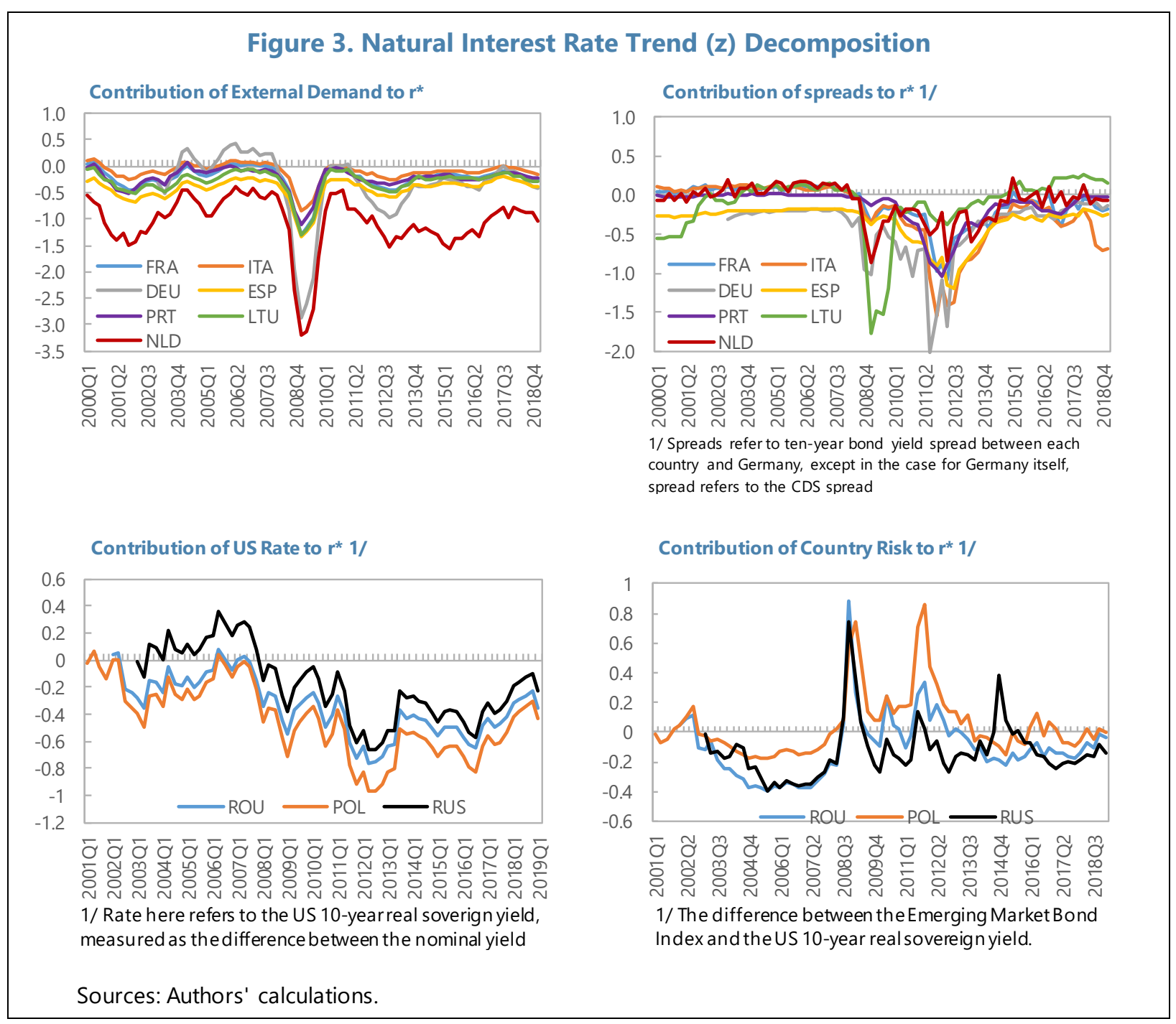


As noted, even after we model $z_{t}$ as a function of economic variables, there remains a relatively large unexplained component of $r^{*}$ for most Euro Area countries (Figure 2 and Annex VI). This may reflect a common factor influencing r* (Jordà and Taylor, 2019), coupled with country-specific factors. These could include fiscal shocks (Rachel and Summers, 2019), the slow deleveraging process following the GFC, and financial cycles (Belke and Klose, 2018; Borio et al, 2019). In addition, a growing body of literature discusses the importance of demographics. Brand et al. (2018) and Bielecki et al. (2018) emphasize the role of demographic trends, which could extend beyond their impact on growth itself. Depending on which of these factors are thought to be most relevant, one's view of the future path of interest rates may be affected. For example, if one thinks that the unexplained part of $z_{t}$ (and $\mathrm{r}^{*}$ ) reflects the protracted deleveraging process, there may be room for the wedge between $r^{*}$ and $g$ to diminish further over time (testing this conjecture, however, remains part of the agenda for future work).

As in the Euro Area countries, $\mathrm{r}^{*}$ estimates for emerging Europe are more volatile when modeling $z_{t}$ as a function of economic variables. The volatility of $\mathrm{r}^{*}$ increases following global shocks affecting Emerging Economies (like the "taper tantrum"), or country-specific shocks (like the dual shock of western sanctions and lower oil prices for Russia in 201415). ${ }^{15}$ A decomposition of the exogenous variables affecting $r^{*}$ shows that effects from the decline in the U.S. long-term interest rate have pushed $r^{*}$ downwards, while increases in country risk premium (as measured by the EMBI) pushed $r^{*}$ upwards. This impact on $r^{*}$ of changes in the EMBI is in contrast with the impact of changes in the 10-year spread in Euro Area countries such as Portugal or Spain. This reflects in part deliberate choices in the empirical implementation of the model and should thus be taken with some caution (see the prior distributions of the relevant parameters in annex IV). A motivation for these choices is the role of interest rates in affecting external equilibrium in an emerging economy with a currency of its own. In addition, the use of specification (9) in the case of Russia shows that the negative impact on $r^{*}$ of decreases in global interest rates and reductions in country risk has been more than offset by increases in the perception of economic policy uncertainty, which explains a large part of $z_{t}$ (see Figure 2 and Annex VI). In turn, considering the REER instead of policy uncertainty suggests that the contribution of the former to $r^{*}$ is small, which may be reflecting a correlation of the exchange rate with the other variables in the equation (U.S. rate and EMBI).

\section{Factor Models}

In the previous section we estimated models that drew indirect inferences about $r^{*}$ from real developments. As it were, these models look for $r^{*}$ by assuming it must help influence the evolution of output gaps and must be in turn influenced by potential growth. But these "real variables" are themselves subject to uncertain estimation, as we do not directly observe potential growth and output gaps. For this reason, it seems useful to complement the analysis

\footnotetext{
${ }^{15}$ The increased volatility discussed in the text is also reflected in a wider distribution of $\mathrm{r}^{*}$, making the median $r^{*}$ a more uncertain policy reference.
} 
by using approaches that more directly look at interest rates to make inferences about $\mathrm{r}^{*}$. In this logic, financial market data can be used to extract information about $\mathrm{r}^{*}$. Factor models assume that the real interest rate should fluctuate around $r^{*}$ and that the difference between them approaches zero as real and nominal shocks dissipate through time. Although these models are agnostic about the economic drivers of natural rates, they can offer a useful set of estimates that can be contrasted with those coming from more structural or semi-structural models.

In this regard, the models proposed by Del Negro et al. (2017) and (2018) extract $\mathrm{r}^{*}$ as a deep trend from inflation, real short-term interest rates and real long rates using a Kalman filter with Bayesian estimation techniques (see Annex V for details). The trend real short rate is defined here as the measure of $r^{*}$. Real variables are calculated from inflation data, nominal short interest rates, and nominal long interest rates. The models further assume that that these variables are cointegrated as follows:

$\pi_{t}=\pi_{t}^{*}+e_{t}$

$i_{t}^{3 m}=\pi_{t}^{*}+r_{t}^{*}+u_{t}$

$i_{t}^{10 y r}=\pi_{t}^{*}+r_{t}^{*}+t p_{t}^{*}+v_{t}$

where $\pi_{t}^{*}$ is trend inflation, $i_{t}^{3 m}$ is the three-month T-bill rate, $i_{t}^{10 y r}$ is the 10 -year bond yield, $t p_{t}^{*}$ is the trend term premia, and $e_{t}, u_{t}$ and $v_{t}$ are shocks (which can be persistent and correlated with each other). The trend components are assumed to follow a random walk and are subject to 'white-noise' shocks.

For the Euro Area, we estimate common factors on $\pi_{t}^{*}, r_{t}^{*}$ and $t p_{t}^{*}$ (the 'Euro Area factors'), as well country-specific trends, following Del Negro et al. (2018). The results show a clear decline in $r^{*}$ for all Euro Area countries of around 2 percentage points, very similar to the estimates from the L-W framework (Figure 4). In contrast with the estimates from the previous section, however, our $\mathrm{r}^{*}$ estimates from Factor models do not show a deep fall in natural rates during crises periods, nor the subsequent modest rebound observed in L-W estimates. In fact, the $\mathrm{r}^{*}$ estimates from the Factor models are negative at around -1 percent at mid-2019. This reflects the fact that real rates both at the long and the short end of the yield curve remain near historic lows, together with the absence of structural features in these type of models (as opposed to the L-W framework).

Compared to the L-W models, the co-movement of $\mathrm{r}^{*}$ between countries is also much closer, reflecting the explicit modeling of a common factor and the joint estimation procedure. In this regard, Annex VI includes a comparison of our $r^{*}$ estimates using different methodologies. There seems to be a broad movement towards similar $\mathrm{r}^{*}$ levels rates since the early 2000s, perhaps reflecting greater economic and financial integration following the adoption of the euro, and at times some mispricing of risk, with interest rates in the south of Europe very close to those in Germany. More recently, however, there has been some 
divergence, which could reflect the fragmentation of financial markets since the GFC, a clearer differentiation of country risk, and country-specific shocks.

In the case of emerging Europe, we use Del Negro et al. (2017) to estimate r*. Concretely, our $r^{*}$ estimates are significantly higher than those for Euro Area countries, which is in line with the results obtained using the L-W framework. Among other drivers, these results reflect that real rates in emerging Europe are higher than those in the Euro Area throughout the sample. In the case of Russia, $\mathrm{r}^{*}$ falls from around 4 percent in the early 2000 s to closer to 2 percent by 2018. Within this broad decline, however, there is jump in 2008 (GFC) and 2014 (following sanctions), likely as a result of a spike in the risk premium. These peaks while not identical in timing or duration-are also found in the L-W model. In Poland, the decline in $r^{*}$ was similarly in size-but was much steadier-reflecting perhaps smaller and/or fewer shocks compared to Russia. This downward trend is also more pronounced than the estimates derived from the L-W model. As a caveat, trend-cycle decompositions are less suited for emerging economies as structural breaks are frequent. ${ }^{16}$

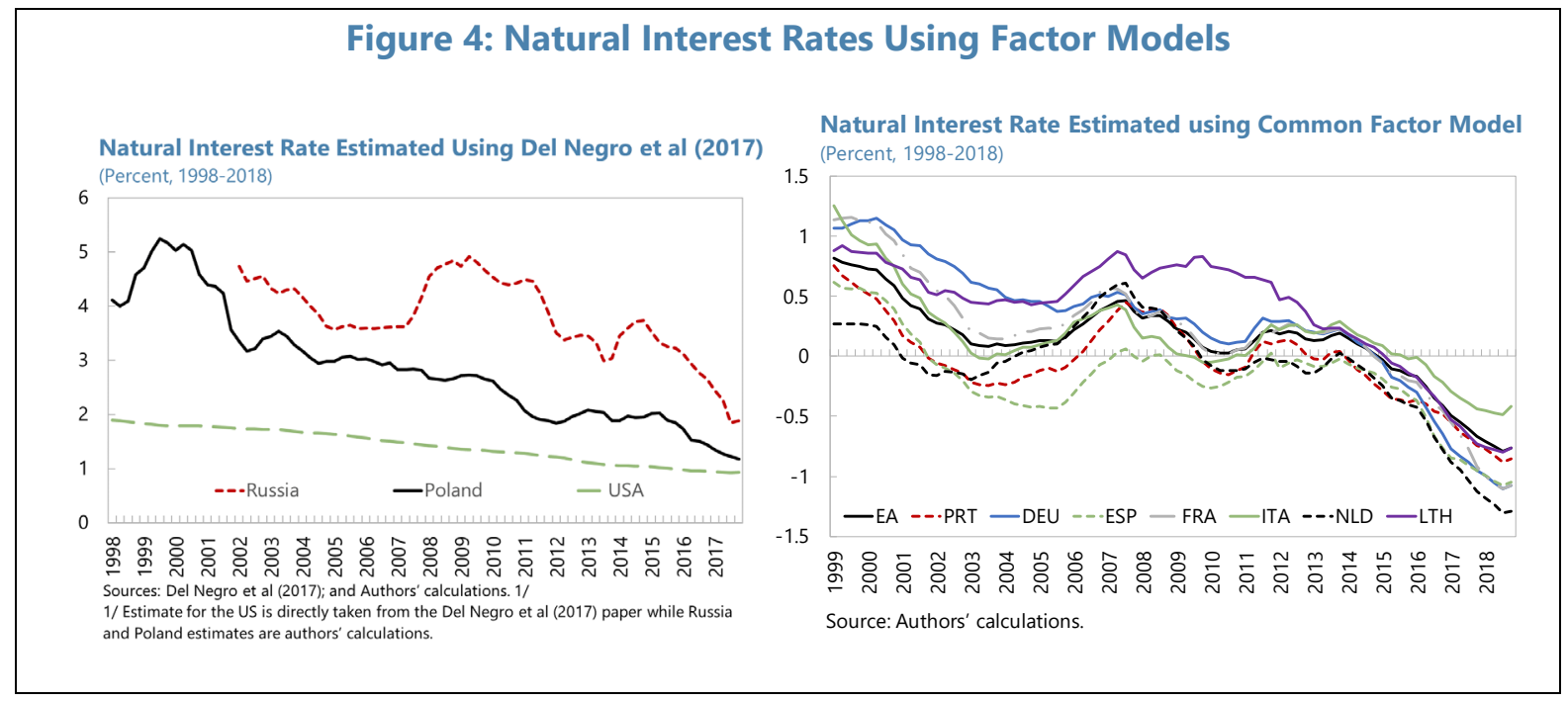

Co-movement of $r *$ Within the Euro Area

Countries within a currency union do not need to have the same natural rates or trend growth. However, one can expect some co-movement of these series, especially as countries become more integrated. We explore the time-varying interdependence of $r^{*}$ across Euro Area countries in our sample via a multivariate Dynamic Conditional Correlation (DCC-) GARCH model with one lag. We use our $r^{*}$ estimates and trend growth obtained from the application of L-W model where $z_{t}$ is modeled as a function of certain external variables. As cautioned in Holston et al. (2017), these series themselves are median estimates with a high level of uncertainty, and thus, the interpretation of the coefficients and statistical significance of statistical models should be taken with care. ${ }^{17}$

\footnotetext{
${ }^{16}$ We did not run this model for Romania due to insufficient data.

17 The model is estimated with Maximum Likelihood and Gaussian distributed errors.
} 
The covariance estimates are almost always positive, but strengthen or weaken over time, indicating that $r^{*}$ across the Euro Area countries in our sample co-move, but not always to the same degree (Figure 5). In periods of distress, such as the GFC and the sovereign debt crisis, these estimates become more volatile. Covariances increase, but dispersion in bilateral covariances also increase. For example, $\mathrm{r}^{*}$ estimates for Spain and Portugal show much stronger co-movement than between France and Germany during the 2011-14 period. Trend growth estimates exhibit much lower and, in some cases, slightly negative covariances. Their covariances are also higher and more dispersed during the sovereign debt crisis. The highest covariances in trend growth are generally between Spain and three other countries (Portugal, the Netherlands, and Italy) while Germany displays very low co-movement with other countries.

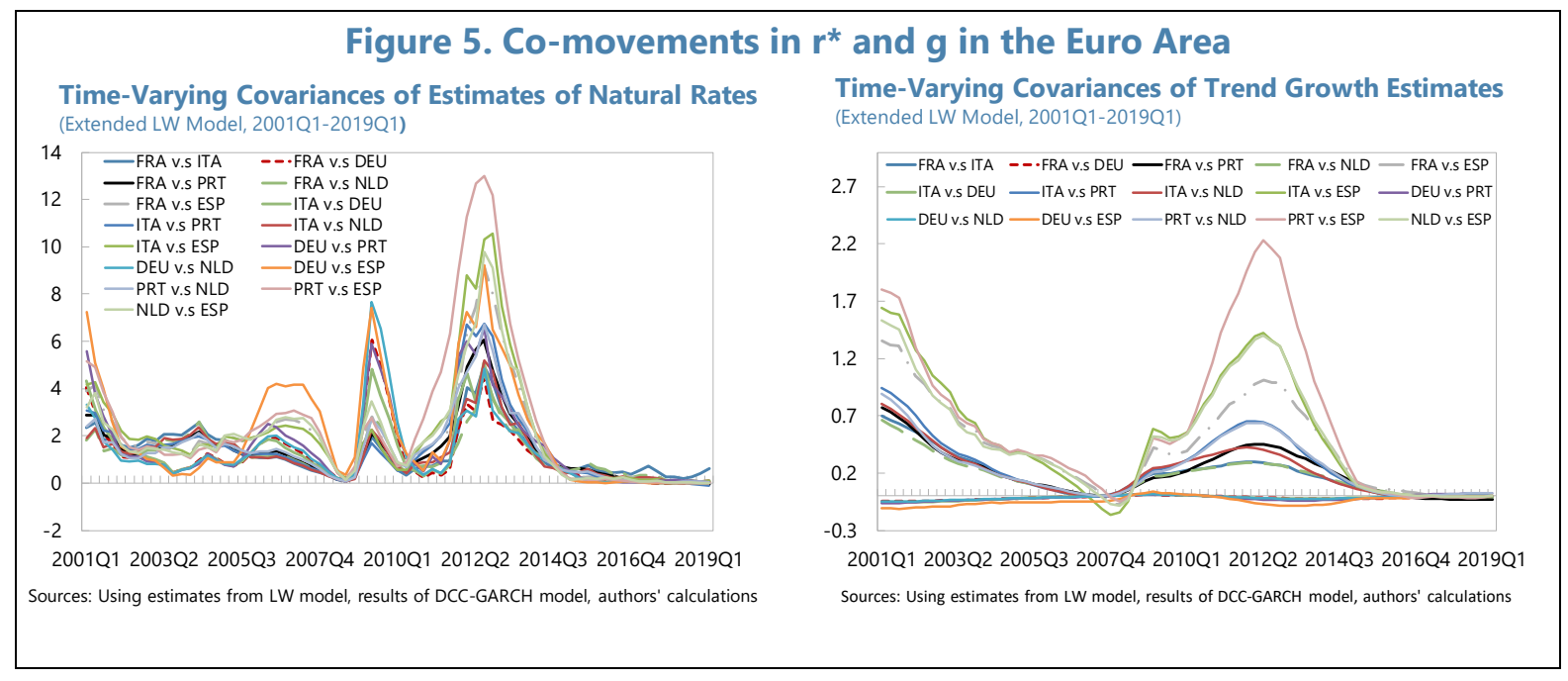

What do Forward Interest Rates and the Term Structure say About the Future Path of $r^{*}$ ?

Despite uncertainty, financial markets provide information on the direction that financial markets "expect" $r *$ to take in the future. If actual and natural rates of interest converge over the medium term, as nominal and real shocks dissipate, financial market data can be used to assess the market's implicit "views" on the future path of $r^{*}$. Market data also sheds light on the terminal rate toward which policy interest rates may converge as some form of steady state or equilibrium is approached. ${ }^{18}$ To this end, we use two techniques to assess market's expectations about the future path of $\mathrm{r}^{*}$ :

- Forward interest rates. The forward swap market on government debt gives an indication of the future path of short rates. Concretely, we use the three-month treasury bill, five-years ahead, as a proxy for the (nominal counterpart) of the neutral rate of interest. The relatively long period (five years) is chosen because it is judged likely to be

\footnotetext{
${ }^{18}$ For an exercise combining an arbitrage-free term structure model and a version of L-W, see Brand et al (2020).
} 
enough for nominal rigidities not to bind. Inflation expectations are used to convert nominal rates into real rates.

- Term structure. We use a version of the Nelson-Siegal term structure model (Christensen et al, 2011) to fit the yield curve for a country's government debt through time. This allows to separate the expected sequence of short-term rates from the term premium in a way that ensures that arbitrage conditions hold. From this, we derive the implied path of future nominal short rates (three-month treasury bill), consistent with this yield curve, and we use it as a proxy for the (nominal) natural rate in the future-specifically, fiveyears ahead. Inflation expectations are used again to convert nominal rates into real rates.

Figure 6 shows that for nearly all Euro Area countries, as of June 2019, markets expected real interest rates to remain well below zero for at least the following five years. While market expectations suggested that real rates would increase somewhat from the levels observed as of mid-2019 (indicated by the blue dots), their expected values were below the range of $\mathrm{r}^{*}$ estimates presented in this paper. Thus, while the analysis of previous sections suggested that real rates should rise only moderately (except in Italy) from the levels observed in mid-2019, markets seemed to bet that $\mathrm{r}^{*}$ and $\mathrm{r}$ were unlikely to increase even that


much in the future, let alone move towards pre-GFC levels. This has important implications for policy, considered below. In emerging Europe, market data should be viewed with more caution given the likely higher liquidity and credit premia associated with these instruments-this may explain part of the significant difference between our estimates of $r^{*}$ and the path implied by markets. Nevertheless, in both Poland and Romania, market data suggested a modest increase in real rates in the following years, but remaining well below our estimates of $\mathrm{r}^{*}$. And in Russia, this analysis suggested that real rates would remain near mid-2019 levels, and above $\mathrm{r}^{*}$, over the medium term. 


\section{Policy Implications}

\section{Monetary Conditions}

The estimate of $r^{*}$ compared to observed values of $r$ provides information on the stance of monetary policy. In countries that issue their own currencies, the $r-r^{*}$ gap provides a direct assessment of the policy stance, while in countries that are members of a monetary union, these gaps indicate how the common monetary policy is "felt" in individual member countries, whose specific conditions will likely differ. In any case, the $r-r^{*}$ gap has a direct bearing on the way the output gap evolves over time: the larger the positive (negative) interest rate gap, the more contractionary (expansionary) is the monetary impulse.

Evidently, the complications surrounding the estimation of $r^{*}$ translate into uncertainty in the assessment of the monetary stance. These challenges are more pressing in real time given lags in data production and publication (Grigoli et al, 2015) and end-point issues. This implies that estimates of $r^{*}$ need to be complemented by the analysis of other variables and the use of judgment to produce a thorough assessment of monetary conditions. The discussion below is based mostly on an examination during the sample period of the $r-r^{*}$ gap, and thus should be taken as indicative only.

With these caveats, we estimate the monetary stance for the countries in our sample using $\mathrm{r}^{*}$ estimates derived from the application of the L-W framework when $z_{t}$ is modeled as a function of economic variables. Real interest rates are calculated as the difference between the Euro Area one-week inter-bank rate and five-year ahead inflation expectations. ${ }^{19}$ While inflation expectations in Euro Area countries differ, such differences are small, implying a similar real short-term interest rate for all countries. Figure 7 shows that that prior to the GFC, monetary conditions were loose, but began to tighten in 2007 . Once the severity of the GFC was fully realized, following Lehman's failure, rates fell by over 3 percent within a one-year period, and monetary conditions eased substantially in all countries. Given that the ECB was close to the effective lower bound (ELB) by 2012, however, the room for further policy cuts was limited, and the subsequent changes in the $r-r^{*}$ gap were driven largely by the evolution of $r^{*}$. Toward the end of the period under study, the analysis point to an accommodative monetary conditions in all Euro Area countries, with the $r-r^{*}$ gap at around -2 percent in 2019:Q1.

But there are important variations among Euro Area countries. For instance, Figure 7 shows that in the case of France, the $r-r^{*}$ gap peaked by mid-2008 (increasing by over 2 percentage points from 2005 to 2008), and plummeted thereafter, falling below zero exactly at the peak of the rate cycle (2008:Q3). That is, given France's own $r^{*}$, the common policy was relatively soon having expansionary effects there. As the GFC moved into the

\footnotetext{
${ }^{19}$ This represents the closest approximation to the policy interest rate over this period. Prior to 2009, the interbank rate moved closely with the ECB's Main Refinancing Operation rate, but since then it has more closely followed the Deposit Rate.
} 
Euro Area, however, $\mathrm{r}^{*}$ continued to decline markedly in the countries most affected by the crisis, such as Portugal and Spain. In these countries, the monetary conditions, as reflected in their interest rate gaps, were tight in mid-2008 and remained tighter for longer. This means that the real interest rate fell for all countries, but such a decline was not equally effective in creating expansionary conditions everywhere, as the output gaps and hence the need for accommodation varied across countries (See Annex VI). Eventually, monetary conditions turned expansionary even for these other countries.

Figure 7 combines information on interest rate gaps with information on output gaps and inflation gaps (relative to target). This shows very crudely how well monetary conditions aligned at different points with the inflation and output gaps, as in a simple Taylor rule. In countries such as the Netherlands, where $r^{*}$ did not sink so low during the periods of stress, the single Euro Area policy delivered appropriate monetary conditions, although towards the end of the sample period conditions remained accommodative while the output gape was turning positive. In other countries, with sharper movements in $r^{*}$, the $r-r^{*}$ gap was unable to deliver the accommodation that was desirable in view of their output gaps. This was the case, for example, in Spain and Portugal during the euro area crisis. Between 2017 and 2019, output gaps have narrowed (and likely closed) for many Euro Area countries, but the r- $\mathrm{r}^{*}$ gap continues to be negative for all. This is explained in part by the persistence of inflation below 2 percent.

In the case of emerging Europe, monetary policy seems to have been broadly pro-cyclical in Russia, and more so prior to the GFC. The description by the Central Bank of Russia of its monetary policy stance in 2019 as "moderately tight" seems in line with the results we obtain. In the case of Poland and Romania, the monetary policy stance seems to have been broadly counter-cyclical during the global financial crisis and the taper tantrum, but has become pro-cyclical in recent years.

An issue that deserves consideration is the impact of UMPs on monetary conditions. The foregoing analysis implicitly assumes that monetary conditions are adequately described by the estimated value of the $r-r^{*}$ gap. However, after hitting the ELB, the ECB started using new instruments, which are not properly captured by the value of $r$ in that gap. 'Shadow' interest rates (Krippner (2015), Wu and Xia (2016)), can be used to assess the stimulus arising from asset purchases and forward guidance, actions that the ECB implemented once policy rates reached the ELB. However, this is not as simple as replacing an estimated shadow rate for an observed policy rate and comparing it to $\mathrm{r}^{*}$. Assessing the monetary policy stance using shadow rates would require $r^{*}$ estimates that are constructed explicitly considering UMPs, including a different transmission from the interest rate gap to the output gap in the IS Curve. Estimated shadow rates would need to be an input into the calculation of $r^{*}$ estimates that could then be used to obtain an alternative measure of the monetary stance in the presence of UMPs. This is an interesting avenue for future research. Our conjecture is that both the level of (shadow) $r$ and $r^{*}$ are lower because of UMPs, but an assessment of the impact of UMPs on the monetary stance would require further analysis. 


\section{What do our $r *$ Estimates Imply for Monetary Policy in the Future?}

In the Euro Area, given the difficulties encountered in hitting the inflation target in recent years, and in a scenario where the level of $r^{*}$ remains not far above the values estimated above, it is likely that monetary policy may need to resort to UMPs more often in the future. In other words, UMPs may be no longer 'unconventional' ${ }^{20} \mathrm{~A}$ frequent use of such policies will likely result in new policy questions: is there an optimal size of central bank assets beyond which further increases are sub-optimal; is there an ELB on long term rates; what policies may lower the ELB on policy rates; are there limits to quantitative easing; or is 'helicopter money' a viable policy tool (Turner, 2015)? This in addition to questions being asked already, such as what adverse side effects flow from negative interest rates and asset purchases, and how they can be mitigated.

\section{Can We Say Anything About the Future Path of r*?}

Although the future path of $r^{*}$ is highly uncertain, it is possible to speculate on the factors that may affect it. Firstly, following the onset of the pandemic, it is extremely difficult to form a view on potential growth, although over the medium term it is likely that long term drivers, such as demographics, would end up by reasserting their influence. In light of our discussion of the effects of country risk (measured by sovereign spreads) on $r^{*}$ in EMs and advanced economies, the impact of the pandemic on these groups of countries could again cause $r^{*}$ to diverge between Euro Area members and other countries in Europe. It is harder to tell what increased uncertainty in the near term means for $\mathrm{r}^{*}$, since the variable used in the analysis captured domestic uncertainty, whereas COVID-19 has brought about global uncertainties. However, as discussed before, there is a large unexplained component of $r^{*}$ in our estimates, which "drove" its decline beyond that of potential growth in many countries ( $\varepsilon_{t}^{Z}$ in expressions (6) and (7), after controlling for REER, external demand and country risk indicators). This unexplained component may be driven by very low frequency events, notably the protracted deleveraging process in many countries in the last several years of the period under study. Given the ongoing re-leveraging taking place during the pandemic, and its likely legacy, $r^{*}$ is likely to remain below $g$, as deleveraging must begin again - as long as risk components remain contained and do not dominate movements in $\mathrm{r}^{*}$. Other structural factors that are likely to affect $r *$ include demographic trends with an impact that goes beyond their effect on potential growth (as already discussed above), as the implementation of structural reforms to raise productivity (which could offset the drag of demographics on $\mathrm{r}^{*}$ ) is lagging. Further research is needed to explore these and other conjectures. ${ }^{21}$

\footnotetext{
20 This, in fact, already happened with the announcement of the Pandemic Emergency Purchase Program launched by the ECB in March 2020, although the shocks motivating this policy response are extraordinary.

${ }^{21}$ Kiley (2015), Cukierman (2016), Taylor and Wieland (2016), Krustev (2018), and Belke and Klose (2019) have argued that the omission of factors that are likely to influence output fluctuations, such as credit or the financial cycle, may result in misspecification and affect inference as regards the neutral rate of interest.
} 
Figure 7. Monetary Conditions

Euro Area Monetary Conditions, r-r*

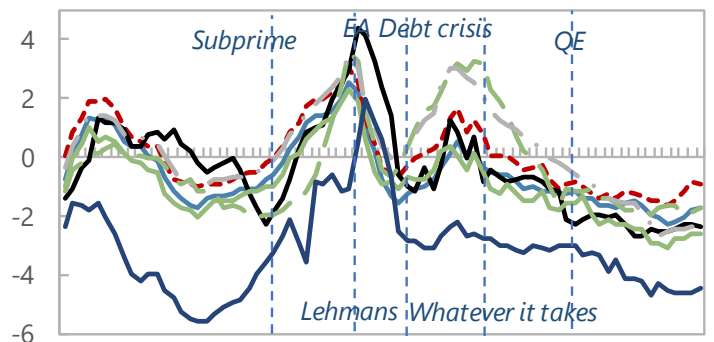

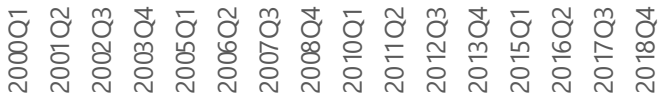

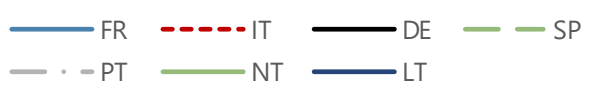

Spain

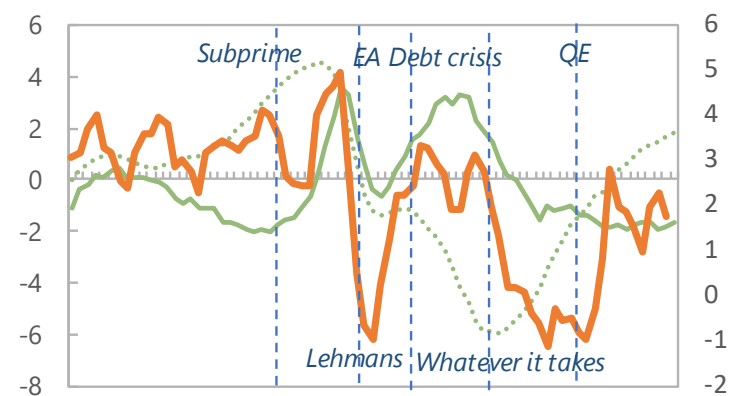

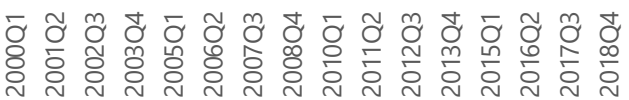

Monetary conditions, $r-$

Monetary Conditions, r-r* vs Output Gap, under LW with $\mathrm{z}$ as a function of other variables

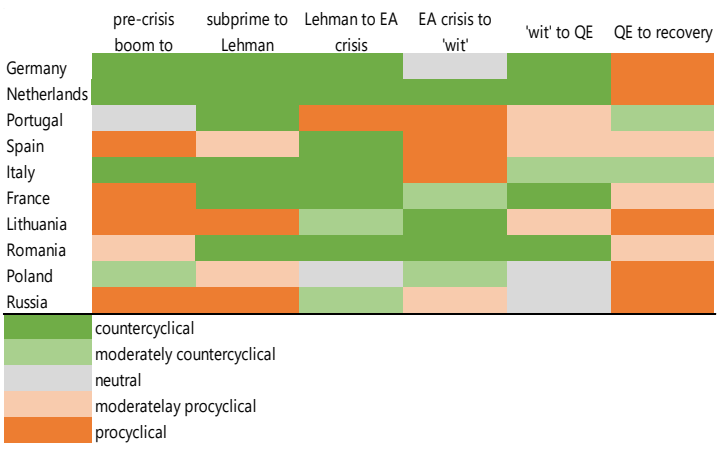

Netherlands

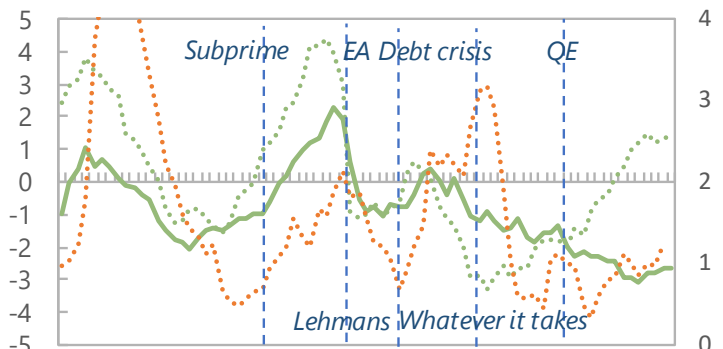

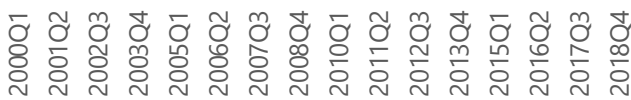

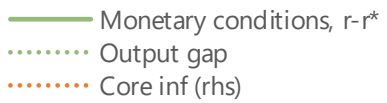

Russia

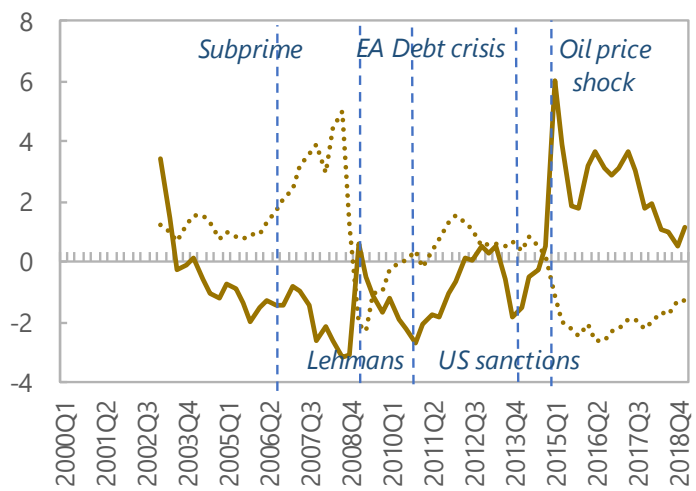

Monetary conditions, $r-r^{*} \quad \ldots . . .$. Output gap

Monetary Conditions, r-r* vs Core Inflation, under LW with $\mathrm{z}$ as a function of other variables

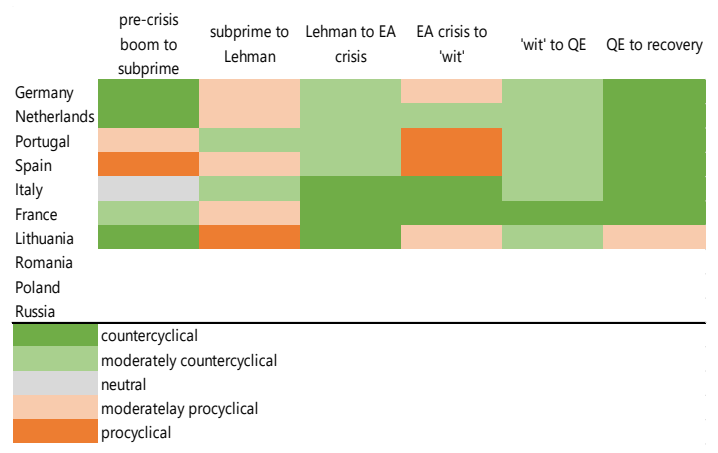

Sources: Authors' calculations. 


\section{Implications for Debt Sustainability and Fiscal Policy}

The link between $r^{*}$ and debt dynamics is important but nuanced. A lower borrowing cost supports public debt sustainability, as it is clear from the standard debt dynamics equation:

$\Delta d_{t}=\frac{r_{t}^{e}-g_{t}}{1+g_{t}} d_{t-1}-p b_{t}$

Expression (11) states that changes in public debt $\left(\Delta d_{t}\right)$ depend on the debt stock $\left(d_{t-1}\right)$, the government's primary balance $\left(p b_{t}\right)$, the real effective interest rate on public debt $\left(r_{t}^{e}\right)$, and real growth $\left(g_{t}\right)$. In principle, a lower $\mathrm{r}^{*}$ should in due course translate, other things equal, into a lower $r_{t}^{e}$. However, there are few additional factors to consider.

First, a lower r* may also imply lower potential growth. As already discussed, many of the factors that drive $\mathrm{r}^{*}$ also affect potential growth, including demographics and productivity, even if the relationship is not one-for-one. Given that it is the difference between $r$ and $g$ that is relevant for debt sustainability (equation 11), these effects could mitigate each other to a significant degree. In this regard, our estimates suggest that the level of $r^{*}$ decreased by 2 percentage points (on average) when comparing the post-GFC with the pre-GFC period, while trend growth fell by around 1 percent. Therefore, the decline in the r-g differential was half as large as the decrease in $\mathrm{r}^{*}$. Even so, the improvement in the $\mathrm{r}-\mathrm{g}$ differential did provide additional fiscal space. Setting equation (11) to zero, it follows that a lower r-g gap implies a lower debt-stabilizing primary balance (DSPB). Compared to pre-GFC period, the DSPB declined by nearly 1 percentage points of GDP on average for our sample of countries, assessed at 2018 debt ratios (top right chart in Figure 8). ${ }^{22}$

Second, the stability of the path of $\mathrm{r}^{*}$-g determines how durable the additional policy space is. For example, $\mathrm{r}^{*}$ - $\mathrm{g}$ was still below pre-crisis levels for most countries by the end of the period under study (except Lithuania); but it had partially recovered from its crisis lows. However, the extent and persistence of the policy space provided by this lower $\mathrm{r}^{*}$-g differential is subject to significant uncertainty in a forward-looking sense - as it was shown by the collapse in $\mathrm{g}$ arising from the pandemic, and its impact on debt dynamics all over the world. Moreover, some of the extra space generated by the low $r^{*}$-g observed in the late part of the sample period had been used already in some cases by the late 2010s (assessed again at 2018 debt ratios). Some highly indebted countries (France, Italy, and Spain) used the available space to help stabilize debt with a lower primary balance, rather than reduce debt ratios (as indicated by the red bar in the left-middle chart of Figure 8); in Romania, although with lower debt levels, the primary balance was not enough to stabilize debt. This left those countries exposed to changes in funding conditions or market sentiment. In contrast, Portugal and low-debt countries in the Euro Area (Germany, Netherlands, and Lithuania), Poland and

\footnotetext{
${ }^{22}$ The pre-crisis period is 2000-2007, the crisis period 2008-2013 and the post-crisis period 2013-2019. The rg gaps shown are calculated using the LW estimates of the natural rate $\mathrm{r}^{*}$ for those periods.
} 
Russia fully used the extra fiscal space, and created more, to reduce debt faster (see the shaded bars in the left-middle chart of Figure 8).

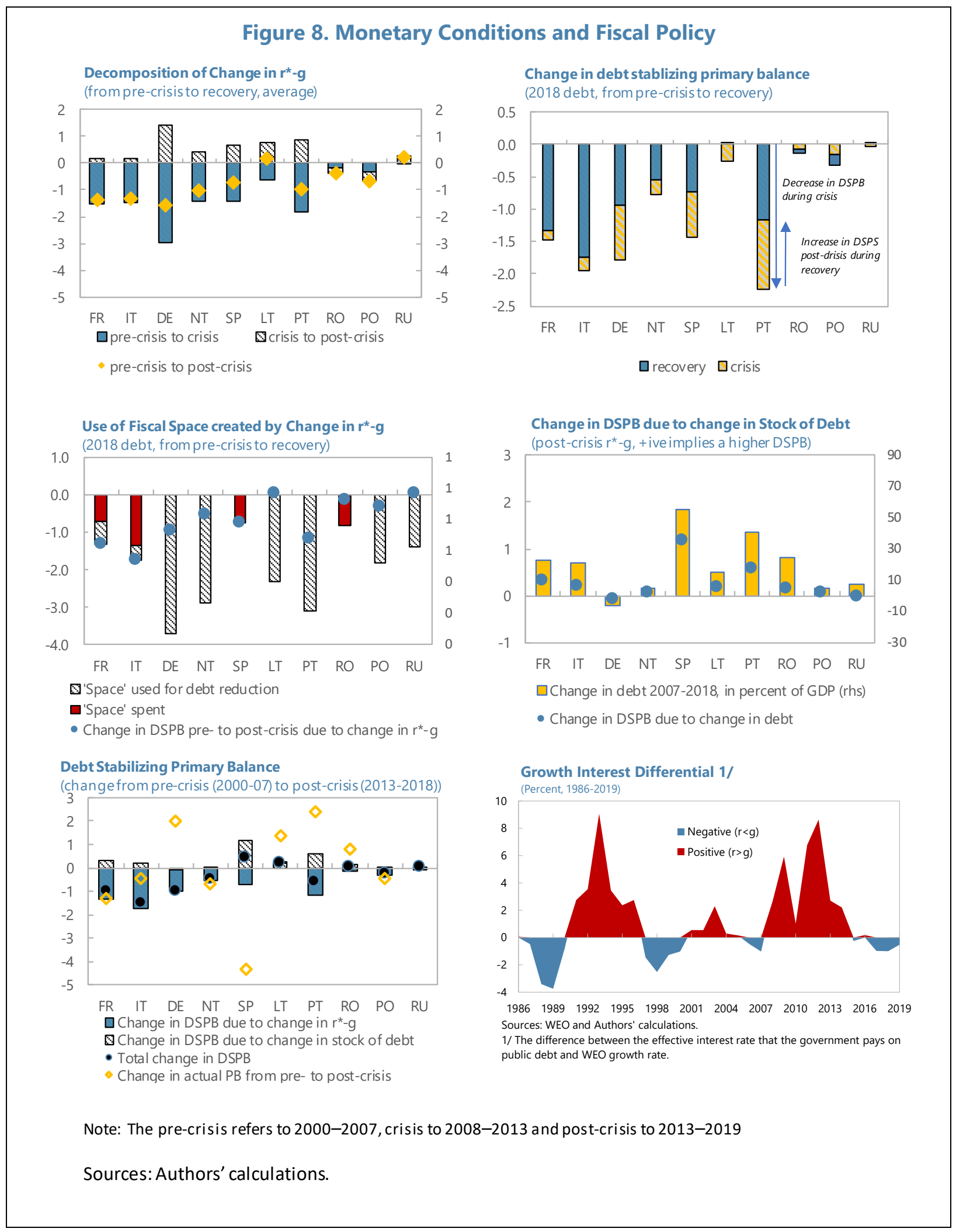

CInternational Monetary Fund. Not for Redistribution 
Furthermore, all countries except Germany experienced an increase in debt during the global financial crisis that implied an increase in the DSPB, offsetting part of the fiscal space generated by the lower $r^{*}$-g (middle right chart of Figure 8). For some countries such as Spain, this effect can be significant given the large increase in public debt and can even exceed the fiscal space generated by the lower $r^{*}$-g towards the end of the sample period (lower left chart of Figure 8).

Third, the relationship between $\mathrm{r}^{*}$ and the effective interest rate is not one-for-one. $\mathrm{r}^{*}$ represents a short rate, but government borrowing will include a term premium which will vary through time and by maturity at any given moment. Furthermore, the pass-through from a change in current borrowing costs to the effective interest rate is gradual as existing debt rolls over. In contrast, as noted, a deep recession can cause debt dynamics to deteriorate rapidly (through so-called denominator effects). As illustrated in the case of Portugal (bottom-right chart in Figure 8), which shows the effective interest rate minus the actual growth rate (equation 13), these factors can cause rapid and unexpected shifts in the interest rate-growth differential, changing debt dynamics in the near term.

Fourth, credit risk premia critically affect debt sustainability. Risk premia are affected by both domestic factors (expectations about growth and fiscal policies against the backdrop of the size of debt ratios) and by external market conditions. Swift changes in market perceptions can cause rapid increases in long-term rates. Although these may only work their way slowly into higher effective rates, highly indebted countries are particularly vulnerable. In those cases, an abrupt increase in interest rates may well be the result of the sudden drop in demand for these debt securities (a 'sudden stop').

Finally, two points about the primary balance itself. Some of the main forces driving both $\mathrm{r}^{*}$ and $g$ lower will independently affect the primary balance-demographic trends are a main factor in this regard, as aging increases dependency ratios. Thus, lower $\mathrm{r}^{*}$-g may reduce somewhat the DSPB; but maintaining a given primary balance will become increasingly hard over time, putting pressure on sustainability and calling for fiscal prudence even if $\mathrm{r}^{*}$ - $\mathrm{g}$ is lower. In addition, as noted earlier, in a relatively low $r^{*}$ environment, the likelihood could be high that monetary policy may be constrained by the effective lower bound when stimulus is needed. Given questions about the continued effectiveness of UMP, there is a chance that fiscal policy will be called to play an important role in economic stabilization in many countries. To be able to take on that role, it is important to build and maintain appropriate fiscal space. That is, policy makers need to look beyond the considerations embodied in the first term of equation 11, to ask how much room do they need to use the second term of that equation in a discretionary way for demand management purposes. 


\section{Conclusions}

In this paper we estimate $r^{*}$ for a sample of European countries between 2000 and 2019 and try to identify its main drivers. Significant uncertainty around $r^{*}$ estimates and large unexplained components for some countries suggests that our results should be interpreted with caution. Indeed, uncertainty around any $\mathrm{r}^{*}$ estimate creates challenges for policy formulation and implementation. In this context, any policy judgment should be considered jointly with other economic information and analysis. That said, some broad patterns emerged from the analysis that deserve consideration.

In line with much of the literature, our results suggest that natural rates have declined in our sample of European countries in the last 20 years. A significant part of that decline is accounted for by a fall in potential growth. This decline is larger in the advanced European economies compared to that in emerging Europe. However, this is not the full story: the fall in natural rates after the GFC has been more pronounced than the fall in potential growth rates, giving rise to a wedge between the two. This wedge became large during the GFC and has since only moderately decreased in the group of advanced European economies. For emerging Europe, and consistent with the more moderate decrease in $\mathrm{r}^{*}$, the wedge increased notably less over the whole sample period.

Part of this wedge between $\mathrm{r}^{*}$ and $\mathrm{g}$ can be attributed to external factors including trade, capital flows, and changing risk perception. Interestingly, these factors can affect emerging markets and reserve currency countries differently. In particular, the country risk premium is found to push the natural rate upwards in Russia, as capital mobility ensures that riskadjusted real returns are arbitraged. However, risk increases in reserve currency countries may temporarily decrease $\mathrm{r}^{*}$ as lower real rates appear to be needed by the economy to compensate for the adverse impact of higher risk.

Nevertheless, even after taking these variables into account, large residuals remain - that is, the wedge between $r^{*}$ and $g$ remains in large part unexplained. This might reflect slowmoving factors that are capable of significantly altering saving and/or investment behavior. A candidate explanation for this continuing wedge is the protracted deleveraging process in both the public and the private sectors, especially in the Euro Area. (Testing this conjecture is part of our future research agenda.) If deleveraging has been a main driver of the wedge between $\mathrm{r}^{*}$ and $\mathrm{g}$ in recent years, then this wedge may be expected to persist if the conditions surrounding the pandemic result in re-leveraging in the near term, which economic agents may need again to correct over time.

In any event, any rise in $\mathrm{r}^{*}$ is likely to take time, and it is very difficult to imagine that $\mathrm{r}^{*}$ could rise above $g$ anytime soon, particularly in advanced economies. In the future, even without any additional shocks to the economies, both $\mathrm{r}^{*}$ and $\mathrm{g}$ will likely remain lower than they were in the early 2000 s, as it is hard to see European growth rates increase. 
The implications of a persistently low natural rates for macroeconomic policy are major.

- For monetary policy, a persistently low $\mathrm{r}^{*}$ in the absence of higher inflation, will permanently increase the likelihood of hitting the ELB. This could make UMPs a tool of first-resort even during moderate downturns, let alone larger shocks. This possibility is much more significant in the Euro Area than in emerging Europe.

- A related issue concerns the contribution of fiscal policy to stabilize demand. Looking beyond the COVID crisis, one can see that in a currency area, interest rates will not necessarily evolve in a way that favors the stabilization needs of any particular country at any given time. This is especially true during periods of very low interest rates, when conventional monetary policy is potentially limited in its ability to provide a stimulus. This does raise the stakes for fiscal policy as a demand stabilization instrument - provided there is fiscal space.

- There is, to some extent, better hope for monetary policy-based stabilization in a country with a currency of its own. However, even there, monetary policy may be unable to always act in response to domestic output gaps if it must also respond to capital account shocks and exposures. This tradeoff is particularly acute for emerging economies where currency mismatches tend to be more acute. In this environment, changes in market risk appetite can be sudden and produce large reversal of capital flows, forcing a procyclical monetary policy stance.

- A controversial question is whether, in view of the low $\mathrm{r}^{*}$, countries should not be too concerned about the prospects of carrying more debt. In fact, a lower $r^{*}$ should, all things being equal, increase fiscal space. Nevertheless, we find in some countries that, even before the pandemic, debt ratios had already increased, reflecting to different degrees recessionary conditions and countercyclical fiscal policy responses, which were not subsequently reversed, largely using up the space created by lower $r^{*}$. Furthermore, higher debt levels carry higher risks, and spikes in the term and risk premium can dominate favorable movements in $\mathrm{r}^{*}$. With lower $\mathrm{r}^{*}$, there is also an increased likelihood of hitting the ELB, which reduces the scope for monetary policies to downturns and places a premium on the conservation of fiscal space for adopting a countercyclical stance when needed. Thus, care should be exercised in judging whether low $\mathrm{r}^{*}$ can justify a high tolerance for high debt ratios. 


\section{References}

Andrade, Philippe, Jordi Galí, Hervé Le Bihan, and Julien Matheron, 2019, “The Optimal Inflation Target and the Natural Rate of Interest" BPEA Conference Draft, Fall.

Auclert, Adrien, and Matthew Rognlie, 2018, "Inequality and Aggregate Demand." No. w24280. National Bureau of Economic Research.

Baker, Scott, Nicholas Bloom, and Steven J. Davis, 2016, "Measuring Economic Policy Uncertainty, "The Quarterly Journal of Economics, Vol. 131(4), 1593-1636.

Barsky, R, Alejandro Justiniano, and Leonardo Melosi, 2014, "The Natural Rate of Interest and its Usefulness for Monetary Policy," American Economic Review: Papers \& Proceedings, Vol. 104, No. 5, 37-43.

Belke, Ansgar, and Jens Klose, 2019, "Equilibrium Real Interest Rates and the Financial Cycle: Empirical Evidence for Euro Area Member Countries." Economic Modelling.

Beyer, Robert C.M. and Volker Wieland, 2019, "Instability, imprecision and inconsistent use of equilibrium real interest rate estimates," Journal of International Money and Finance, Vol. 94, 1-14

Bielecki, Marcin, Marcin Kolasa, and Michał Brzoza-Brzezina, 2018, "Demographics, Monetary Policy and the Zero Lower Bound," 2018 Meeting Papers 810, Society for Economic Dynamics.

Blanchard, Olivier, Giovanni Dell'Ariccia, and Paolo Mauro, 2010, "Rethinking Macroeconomic Policy," Journal of Money, Credit, and Banking, Vol. 41, No. 1, 199-215.

Borio, Claudio, Piti Disyatat, and Phurichai Rungcharoenkitkul, 2019, "What Anchors for the Natural Rate of Interest?”, BIS Working Papers, No 777.

Brand, Claus, Marcin Bielecki, and Adrian Penalver, 2018, "The Natural Rate of Interest: Estimates, Drivers, and Challenges to Monetary Policy." ECB Occasional Paper 217.

Brand, Claus and Falk Mazelis, 2019, "Taylor-Ryle Consistent Estimates of the Natural Rate of Interest,” ECB Working Paper No. 2257.

Brand, Claus, Gavin Goy and Wolfgang Lemke, 2020, "Natural Rate Chimera and Bond Pricing Reality," DNB Working Paper No. 666.

Carvalho, Alexandre A.Z.D, 2018, "Differences in Natural Interest Rates in the Eurozone," Student Master Thesis, NOVA - School of Business and Economics.

Christensen, J. H.E., Francis X. Diebold, and Glen Rudebusch, 2011, "The Affine ArbitrageFree Class of Nelson-Siegel Term Structure Models," Journal of Econometrics, Vol 164, No. $1,4-20$. 
Cukierman, Alex, 2016, "Reflections on the Natural Rate of Interest, its Measurement, Monetary Policy and the Zero Lower Bound”, CEPR Discussion Paper 11467.

Cynamon, Barry Z., and Steven M. Fazzari, 2015, "Inequality, the Great Recession and Slow Recovery." Cambridge Journal of Economics 40, no. 2, 373-399.

Del Negro, Marco, Domenico Giannone, Marc P. Giannoni, and Andrea Tambalotti, 2017, "Safety, Liquidity, and the Natural Rate of Interest." Brookings Papers on Economic Activity 2017, no. 1, 235-316.

Del Negro, Marco, Domenico Giannone, Marc P. Giannoni, and Andrea Tambalotti, 2019, "Global Trends in Interest Rates," Journal of International Economics, Elsevier, vol. 118(C), $248-262$.

Döttling, Robin, German Gutierrez Gallardo, and Thomas Philippon, 2017, "Is There an Investment Gap in Advanced Economies? If so, Why?" Investment and Growth in Advanced Economies, ECB: Frankfurt am Main.

Dynan, Karen E., Jonathan Skinner, and Stephen P. Zeldes, 2004, "Do the Rich Save More?", Journal of Political Economy 112, no. 2, 397-444.

Fries, Sébastien, Jean-Stéphane Mésonnier, Sarah Mouabbi, and Jean-Paul Renne, 2018, "National Natural Rates of Interest and the Single Monetary Policy in the Euro Area." Journal of Applied Econometrics 33, no. 6,763-779.

Galí, Jordi, 2008, Monetary Policy, Inflation and the Business Cycle: An Introduction to the New Keynesian Framework (New Jersey: Princeton University Press).

Garnier, Julien and Bjørn-Roger Wilhelmsen, 2009, "The Natural Rate of Interest and the Output Gap in the Euro Area: A Joint Estimation", Empirical Economics, 36, issue 2, 297-319.

Grigoli, Francesco, Alexander Herman, Andrew Swiston, and Gabriel Di Bella, 2015. "Output gap uncertainty and real-time monetary policy," Russian Journal of Economics, Elsevier, vol. 1(4), 329-358.

Hakkio, Craig S. and A. Lee Smith, 2017, Bond Premiums and the Natural Real Rate of Interest, Kansas Fed Economic Review.

Holston, K., T. Laubach, and J. C. Williams, 2017, "Measuring the Natural Rate of Interest: International Trends and Determinants," Journal of International Economics, Vol. 108, Supplement 1, S39-S75.

Jordà, Òscar, and Alan M. Taylor, 2019, "Riders on the Storm," Federal Reserve Bank of San Francisco Working Paper 2019-20. Available at https://doi.org/10.24148/wp2019-20.

Kiley, Michael T, 2015, "What Can the Data Tell Us About the Equilibrium Real Interest Rate?” FEDS Working Paper, No. 2015-077 (Washington, DC: Federal Reserve Board). 
Krippner, Leo, 2015, Zero Lower Bound Term Structure Modeling: A Practitioner's Guide (New York: Palgrave-Macmillan).

Krustev, Georgi, 2018, "The Natural Rate of Interest and the Financial Cycle". ECB Working paper Series No 2168.

Laubach, Thomas and John C. Williams, 2003, "Measuring the Natural Rate of Interest," Review of Economics and Statistics, Vol. 85, No. 4, 1063-70.

Laubach, Thomas, and John C. Williams, 2016, "Measuring the Natural Rate of Interest Redux." Business Economics, Vol 51(2), 57-67.

Lewis, Kurt F., and Francisco Vazquez-Grande, 2017, "Measuring the Natural Rate of Interest: Alternative Specifications." Finance and Economics Discussion Series 59.

Lunsford, Kurt G. and Kenneth D. West, 2018, "Some Evidence on Secular Drivers of U.S. Safe Real Rates," NBER Working Paper No. w25288 (Cambridge, MA: National Bureau of Economic Research).

Magud, Nicolas E., and Evridiki Tsounta (2012), "To cut or not to cut? That's the (Central Bank's) Question. In Search of the Neutral Interest Rate in Latin America”, IMF Working Paper, 12/243, Washington, International Monetary Fund.

Mésonnier, Jean-Stéphane and Jean-Paul Renne, 2007, “A Time-varying "Natural" Rate of Interest for the Euro Area", European Economic Review, 51, issue 7, 1768-1784.

Pescatori, Andrea and Jarkko Turunen, 2015, "Lower for Longer; Neutral Rates in the United States," IMF Working Papers 15/135 (Washington: International Monetary Fund).

Rachel, Lukasz and Thomas D. Smith T, 2017, "Secular Drivers of the Global Real Interest Rate,” International Journal of Central Banking, Vol 3. No 13.

Rey, Hélène, 2018, "Dilemma not Trilemma: The Global Financial Cycle and Monetary Policy Independence”, NBER Working Paper No. 21162.

Saez, Emmanuel, and Gabriel Zucman, 2014, "Wealth Inequality in the US since 1913." NBER Working Paper. Available at http://gabriel-zucman. eu/uswealth.

Stock, James, and Mark Watson, 1998, Median "Unbiased Estimation of Coefficient Variance in a Time Varying Parameter Model," Journal of the American Statistical Association. Vol. 93: 349-358.

Stock, James H., 1991, "Bayesian Approaches to the "Unit Root" Problem: A Comment", Journal of Applied Econometrics, Vol. 6, issues 4, 403-411.

Summers, Lawrence, 2014, "U.S. Economic Prospects: Secular Stagnation, Hysteresis, and the Zero Lower Bound," Business Economics, Vol 49 (2). 
Talyor, John B. and Volker Wieland, 2016, "Finding the Equilibrium Real Interest Rate in a Fog of Policy Deviations," Business Economics, Palgrave Macmillan; National Association for Business Economics, vol. 51(3), 147-154.

Turner, Adrair, 2015, “The Case for Monetary Finance - An Essentially Political Issue”, paper presented at Sixteenth Jacques Polak Annual Research Conference, International Monetary Fund.

Weber, Axel A., Wolfgang Lemke, and Andreas Worms, 2008, 'How useful is the concept of the natural real rate of interest for monetary policy?', Cambridge Journal of Economics, 32(1), 49-63.

Wicksell, Knut, 1936, Interest and Prices, originally published in 1898, translated by R.F. Kahn (London: Macmillan Publishers).

Woodford, Michael, 2003, Interest and Prices: Foundations of a Theory of Monetary Policy (New Jersey: Princeton University Press).

Wu, Jing Cynthia and Fan Dora Xia, 2016, "Measuring the Macroeconomic Impact of Monetary Policy at the Zero Lower Bound", Journal of Money, Credit, and Banking, 2016, 48(2-3), 253-291. 


\section{AnNex I. Defining The Natural Rate}

A good organizing principle to discuss various common conceptions of $\mathrm{r}^{*}$ is to consider the specific linkage to the supply side of the economy and the time horizon of reference.

A familiar view of r* emphasizes its linkages with the supply or productive side of an economy, while abstracting from inflation. In this view, over the medium-to-long-term, $r^{*}$ is anchored by structural factors like technological progress, demographics, and household preferences, which are also thought to affect potential growth. The following representation by Gali (2008), which builds on the standard consumption Euler equation in a New Keynesian-style model, is useful to show the structural determinants of $\mathrm{r}^{*}$ :

$r_{t}^{*}=\rho+\sigma \frac{1+\varphi}{\sigma(1-\alpha)+\varphi+\alpha} E_{t}\left(\Delta a_{t+1}\right)$

In this expression, $\rho$ is the household's discount rate over time; $(1-\alpha)$ and $\alpha$ are the labor and capital shares of production, respectively $(\alpha<1) ; \varphi$ is the marginal disutility of work, and; $a_{t}$ is the log of the level of technological progress, and $\sigma$ determines the curvature of the consumer's utility function. In this expression, $\mathrm{r}^{*}$ is essentially the marginal product of capital along an optimal path in an intertemporal consumption/investment problem that is usually formulated without any reference to inflation: as a pure real economy problem.

Expression (AI.1) suggests that $\mathrm{r}^{*}$ and trend output growth will be closely linked, as they depend on similar sets of fundamentals; but it allows their paths to drift apart. For instance, Rachel and Smith (2015) note that in models of this sort, a given fall in trend productivity growth could lead to a larger fall in $\mathrm{r}^{*}$, depending on the consumer's intertemporal elasticity of substitution. This 'supply-side' concept is often evoked by the expression 'natural rate' of interest. Although our focus is on the output gap and inflation, we retain the label "natural" and use it interchangeably with the term 'neutral rate.'

r* is, in fact, often discussed in terms of output gaps and inflation-an 'equilibrium-related' notion of $r *$ that incorporates price variations explicitly, and often centrally. This is clearly useful when thinking about monetary policy. If inflation were at the central bank's target, and output at its potential, the real interest rate that would keep the economy from leaving this blissful state is defined as the natural rate. This notion is closely linked to a concept of $\mathrm{r}^{*}$ as the real value of the constant term in a Taylor rule: that is, the policy rate that would keep the economy in its present state starting from closed output and inflation gaps. In this view, the real value of the natural rate would be invariant over the cycle by definition, or at least over the central bank's policy horizon, and it would be a reference point for the central bank's policy choices as it tries to steer the economy towards inflation stability. 
Thus, $\mathrm{r}^{*}$ is a construct used to assess equilibrium conditions in an economy, and so observed/actual real interest rates ( $r$ ) need not be equal to $r^{*}$ at any given moment. ${ }^{1}$ It is easy to extrapolate these ideas into a long-term vision of interest rates. After all, in the long term all current day shocks should have dissipated. So, we expect that in the long run, just like the output gap should be closed and inflation stable, interest rates should find themselves at their natural level.

Other notions of the natural rate accommodate greater variation through time. Woodford (2003) defines $r^{*}$ as a benchmark for economies that operate in conditions other than total price flexibility. Accordingly, $\mathrm{r}^{*}$ is the rate at which income is at its potential in an economy with flexible prices. This definition suggests that there exists a 'neutral' equilibrium real interest rate in the current period, as an economy operating with price and other rigidities in the short-term is affected by shocks. This view of $r^{*}$ is the closest to the definition we use in this paper. This level of the rate would normally be expected to differ from the eventual long-term "resting place" for interest rates, toward which $r^{*}$ should converge as the effects of temporary shocks run their course and prices, given the needed time, adjust.

At these higher frequencies, $\mathrm{r}^{*}$ can be conceived as a reference point for economic dynamics out of equilibrium. In the presence of short-term nominal rigidities, a simple version of the IS curve illustrates the relationship between the output gap and the interest rate gap:

$\tilde{y}_{t}=\alpha_{1} \tilde{y}_{t-1}-\beta_{1}\left(i_{t-1}-E_{t}\left(\pi_{t}\right)-r_{t-1}^{*}\right)$

In expression (AI.2), $\tilde{y}$ is the output gap; $i_{t}$ is the nominal interest rate (typically the policy rate), and; $\pi_{t}$ is inflation. Nominal shocks are captured by innovations to $i_{t}$, while real shocks can be understood as affecting $r^{*}$, with the second term in the right-hand side representing the 'interest rate gap'. In turn, $\alpha_{1}$ denotes output gap persistence while $\beta_{1}$ represents the output gap sensitivity to changes in the interest rate gap. Provided $\alpha_{1}<1$, an economy represented by equation (AI.2) would tend, in due course, to return to equilibrium of its own accord; but it can do it more rapidly or more slowly depending on the difference between the real interest rate from the natural level at a particular point in time. That is, depending on whether monetary conditions are contractionary or expansionary. As it is influenced by real shocks (possibly from changes in fiscal policy, financial conditions, external demand, and terms of trade, among others), $r_{t}^{*}$ can move at economic-cycle frequencies and exhibit volatility even in the short-term.

In fact, in expression (AI.2), $r_{t}^{*}$ is like a "sufficient statistic" that summarizes all information on relevant real shocks that a policy maker would require at a point in time to choose $r_{t}$ with a view to steering the economy through the cycle and promote a fast return of the economy to equilibrium. In an extreme version of this line of thought, using a DSGE framework, Barsky

\footnotetext{
${ }^{1}$ Strictly speaking, $r$ is not directly observable either, as inflation expectations are not observable; but nominal interest rates from which $r$ is derived are.
} 
et al (2014), argues that $\mathrm{r}^{*}$ can be highly volatile and procyclical in the near term, and that a policy rule where the (real) policy rate tracks $r_{t}{ }^{*}$ would improve welfare and achieve full macroeconomic stability. ${ }^{2}$ They clarify, however, that given large uncertainties around the accuracy of $r_{t}^{*}$ estimates and monetary policy lags, attempting to track a volatile estimate of $r^{*}$ may in practice lead to suboptimal outcomes.

\footnotetext{
${ }^{2}$ Barsky et al (2014) contends that such a policy rule would work well when demand shocks dominate, and both prices and quantities move in the same direction, but less so in the presence of mark-up supply shocks.
} 


\section{AnNeX II. TeChNical Details on The L-W MOdel}

The framework is relatively simple: it proposes a small scale closed-economy model, that includes a Phillips curve and an IS curve, allowing the simultaneous estimation of the $r^{*}$, trend output and potential growth (all of them unobserved variables), from observable data via the Kalman filter (Kalman, 1960). The original L-W model was calibrated to fit the U.S. economic data; a more recent version can be found in Holston et al. (2016). Variations of the L-W model for the Euro Area are discussed in Mésonnier and Renne (2007) or Garnier and Wilhelmsen (2009). Weber et al. (2008) criticize L-W pointing out that it does not allow to identify the individual driving forces behind the movements of the $\mathrm{r}^{*}$; and, that interlinkages among economic variables are difficult to interpret. They contend that a more detailed framework could help with such issues. ${ }^{1}$

The version in this paper follows Pescatori and Turunen $(2015) .{ }^{2}$ Concretely, the model has an IS-Curve that relates the output gap $\left(\tilde{y}_{t}\right)$ in the current period to the stance of monetary policy $\left(r_{t-j}-r_{t-j}^{*}\right)$ of the last two quarters, and autoregressive terms:

$\tilde{y}_{t}=\alpha_{1} \tilde{y}_{t-1}+\alpha_{2} \tilde{y}_{t-2}-\frac{\alpha_{r}}{2} \sum_{j=1}^{2}\left(r_{t-j}-r_{t-j}^{*}\right)+\varepsilon_{t}^{I S}$

In equation (AII.1), the neutral real rate $\left(r_{t}^{*}\right)$ is endogenous, while the real observed rate $\left(r_{t}=\right.$ $i_{t}-\pi_{t+1}^{e}$ ) is exogenous (policy determined) and equal to the difference between the nominal policy rate $\left(i_{t}\right)$, and one-year ahead inflation expectations $\left(\pi_{t+1}^{e}\right) ; \varepsilon_{t}^{I S}$ is an iid shock with standard deviation $\sigma^{I S}$.

In turn, the output gap is equal to the difference between output $\left(y_{t}\right)$ and potential $\left(y_{t}^{N}\right)$,

$\tilde{y}_{t}=y_{t}-y_{t}^{N}$

Potential output $\left(y_{t}^{N}\right)$ is driven by trend growth $\left(g_{t}\right)$ and a temporary iid shock $\left(\varepsilon_{t}^{N}\right)$ with standard deviation $\sigma^{N}$,

$y_{t}^{N}=y_{t-1}^{N}+g_{t}+\varepsilon_{t}^{N}$

Trend growth is defined as random walk with a persistent shock $\left(\varepsilon_{t}^{g}\right)$,

$g_{t}=g_{t-1}+\varepsilon_{t}^{g}$

\footnotetext{
${ }^{1}$ Laubach and Williams (2016) emphasize another issue that is directly attributed to the Kalman filter: using in-sample forecasts as future data points results in a lagged time-series, making the two-sided estimation procedure an undesirable option for policy makers. A one-sided estimation of the L-W model, i.e. estimating the model without fine-tuning the parameters, is possible, but leads to an increase in estimation uncertainty.

However, the method is easy to employ and does not require very strong assumptions. Laubach and Williams (2016) show that one-sided estimates of the neutral rate only slightly deviate from the two-sided results and can be still employed in other macroeconomic models

${ }^{2}$ The description in this section follows Osorio (2016).
} 
The model also includes an open-economy backward looking Phillips Curve relating (core) inflation to the output gap and the gap between domestic currency import price and core inflation,

$\pi_{t}=\beta_{1} \pi_{t-1}+\frac{\beta_{2}}{3} \sum_{j=2}^{4} \pi_{t-j}+\frac{1-\beta_{1}-\beta_{2}-\beta_{0}}{4} \pi_{t-5}+\frac{1-\beta_{1}-\beta_{2}}{4} \sum_{j=6}^{8} \pi_{t-j}+\beta_{y} \tilde{y}_{t-1}+\beta_{m} \pi_{t-1}^{m}+$ $\varepsilon_{t}^{P C}$

Import price inflation $\left(\pi_{t}^{m}\right)$ is taken as exogenous. ${ }^{3}$ The determinants of the $r_{t}^{*}$ are trend growth $\left(g_{t}\right)$ and an exogenous process $\left(z_{t}\right)$ capturing variables other than trend growth,

$r_{t}^{*}=c g_{t}+z_{t}$

Trend growth and $\mathrm{r}^{*}$ are linked by a constant, $c>0$. In the case of emerging economies, an alternative specification makes the exogenous process dependent on a news index of economic policy uncertainty $\left(p_{t}\right)$, country risk $\left(c_{t}\right)$, the US 10-year real sovereign yield $\left(e_{t}\right)$, and autoregressive terms,

$z_{t}=\delta_{1} z_{t-1}+\delta_{2} z_{t-2}+\delta_{c} \Delta c_{t}+\delta_{p} \Delta p_{t}+\delta_{e} \Delta e_{t}+\varepsilon_{t}^{z}$

Another specification for emerging Europe replaces the economic policy uncertainty index by the real effective exchange rate (REER) (as, in principle, short-term REER fluctuations should be associated with both changes in economic policy uncertainty, which affect international financial flows, and with changes in the terms of trade, which affect the current account).

These specifications allow for the model to determine trend growth, and thus the output gap, endogenously (equations AII.2-4), and also using the output gap estimates in the WEO database $\left(\tilde{y}_{t}^{W E O}\right)$ as a noisy signal for the unobserved output gap,

$\tilde{y}_{t}^{W E O}=\tilde{y}_{t-1}+\mu_{t}+\varepsilon_{t}^{\mu}$

The use of $\tilde{y}_{t}^{W E O}$ may help anchoring the filter, in particular in relatively short samples. Noise $\left(\mu_{t}\right)$ is assumed to follow an autoregressive process,

$\mu_{t}=\rho_{m} \mu_{t-1}+\varepsilon_{t}^{\mu}$

\section{Data and Definitions}

Estimates of $\mathrm{r}^{*}$ using L-W are obtained using quarterly data spanning the period, mostly from 2000:Q1 to 2019:Q1.

\footnotetext{
${ }^{3}$ In reality, the nominal exchange rate is endogenous and, ideally could be made an integral part of the model together with the REER. A model along these lines is proposed by Berger and Kempa (2014).
} 
Real interest rate. The observed real interest rate (in percent) is obtained by subtracting the quarterly average of the central bank's nominal policy rate minus the quarterly average of one-year ahead headline inflation expectations from Consensus Economics. In the case of Russia, the policy rate time series takes into consideration the changes in its definition, as stated by the Central Bank of Russia (CBR). For Romania it is the interbank rate.

Core and import price inflation. Core and import price inflation are annualized quarter on quarter changes expressed in percent calculated from seasonally-adjusted series reported by Haver. In particular, import price inflation is calculated from underlying prices expressed in domestic currency and proxied by the GDP deflator on imports.

U.S. 10-year real sovereign yield. It refers to the nominal yield on 10-year treasury bonds deflated by Long-Term inflation expectations as reported by Haver.

Real Effective Exchange Rate (REER). In all countries, the REER data comes from the IMF's World Economic Outlook (WEO) database.

Spread. In Euro Area countries it is measured as the difference between the 10 -year country's government yield relative to Germany's 10-year government yield.

Policy uncertainty index. In emerging Europe economies, the economic policy uncertainty is measured by the news-based index of economic policy uncertainty developed in Baker, Bloom, and Davis (2016). Not available for Romania, but available for all other countries.

Country Risk. In emerging Europe economies, it is measured by the difference between the Emerging Market Bond Index (EMBI) and the international risk-free international interest rate is proxied by the U.S. 10-year real sovereign yield. 


\section{Annex III. Model Priors: Review of The Literature}

Since the publication of the seminar work of Laubach and Williams (L-W, 2003), many researchers have continued using semi-structural models to estimate the natural rate of interest. Some of them extent or modified the L-W model by incorporating a Taylor rule, a stationary Phillips curve, and a second dimension of economic activity like unemployment (Brand and Mazelis, 2019), or by incorporating an equation for unemployment gap fluctuations and credit conditions in the Phillips curve (Kiley, 2015), or by incorporating the financial cycle for private sector-leverage (Krustev, 2018; Belke and Klose, 2019).

With respect to the model estimation, both the estimation of the model in sequential steps and computing the median unbiased estimator and Bayesian estimation are the predominant estimation methodologies. Following Pescatori and Turunen (2015), we estimate the model parameters using Bayesian techniques. Among the model parameters that need to be calibrated, the prior assumptions on the variance of the error terms on $\varepsilon_{t}^{N}$ (potential output), $\varepsilon_{t}^{y}$ (output gap) and $\varepsilon_{t}^{g}$ (potential output growth rate) are very important, as they influence how the variance of $\mathrm{r}^{*}$ responds to (the level and trend) shocks to potential growth and to the unexplained component, $z_{t}$. In other words, they determine how closely $\mathrm{r} *$ follows $\mathrm{g}$.

Tables AIII. 1 presents a range of estimates, including ours, of $\lambda_{g}=\frac{\sigma_{g}}{\sigma_{N}}$ and $\lambda_{z}=\frac{\sigma_{z}}{\sigma_{y}} \frac{a_{r}}{\sqrt{2}}$ from selected papers. Either estimated or calibrated, we find a wide range of values as reflected by the ratio of $\frac{\lambda_{g}}{\lambda_{z}}$. The priors for these parameters have been selected such that they are within the range of values observed in the selected papers.

Sensitivity analysis: The sum of the priors for the autoregressive components of $\mathrm{z}$ used in the baseline analysis is 0.99 . To perform a sensitivity analysis, we introduce a small change and run the exercise with a sum of 0.96, which is similar to the value presented in Laubach and Williams (2003). The results show that for the crisis-trough period and the last data point (2019:Q1), r* is larger for most of the countries in our sample (see Table AIII.2). 


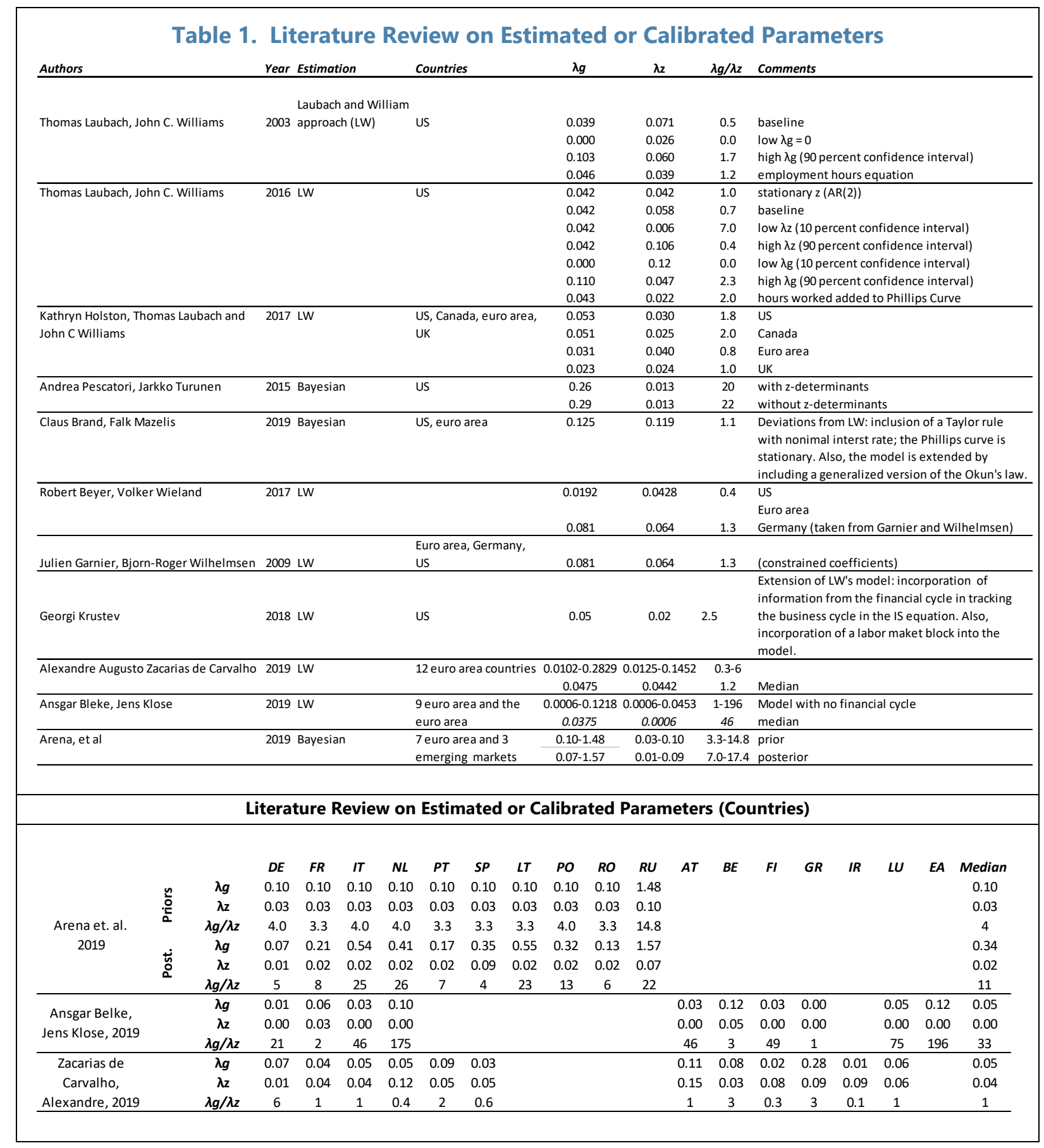


Table 2. Sensitivity Analysis on the Autoregressive Components of the Z Process

\begin{tabular}{|c|c|c|c|c|c|c|c|c|c|c|}
\hline Difference (0.96 -0.99) & FR & IT & $\mathrm{DE}$ & NT & SP & LT & PT & RO & $\mathrm{PO}$ & RU \\
\hline \multicolumn{11}{|l|}{$\mathrm{r}^{*}$} \\
\hline Average pre-crisis & 0.2 & 0.0 & 0.0 & 0.4 & 1.0 & 1.0 & 0.4 & 0.5 & 0.3 & -1.0 \\
\hline Crisis trough & 0.2 & 0.5 & 0.1 & 0.5 & -2.4 & 0.9 & -0.9 & 0.5 & 0.8 & 0.4 \\
\hline Last observation (2019Q1) & 0.5 & 0.7 & 0.7 & 0.8 & -0.1 & 1.0 & 0.7 & 0.6 & 1.0 & 0.5 \\
\hline \multicolumn{11}{|l|}{ g } \\
\hline Average pre-crisis & 0.0 & 0.0 & 0.0 & 0.0 & 0.0 & 0.0 & 0.0 & 0.0 & -0.1 & -1.2 \\
\hline Crisis trough & 0.0 & 0.0 & 0.0 & 0.0 & 0.7 & 0.0 & 0.1 & -0.1 & -0.1 & 0.6 \\
\hline Last observation (2019Q1) & 0.0 & 0.0 & 0.0 & 0.0 & -0.1 & 0.0 & 0.0 & 0.0 & 0.0 & 0.5 \\
\hline \multicolumn{11}{|l|}{$r^{*}-g$} \\
\hline Average pre-crisis & 0.2 & 0.0 & 0.0 & 0.4 & 1.1 & 1.0 & 0.4 & 0.4 & 0.4 & 0.2 \\
\hline Crisis trough & 0.2 & 0.6 & 0.1 & 0.6 & -3.1 & 0.9 & -0.9 & 0.5 & 1.1 & -0.1 \\
\hline Last observation (2019Q1) & 0.5 & 0.8 & 0.7 & 0.8 & 0.0 & 1.0 & 0.7 & 0.5 & 1.0 & 0.0 \\
\hline
\end{tabular}




\section{ANNEX IV. PRIOR AND POSTERIOR DISTRIBUTIONS OF PARAMETER AND SHOCK ESTIMATES}

The model's parameters presented in Annex II are estimated using Bayesian methods following Pescatori and Turunen (2015). Table AIV.1, below, shows the Bayesian priors and posterior estimates for the parameters of the model. The priors were set using information from Pescatori and Turunen and single-equation regression analysis. Priors are tight for the standard deviation of $c$, as well as for the output gap persistence $\left(\alpha_{1}+\alpha_{2}\right)$ and the persistence of the exogenous process $\mathrm{z}\left(\delta_{1}+\delta_{2}\right)$. In contrast, the priors for the ratio of the standard deviations od trend growth and potential output $\left(\lambda_{g}\right)$ and the ratio of the standard deviations of the error of the z-process and IS curve $\left(\lambda_{z}\right)$ are wider. The priors for all standard deviations are inverse gamma and distributed in line with Bayesian DSGE literature (OsorioButrón, 2016).

\begin{tabular}{|llc|}
\hline & \multicolumn{1}{c}{ Table 1. Definitions and Distributions of Key Parameters } \\
\hline D & & Distribution \\
\hline I1 & Autertemporal elasticity of substitution & gamma \\
rhod & d1 +d2 (Autoregressive coefficients on z) & gamma \\
a1 & Autoregressive coefficient on output gap & beta \\
rhoA & the sum of a1 and a2 & gamma \\
a_r & Coefficient on interest rate gap in the IS curve & beta \\
by & Coefficient on output gap in the Phillips curve & gamma \\
b1 & Autoregressive coefficient on inflation in Phillips curve & beta \\
b2 & AR coef. On further lags in inflation in PC & beta \\
dc & Coefficient in z equation for spread (bond yield, CDS) & beta \\
de & Coefficient in z equation for trading partner growth & normal \\
dp & Coefficient in z equation for REER gap & normal \\
lambdag & Variation in trend growth & normal \\
lambdaz & Variation in natural interest rate trend (z) & inv. Gamma \\
eps_n & Shock to potential output equation & inv. Gamma \\
eps_IS & Shock to the IS curve & inv. Gamma \\
eps_PC & Shock to the Phillips curve & inv. Gamma \\
eps_nu & Shock to output gap noise & inv. Gamma \\
eps_me & Shock to output gap signal & inv. Gamma \\
\hline
\end{tabular}




\begin{tabular}{|c|c|c|c|c|c|c|c|c|c|c|c|}
\hline \multirow[b]{2}{*}{ Portugal } & \multirow[b]{2}{*}{ Description } & \multirow[b]{2}{*}{ Prior } & \multirow[b]{2}{*}{ Std. Dev } & \multicolumn{4}{|c|}{ With WEO output gap, Z modelled as a RW } & \multicolumn{4}{|c|}{$\begin{array}{l}\text { With WEO output gap, Z modelled as an } \\
\text { AR(2) with explanatory variables }\end{array}$} \\
\hline & & & & Mode & Median & 10th & 90th & Mode & Median & 10th & 90th \\
\hline c & elasticity of substitution & 1.00 & 0.05 & 1.01 & 1.01 & 0.95 & 1.07 & 0.98 & 1.00 & 0.94 & 1.06 \\
\hline $\mathrm{d} 1$ & AR coef. on z & 0.85 & 0.25 & & & & & 1.03 & 0.89 & 0.59 & 1.28 \\
\hline rhod & $\mathrm{d} 1+\mathrm{d} 2$ (AR coefs. On z) & 0.99 & 0.00 & & & & & 0.99 & 0.99 & 0.99 & 0.99 \\
\hline a1 & AR coef. on output gap & 1.01 & 0.10 & 1.13 & 1.14 & 1.04 & 1.25 & 1.15 & 1.13 & 1.02 & 1.25 \\
\hline rhoA & $\begin{array}{l}a 1+a 2 \\
\text { Coef.on interest rate gap in IS }\end{array}$ & 0.91 & 0.05 & 0.93 & 0.94 & 0.90 & 0.97 & 0.94 & 0.94 & 0.89 & 0.97 \\
\hline$a_{-} r$ & curve & 0.08 & 0.05 & 0.06 & 0.09 & 0.03 & 0.17 & 0.05 & 0.08 & 0.02 & 0.17 \\
\hline by & Coef. On output gap in PC & 0.05 & 0.01 & 0.06 & 0.05 & 0.04 & 0.06 & 0.05 & 0.05 & 0.04 & 0.06 \\
\hline b1 & $\begin{array}{l}\text { AR coef. On inflation in PC } \\
\text { AR coef. On further lags in }\end{array}$ & 0.19 & 0.10 & 0.18 & 0.21 & 0.12 & 0.31 & 0.19 & 0.22 & 0.13 & 0.32 \\
\hline b2 & $\begin{array}{l}\text { inflation in PC } \\
\text { coefficient in } z \text { equation for }\end{array}$ & 0.46 & 0.10 & & & & & 0.59 & 0.54 & 0.43 & 0.64 \\
\hline $\mathrm{dc}$ & $\begin{array}{l}\text { bond yield spread } \\
\text { coefficient in } z \text { equation for }\end{array}$ & -0.25 & 0.10 & & & & & -0.32 & -0.28 & -0.41 & -0.15 \\
\hline de & $\begin{array}{l}\text { trading partner growth } \\
\text { coefficient in } z \text { equation for }\end{array}$ & 0.25 & 1.00 & & & & & 0.30 & 0.23 & -0.06 & 0.54 \\
\hline $\mathrm{dp}$ & REER gap & 0.25 & 1.00 & 0.42 & 0.21 & -0.10 & 0.51 & 0.37 & 0.20 & -0.10 & 0.52 \\
\hline lambdag & variation in trend growth & 0.10 & inf. & 0.15 & 0.17 & 0.08 & 0.27 & 0.17 & 0.17 & 0.10 & 0.28 \\
\hline lambdaz & variation in $r^{\star}$ trend & 0.03 & inf. & 0.01 & 0.02 & 0.01 & 0.05 & 0.02 & 0.03 & 0.01 & 0.11 \\
\hline eps_n & Shock to potential output eq. & 0.53 & inf. & 0.21 & 0.22 & 0.18 & 0.27 & 0.21 & 0.22 & 0.18 & 0.27 \\
\hline eps_IS & Shock to IS curve & 0.70 & inf. & 0.59 & 0.59 & 0.52 & 0.66 & 0.64 & 0.58 & 0.51 & 0.67 \\
\hline eps_PC & Shock to PC & 0.81 & inf. & 1.19 & 1.20 & 1.08 & 1.34 & 1.25 & 1.21 & 1.09 & 1.34 \\
\hline eps_nu & Shock to output gap noise & 0.25 & 0.50 & 0.30 & 0.29 & 0.26 & 0.34 & 0.30 & 0.29 & 0.26 & 0.34 \\
\hline eps_me & Shock to output gap signal & 0.22 & 0.50 & 0.24 & 0.27 & 0.24 & 0.31 & 0.27 & 0.27 & 0.24 & 0.31 \\
\hline & & & & \multicolumn{4}{|c|}{ With WEO output gap, Z modelled as a RW } & \multicolumn{4}{|c|}{$\begin{array}{c}\text { With WEO output gap, } Z \text { modelled as an } \\
\text { AR(2) with explanatory variables }\end{array}$} \\
\hline Spain & Description & Prior & Std. Dev & Mode & Median & 10th & 90th & Mode & Median & 10th & 90th \\
\hline c & elasticity of substitution & 1.00 & 0.05 & 0.98 & 1.00 & 0.94 & 1.07 & 0.99 & 1.00 & 0.94 & 1.07 \\
\hline d1 & AR coef. on z & 0.85 & 0.25 & & & & & 0.88 & 0.90 & 0.60 & 1.27 \\
\hline rhod & $\mathrm{d} 1+\mathrm{d} 2$ (AR coefs. On z) & 0.99 & 0.00 & & & & & 0.99 & 0.99 & 0.99 & 0.99 \\
\hline a1 & AR coef. on output gap & 1.20 & 0.10 & 1.26 & 1.33 & 1.19 & 1.48 & 1.32 & 1.30 & 1.16 & 1.45 \\
\hline rhoA & $\begin{array}{l}a 1+a 2 \\
\text { Coef.on interest rate gap in IS }\end{array}$ & 0.91 & 0.05 & 0.93 & 0.92 & 0.88 & 0.96 & 0.92 & 0.92 & 0.87 & 0.95 \\
\hline$a_{-} r$ & curve & 0.15 & 0.05 & 0.16 & 0.18 & 0.11 & 0.26 & 0.17 & 0.19 & 0.12 & 0.27 \\
\hline by & Coef. On output gap in PC & 0.30 & 0.01 & 0.30 & 0.29 & 0.27 & 0.30 & 0.29 & 0.29 & 0.27 & 0.30 \\
\hline b1 & AR coef. On inflation in PC & 0.47 & 0.10 & 0.37 & 0.38 & 0.28 & 0.48 & 0.41 & 0.37 & 0.28 & 0.48 \\
\hline b2 & $\begin{array}{l}\text { AR coef. On further lags in } \\
\text { inflation in PC } \\
\text { coefficient in z equation for }\end{array}$ & 0.35 & 0.10 & & & & & 0.26 & 0.34 & 0.23 & 0.46 \\
\hline dc & $\begin{array}{l}\text { bond yield spread } \\
\text { coefficient in } z \text { equation for }\end{array}$ & -0.25 & 0.10 & & & & & -0.24 & -0.29 & -0.42 & -0.16 \\
\hline de & $\begin{array}{l}\text { trading partner growth } \\
\text { coefficient in } z \text { equation for }\end{array}$ & 0.25 & 1.00 & & & & & 0.31 & 0.24 & 0.00 & 0.50 \\
\hline$d p$ & REER gap & 0.25 & 1.00 & 0.16 & 0.25 & -0.07 & 0.57 & 0.13 & 0.13 & -0.09 & 0.39 \\
\hline lambdag & variation in trend growth & 0.10 & inf. & 0.34 & 0.35 & 0.29 & 0.43 & 0.31 & 0.35 & 0.29 & 0.44 \\
\hline lambdaz & variation in $r^{\star}$ trend & 0.03 & inf. & 0.10 & 0.09 & 0.05 & 0.14 & 0.10 & 0.10 & 0.05 & 0.15 \\
\hline eps_n & Shock to potential output eq. & 0.53 & inf. & 0.11 & 0.12 & 0.10 & 0.14 & 0.12 & 0.12 & 0.10 & 0.15 \\
\hline eps_IS & Shock to IS curve & 0.70 & inf. & 0.23 & 0.25 & 0.21 & 0.29 & 0.25 & 0.25 & 0.20 & 0.30 \\
\hline eps_PC & Shock to PC & 0.81 & inf. & 2.09 & 2.00 & 1.80 & 2.24 & 2.03 & 2.01 & 1.81 & 2.25 \\
\hline eps_nu & Shock to output gap noise & 0.50 & 0.50 & 0.05 & 0.05 & 0.04 & 0.07 & 0.04 & 0.05 & 0.04 & 0.07 \\
\hline eps_me & Shock to output gap signal & 0.50 & 0.50 & 0.04 & 0.04 & 0.03 & 0.06 & 0.05 & 0.04 & 0.03 & 0.06 \\
\hline
\end{tabular}




\begin{tabular}{|c|c|c|c|c|c|c|c|c|c|c|c|}
\hline \multirow[b]{2}{*}{ Italy } & \multirow[b]{2}{*}{ Description } & \multirow[b]{2}{*}{ Prior } & \multirow[b]{2}{*}{ Std. Dev } & \multicolumn{4}{|c|}{ With WEO output gap, Z modelled as a RW } & \multicolumn{4}{|c|}{$\begin{array}{l}\text { With WEO output gap, } Z \text { modelled as an } \\
\text { AR(2) with explanatory variables }\end{array}$} \\
\hline & & & & Mode & Median & 10th & 90th & Mode & Median & 10th & 90th \\
\hline c & elasticity of substitution & 1.00 & 0.05 & 0.98 & 1.00 & 0.94 & 1.07 & 0.97 & 1.00 & 0.94 & 1.07 \\
\hline d1 1 & AR coef. on $z$ & 0.85 & 0.25 & & & & & 0.96 & 0.89 & 0.58 & 1.26 \\
\hline rhod & $\mathrm{d} 1+\mathrm{d} 2$ (AR coefs. On z) & 0.99 & 0.00 & & & & & 0.99 & 0.99 & 0.99 & 0.99 \\
\hline a1 & AR coef. on output gap & 1.60 & 0.10 & 1.59 & 1.55 & 1.46 & 1.64 & 1.50 & 1.53 & 1.44 & 1.61 \\
\hline rhoA & $\begin{array}{l}\mathrm{a} 1+\mathrm{a} 2 \\
\text { Coef.on interest rate gap in IS }\end{array}$ & 0.91 & 0.05 & 0.98 & 0.94 & 0.90 & 0.97 & 0.95 & 0.94 & 0.90 & 0.97 \\
\hline$a_{-} r$ & curve & 0.18 & 0.05 & 0.12 & 0.13 & 0.09 & 0.18 & 0.16 & 0.14 & 0.10 & 0.19 \\
\hline by & Coef. On output gap in PC & 0.09 & 0.01 & 0.09 & 0.09 & 0.08 & 0.10 & 0.09 & 0.09 & 0.08 & 0.10 \\
\hline b1 & $\begin{array}{l}\text { AR coef. On inflation in PC } \\
\text { AR coef. On further lags in }\end{array}$ & 0.35 & 0.10 & 0.39 & 0.35 & 0.27 & 0.45 & 0.39 & 0.36 & 0.27 & 0.45 \\
\hline b2 & $\begin{array}{l}\text { inflation in PC } \\
\text { coefficient in } z \text { equation for }\end{array}$ & 0.31 & 0.10 & 0.28 & 0.32 & 0.21 & 0.42 & 0.26 & 0.31 & 0.20 & 0.41 \\
\hline dc & $\begin{array}{l}\text { bond yield spread } \\
\text { coefficient in z equation for }\end{array}$ & -0.25 & 0.10 & & & & & -0.74 & -0.47 & -0.79 & -0.16 \\
\hline de & $\begin{array}{l}\text { trading partner growth } \\
\text { coefficient in z equation for }\end{array}$ & 0.25 & 1.00 & & & & & 0.10 & 0.20 & -0.09 & 0.48 \\
\hline $\mathrm{dp}$ & CDS spread & 0.25 & 1.00 & & & & & -0.14 & 0.12 & -0.15 & 0.41 \\
\hline lambdag & variation in trend growth & 0.10 & inf. & 0.53 & 0.54 & 0.34 & 0.80 & 0.44 & 0.51 & 0.31 & 0.77 \\
\hline lambdaz & variation in $\mathrm{r}^{\star}$ trend & 0.03 & inf. & 0.01 & 0.02 & 0.01 & 0.06 & 0.02 & 0.02 & 0.01 & 0.04 \\
\hline eps_n & Shock to potential output eq. & 0.13 & inf. & 0.06 & 0.08 & 0.05 & 0.20 & 0.07 & 0.08 & 0.05 & 0.17 \\
\hline eps_ls & Shock to IS curve & 0.45 & inf. & 0.98 & 1.04 & 0.93 & 1.18 & 0.98 & 1.04 & 0.93 & 1.17 \\
\hline eps_PC & Shock to PC & 0.50 & inf. & 0.98 & 1.08 & 0.98 & 1.20 & 1.08 & 1.08 & 0.98 & 1.22 \\
\hline eps_nu & Shock to output gap noise & 0.50 & 0.50 & 0.28 & 0.28 & 0.24 & 0.31 & 0.25 & 0.28 & 0.24 & 0.31 \\
\hline eps_me & Shock to output gap signal & 0.50 & 0.50 & 0.26 & 0.25 & 0.23 & 0.29 & 0.26 & 0.26 & 0.23 & 0.29 \\
\hline
\end{tabular}

\begin{tabular}{|c|c|c|c|c|c|c|c|c|c|c|c|}
\hline \multirow[b]{2}{*}{ Netherlands } & \multirow[b]{2}{*}{ Description } & \multirow[b]{2}{*}{ Prior } & \multirow[b]{2}{*}{ Std. Dev } & \multicolumn{4}{|c|}{ With WEO output gap, Z modelled as a RW } & \multicolumn{4}{|c|}{$\begin{array}{l}\text { With WEO output gap, } Z \text { modelled as an } \\
\text { AR(2) with explanatory variables }\end{array}$} \\
\hline & & & & Mode & Median & 10th & 90th & Mode & Median & 10th & 90th \\
\hline c & elasticity of substitution & 1.00 & 0.05 & 1.00 & 1.00 & 0.94 & 1.06 & 1.00 & 1.00 & 0.94 & 1.06 \\
\hline d1 & AR coef. on z & 0.85 & 0.25 & & & & & 0.65 & 0.84 & 0.55 & 1.22 \\
\hline rhod & $\mathrm{d} 1+\mathrm{d} 2$ (AR coefs. On z) & 0.99 & 0.00 & & & & & 0.99 & 0.99 & 0.99 & 0.99 \\
\hline a1 & AR coef. on output gap & 1.24 & 0.10 & 1.25 & 1.25 & 1.15 & 1.35 & 1.25 & 1.25 & 1.15 & 1.35 \\
\hline rhoA & $\begin{array}{l}\mathrm{a} 1+\mathrm{a} 2 \\
\text { Coef.on interest rate gap in }\end{array}$ & 0.90 & 0.05 & 0.95 & 0.93 & 0.89 & 0.96 & 0.95 & 0.93 & 0.89 & 0.96 \\
\hline$a_{-} r$ & IS curve & 0.10 & 0.05 & 0.07 & 0.07 & 0.03 & 0.12 & 0.07 & 0.07 & 0.03 & 0.12 \\
\hline by & Coef. On output gap in PC & 0.08 & 0.01 & 0.07 & 0.08 & 0.07 & 0.09 & 0.07 & 0.08 & 0.07 & 0.09 \\
\hline b1 & $\begin{array}{l}\text { AR coef. On inflation in PC } \\
\text { AR coef. On further lags in }\end{array}$ & 0.34 & 0.10 & 0.37 & 0.39 & 0.30 & 0.48 & 0.37 & 0.39 & 0.30 & 0.48 \\
\hline b2 & $\begin{array}{l}\text { inflation in PC } \\
\text { coefficient in } z \text { equation for }\end{array}$ & 0.50 & 0.10 & 0.56 & 0.55 & 0.44 & 0.66 & 0.56 & 0.55 & 0.44 & 0.66 \\
\hline dc & $\begin{array}{l}\text { bond yield spread } \\
\text { coefficient in z equation for }\end{array}$ & -0.25 & 0.13 & & & & & -0.29 & -0.27 & -0.43 & -0.10 \\
\hline de & $\begin{array}{l}\text { trading partner growth } \\
\text { coefficient in } z \text { equation for }\end{array}$ & 0.25 & 0.13 & & & & & 0.25 & 0.27 & 0.11 & 0.42 \\
\hline$d p$ & CDS spread & 0.25 & 0.13 & & & & & 0.20 & 0.24 & 0.08 & 0.40 \\
\hline lambdag & variation in trend growth & 0.10 & inf. & 0.30 & 0.41 & 0.24 & 0.66 & 0.30 & 0.41 & 0.24 & 0.66 \\
\hline lambdaz & variation in $\mathrm{r}^{*}$ trend & 0.03 & inf. & 0.02 & 0.02 & 0.01 & 0.03 & 0.02 & 0.02 & 0.01 & 0.03 \\
\hline eps_n & Shock to potential output eq. & 0.10 & inf. & 0.05 & 0.07 & 0.04 & 0.15 & 0.05 & 0.07 & 0.04 & 0.15 \\
\hline eps_IS & Shock to Is curve & 0.45 & inf. & 1.28 & 1.33 & 1.19 & 1.47 & 1.28 & 1.33 & 1.19 & 1.47 \\
\hline eps_PC & Shock to PC & 0.56 & inf. & 1.84 & 1.93 & 1.75 & 2.17 & 1.84 & 1.93 & 1.75 & 2.17 \\
\hline eps_nu & Shock to output gap noise & 0.50 & 0.50 & 0.28 & 0.28 & 0.25 & 0.31 & 0.28 & 0.28 & 0.25 & 0.31 \\
\hline eps_me & Shock to output gap signal & 0.50 & 0.50 & 0.26 & 0.25 & 0.23 & 0.29 & 0.26 & 0.25 & 0.23 & 0.29 \\
\hline
\end{tabular}




\begin{tabular}{|c|c|c|c|c|c|c|c|c|c|c|c|}
\hline \multirow[b]{2}{*}{ Lithuania } & \multirow[b]{2}{*}{ Description } & \multirow[b]{2}{*}{ Prior } & \multirow[b]{2}{*}{ Std. Dev } & \multicolumn{4}{|c|}{ With WEO output gap, Z modelled as a RW } & \multicolumn{4}{|c|}{$\begin{array}{l}\text { With WEO output gap, Z modelled as an } \\
\text { AR(2) with explanatory variables }\end{array}$} \\
\hline & & & & Mode & Median & 10th & 90th & Mode & Median & 10th & 90th \\
\hline c & elasticity of substitution & 1.00 & 0.05 & 1.04 & 0.99 & 0.93 & 1.06 & 1.00 & 1.00 & 0.93 & 1.06 \\
\hline $\mathrm{d} 1$ & AR coef. on z & 0.85 & 0.25 & & & & & 0.71 & 0.80 & 0.53 & 1.15 \\
\hline rhod & $\mathrm{d} 1+\mathrm{d} 2(\mathrm{AR}$ coefs. On $\mathrm{z})$ & 0.99 & 0.00 & & & & & 0.99 & 0.99 & 0.99 & 0.99 \\
\hline a1 & AR coef. on output gap & 1.19 & 0.10 & 1.20 & 1.20 & 1.10 & 1.29 & 1.20 & 1.18 & 1.08 & 1.28 \\
\hline rhoA & $\begin{array}{l}\mathrm{a} 1+\mathrm{a} 2 \\
\text { Coef.on interest rate gap in IS }\end{array}$ & 0.91 & 0.05 & 0.89 & 0.92 & 0.88 & 0.96 & 0.92 & 0.92 & 0.88 & 0.95 \\
\hline$a_{-} r$ & curve & 0.06 & 0.05 & 0.03 & 0.04 & 0.01 & 0.09 & 0.05 & 0.04 & 0.01 & 0.11 \\
\hline by & Coef. On output gap in PC & 0.11 & 0.01 & 0.12 & 0.11 & 0.10 & 0.13 & 0.11 & 0.11 & 0.10 & 0.13 \\
\hline b1 & $\begin{array}{l}\text { AR coef. On inflation in PC } \\
\text { AR coef. On further lags in }\end{array}$ & 0.47 & 0.10 & 0.27 & 0.31 & 0.23 & 0.40 & 0.36 & 0.31 & 0.23 & 0.41 \\
\hline b2 & $\begin{array}{l}\text { inflation in PC } \\
\text { coefficient in z equation for }\end{array}$ & 0.18 & 0.10 & 0.46 & 0.47 & 0.32 & 0.60 & 0.48 & 0.47 & 0.30 & 0.60 \\
\hline $\mathrm{dc}$ & $\begin{array}{l}\text { bond yield spread } \\
\text { coefficient in z equation for }\end{array}$ & -0.25 & 0.10 & & & & & -0.53 & -0.41 & -1.73 & 0.98 \\
\hline de & $\begin{array}{l}\text { trading partner growth } \\
\text { coefficient in } z \text { equation for }\end{array}$ & 0.25 & 1.00 & & & & & 0.66 & 0.71 & -0.65 & 1.92 \\
\hline $\mathrm{dp}$ & REER gap & 0.25 & 1.00 & & & & & 0.27 & 0.25 & 0.12 & 0.37 \\
\hline rhoNu & & 0.96 & & 0.97 & 0.97 & 0.95 & 0.98 & 0.97 & 0.97 & 0.95 & 0.98 \\
\hline lambdag & variation in trend growth & 0.10 & inf. & 0.50 & 0.55 & 0.41 & 0.74 & 0.55 & 0.54 & 0.40 & 0.76 \\
\hline lambdaz & variation in $\mathrm{r}^{\star}$ trend & 0.03 & inf. & 0.02 & 0.02 & 0.01 & 0.05 & 0.03 & 0.03 & 0.02 & 0.06 \\
\hline eps_n & Shock to potential output eq. & 0.53 & inf. & 0.16 & 0.19 & 0.14 & 0.28 & 0.23 & 0.20 & 0.15 & 0.28 \\
\hline eps_IS & Shock to IS curve & 0.70 & inf. & 2.70 & 2.66 & 2.40 & 2.98 & 2.84 & 2.67 & 2.37 & 2.98 \\
\hline eps_PC & Shock to PC & 0.81 & inf. & 3.71 & 3.91 & 3.51 & 4.34 & 3.76 & 3.91 & 3.48 & 4.38 \\
\hline eps_nu & Shock to output gap noise & 0.50 & 0.50 & 0.28 & 0.29 & 0.26 & 0.33 & 0.31 & 0.30 & 0.26 & 0.34 \\
\hline eps_me & Shock to output gap signal & 0.50 & 0.50 & 0.27 & 0.27 & 0.24 & 0.30 & 0.27 & 0.26 & 0.24 & 0.30 \\
\hline & & & & With WE & output ga & $Z$ mode & as a RW & $\begin{array}{l}\text { With WE } \\
\quad \operatorname{AR}(2\end{array}$ & $\begin{array}{l}\text { output gar } \\
\text { with explan }\end{array}$ & $\begin{array}{l}Z \text { mode } \\
\text { tory var }\end{array}$ & $\begin{array}{l}\mathrm{d} \text { as an } \\
\text { les }\end{array}$ \\
\hline Russia & Description & Prior & Std. Dev & Mode & Median & 10th & 90th & Mode & Median & 10th & 90th \\
\hline c & elasticity of substitution & 1.00 & 0.05 & 0.95 & 1.01 & 0.94 & 1.07 & 1.03 & 1.00 & 0.94 & 1.07 \\
\hline d1 & AR coef. on z & 0.90 & 0.25 & & & & & 0.92 & 0.88 & 0.61 & 1.18 \\
\hline rhod & $\mathrm{d} 1+\mathrm{d} 2(\mathrm{AR}$ coefs. On z) & 0.99 & 0.00 & & & & & 0.99 & 0.99 & 0.99 & 0.99 \\
\hline a1 & AR coef. on output gap & 0.75 & 0.10 & 0.91 & 0.87 & 0.75 & 1.00 & 0.83 & 0.87 & 0.76 & 1.00 \\
\hline rhoA & $\begin{array}{l}\mathrm{a} 1+\mathrm{a} 2 \\
\text { Coef.on interest rate gap in IS }\end{array}$ & 0.74 & 0.05 & 0.69 & 0.70 & 0.64 & 0.76 & 0.72 & 0.70 & 0.64 & 0.76 \\
\hline$a_{-} r$ & curve & 0.30 & 0.05 & 0.26 & 0.24 & 0.19 & 0.29 & 0.26 & 0.24 & 0.19 & 0.30 \\
\hline by & Coef. On output gap in PC & 0.10 & 0.01 & 0.11 & 0.10 & 0.09 & 0.12 & 0.10 & 0.10 & 0.09 & 0.11 \\
\hline b1 & $\begin{array}{l}\text { AR coef. On inflation in PC } \\
\text { AR coef. On further lags in }\end{array}$ & 0.50 & 0.10 & 0.64 & 0.60 & 0.50 & 0.68 & 0.67 & 0.59 & 0.51 & 0.68 \\
\hline b2 & $\begin{array}{l}\text { inflation in PC } \\
\text { coefficient in } z \text { equation for }\end{array}$ & 0.12 & 0.10 & 0.12 & 0.12 & 0.03 & 0.25 & 0.04 & 0.13 & 0.04 & 0.26 \\
\hline $\mathrm{dc}$ & $\begin{array}{l}\text { bond yield spread } \\
\text { coefficient in z equation for }\end{array}$ & 0.25 & 0.10 & & & & & 0.17 & 0.20 & 0.08 & 0.33 \\
\hline de & $\begin{array}{l}\text { trading partner growth } \\
\text { coefficient in z equation for }\end{array}$ & 0.25 & 0.30 & & & & & 0.28 & 0.26 & -0.10 & 0.63 \\
\hline$d p$ & CDS spread & 0.25 & 0.30 & & & & & 0.26 & 0.31 & -0.07 & 0.67 \\
\hline lambdag & variation in trend growth & 1.48 & 0.13 & 1.63 & 1.57 & 1.41 & 1.76 & 1.59 & 1.55 & 1.39 & 1.74 \\
\hline lambdaz & variation in $\mathrm{r}^{*}$ trend & 0.10 & 0.13 & 0.05 & 0.07 & 0.04 & 0.14 & 0.06 & 0.07 & 0.04 & 0.16 \\
\hline eps_n & Shock to potential output eq. & 0.70 & inf. & 1.07 & 1.14 & 0.93 & 1.37 & 0.97 & 1.14 & 0.94 & 1.36 \\
\hline eps_IS & Shock to IS curve & 1.00 & inf. & 0.90 & 0.85 & 0.73 & 1.00 & 1.02 & 0.86 & 0.72 & 1.02 \\
\hline eps_PC & Shock to PC & 3.20 & inf. & 1.06 & 1.10 & 0.98 & 1.24 & 1.04 & 1.09 & 0.98 & 1.22 \\
\hline eps_nu & Shock to output gap noise & 0.50 & 0.50 & 0.44 & 0.42 & 0.35 & 0.51 & 0.45 & 0.42 & 0.36 & 0.51 \\
\hline eps_me & Shock to output gap signal & 0.50 & 0.50 & 0.37 & 0.39 & 0.34 & 0.47 & 0.39 & 0.41 & 0.35 & 0.48 \\
\hline
\end{tabular}




\begin{tabular}{|c|c|c|c|c|c|c|c|c|c|c|c|}
\hline \multirow[b]{2}{*}{ Poland } & \multirow[b]{2}{*}{ Description } & \multirow[b]{2}{*}{ Prior } & \multirow[b]{2}{*}{ Std. Dev } & \multicolumn{4}{|c|}{ With WEO output gap, Z modelled as a RW } & \multicolumn{4}{|c|}{$\begin{array}{l}\text { With WEO output gap, } Z \text { modelled as an } \\
\text { AR(2) with explanatory variables }\end{array}$} \\
\hline & & & & Mode & Median & 10th & 90th & Mode & Median & 10th & 90th \\
\hline c & elasticity of substitution & 1.00 & 0.05 & 0.95 & 0.98 & 0.92 & 1.04 & 0.96 & 0.98 & 0.92 & 1.05 \\
\hline d1 & AR coef. on z & 0.85 & 0.25 & & & & & 0.79 & 0.92 & 0.58 & 1.39 \\
\hline rhod & $\mathrm{d} 1+\mathrm{d} 2$ (AR coefs. On $\mathrm{z})$ & 0.99 & 0.00 & & & & & 0.99 & 0.99 & 0.99 & 0.99 \\
\hline a1 & AR coef. on output gap & 0.75 & 0.10 & 0.71 & 0.66 & 0.58 & 0.76 & 0.65 & 0.67 & 0.57 & 0.77 \\
\hline rhoA & $\begin{array}{l}\mathrm{a} 1+\mathrm{a} 2 \\
\text { Coef.on interest rate gap in IS }\end{array}$ & 0.74 & 0.05 & 0.73 & 0.75 & 0.69 & 0.81 & 0.71 & 0.75 & 0.68 & 0.80 \\
\hline$a_{-} r$ & curve & 0.30 & 0.05 & 0.20 & 0.23 & 0.19 & 0.28 & 0.27 & 0.24 & 0.19 & 0.29 \\
\hline by & Coef. On output gap in PC & 0.10 & 0.01 & 0.09 & 0.10 & 0.09 & 0.11 & 0.10 & 0.10 & 0.09 & 0.12 \\
\hline b1 & $\begin{array}{l}\text { AR coef. On inflation in PC } \\
\text { AR coef. On further lags in }\end{array}$ & 0.50 & 0.10 & 0.69 & 0.67 & 0.58 & 0.75 & 0.63 & 0.66 & 0.57 & 0.74 \\
\hline b2 & $\begin{array}{l}\text { inflation in PC } \\
\text { coefficient in } z \text { equation for }\end{array}$ & 0.12 & 0.10 & 0.17 & 0.17 & 0.05 & 0.30 & 0.27 & 0.19 & 0.06 & 0.33 \\
\hline dc & $\begin{array}{l}\text { bond yield spread } \\
\text { coefficient in } z \text { equation for }\end{array}$ & 0.25 & 0.10 & & & & & 0.22 & 0.23 & 0.11 & 0.34 \\
\hline de & $\begin{array}{l}\text { trading partner growth } \\
\text { coefficient in } z \text { equation for }\end{array}$ & 0.25 & 0.20 & & & & & 0.27 & 0.36 & 0.11 & 0.59 \\
\hline$d p$ & CDS spread & 0.25 & 0.30 & & & & & 0.21 & 0.23 & 0.09 & 0.35 \\
\hline lambdag & variation in trend growth & 0.10 & & 0.34 & 0.32 & 0.09 & 0.55 & 0.37 & 0.33 & 0.13 & 0.54 \\
\hline lambdaz & variation in $\mathrm{r}^{*}$ trend & 0.03 & & 0.02 & 0.02 & 0.01 & 0.05 & 0.01 & 0.03 & 0.01 & 0.06 \\
\hline eps_n & Shock to potential output eq. & 0.70 & inf. & 0.23 & 0.26 & 0.19 & 0.40 & 0.18 & 0.25 & 0.19 & 0.35 \\
\hline eps_IS & Shock to IS curve & 1.00 & inf. & 0.79 & 0.78 & 0.69 & 0.88 & 0.75 & 0.77 & 0.69 & 0.88 \\
\hline eps_PC & Shock to PC & 1.50 & inf. & 0.62 & 0.59 & 0.54 & 0.67 & 0.58 & 0.59 & 0.53 & 0.66 \\
\hline eps_nu & Shock to output gap noise & 0.50 & 0.50 & 0.33 & 0.35 & 0.31 & 0.41 & 0.33 & 0.35 & 0.31 & 0.41 \\
\hline eps_me & Shock to output gap signal & 0.50 & 0.50 & 0.29 & 0.30 & 0.26 & 0.34 & 0.31 & 0.30 & 0.26 & 0.35 \\
\hline & & & & With WE & output ga & $Z$ mod & as a RW & $\begin{array}{l}\text { With WE } \\
\quad \operatorname{AR}(2\end{array}$ & $\begin{array}{l}\text { output ga } \\
\text { with expla }\end{array}$ & , Z moc & $\begin{array}{l}\text { d as an } \\
\text { les }\end{array}$ \\
\hline Romania & Description & Prior & Std. Dev & Mode & Median & 10th & 90th & Mode & Median & 10th & 90th \\
\hline c & elasticity of substitution & 1.00 & 0.05 & 1.01 & 0.99 & 0.94 & 1.06 & 1.01 & 0.99 & 0.93 & 1.06 \\
\hline d1 & AR coef. on z & 0.85 & 0.25 & & & & & 0.87 & 0.86 & 0.56 & 1.24 \\
\hline rhod & $\mathrm{d} 1+\mathrm{d} 2(\mathrm{AR}$ coefs. On z) & 0.99 & 0.00 & & & & & 0.99 & 0.99 & 0.99 & 0.99 \\
\hline a1 & AR coef. on output gap & 0.80 & 0.10 & 0.92 & 0.88 & 0.77 & 0.98 & 0.87 & 0.87 & 0.78 & 0.98 \\
\hline rhoA & $\begin{array}{l}\mathrm{a} 1+\mathrm{a} 2 \\
\text { Coef.on interest rate gap in IS }\end{array}$ & 0.80 & 0.05 & 0.89 & 0.87 & 0.83 & 0.90 & 0.88 & 0.87 & 0.82 & 0.90 \\
\hline$a_{-} r$ & curve & 0.10 & 0.05 & 0.08 & 0.08 & 0.04 & 0.12 & 0.06 & 0.08 & 0.04 & 0.13 \\
\hline by & Coef. On output gap in PC & 0.11 & 0.01 & 0.11 & 0.11 & 0.09 & 0.12 & 0.10 & 0.11 & 0.09 & 0.12 \\
\hline b1 & $\begin{array}{l}\text { AR coef. On inflation in PC } \\
\text { AR coef. On further lags in }\end{array}$ & 0.50 & 0.10 & 0.54 & 0.52 & 0.43 & 0.61 & 0.56 & 0.53 & 0.43 & 0.63 \\
\hline b2 & $\begin{array}{l}\text { inflation in PC } \\
\text { coefficient in z equation for }\end{array}$ & 0.12 & 0.10 & 0.18 & 0.17 & 0.05 & 0.33 & 0.04 & 0.16 & 0.04 & 0.30 \\
\hline $\mathrm{dc}$ & $\begin{array}{l}\text { bond yield spread } \\
\text { coefficient in z equation for }\end{array}$ & 0.25 & 0.10 & & & & & 0.24 & 0.25 & 0.12 & 0.38 \\
\hline de & $\begin{array}{l}\text { trading partner growth } \\
\text { coefficient in } z \text { equation for }\end{array}$ & 0.25 & 0.20 & & & & & 0.16 & 0.28 & 0.02 & 0.55 \\
\hline$d p$ & CDS spread & 0.25 & 0.30 & & & & & 0.23 & 0.24 & 0.12 & 0.38 \\
\hline lambdag & variation in trend growth & 0.10 & inf. & 0.06 & 0.13 & 0.05 & 0.24 & 0.12 & 0.14 & 0.06 & 0.27 \\
\hline lambdaz & variation in $\mathrm{r}^{*}$ trend & 0.03 & inf. & 0.02 & 0.02 & 0.01 & 0.07 & 0.01 & 0.02 & 0.01 & 0.05 \\
\hline eps_n & Shock to potential output eq. & 0.70 & inf. & 0.20 & 0.21 & 0.16 & 0.28 & 0.23 & 0.21 & 0.17 & 0.28 \\
\hline eps_Is & Shock to IS curve & 1.00 & inf. & 1.66 & 1.79 & 1.61 & 2.00 & 1.82 & 1.80 & 1.61 & 2.02 \\
\hline eps_PC & Shock to PC & 1.50 & inf. & 1.57 & 1.62 & 1.45 & 1.81 & 1.51 & 1.59 & 1.44 & 1.80 \\
\hline eps_nu & Shock to output gap noise & 0.50 & 0.50 & 0.27 & 0.30 & 0.26 & 0.34 & 0.30 & 0.30 & 0.26 & 0.34 \\
\hline eps_me & Shock to output gap signal & 0.50 & 0.50 & 0.28 & 0.28 & 0.25 & 0.31 & 0.28 & 0.27 & 0.24 & 0.31 \\
\hline
\end{tabular}

CInternational Monetary Fund. Not for Redistribution 


\section{Annex V. Technical Details on Factor Models}

Both the Del Negro et al (2017) and Del Negro et al (2019) papers-henceforth DN17 and DN19-are based upon the same broad structure: a VAR with common (unoberved) trends. This annex will provide a brief summary of the methodology in each paper and outline the data and estimation proceedure for the European countries covered here.

We decompose a vector of observable variables $\left(y_{t}\right)$ into its trend component $\left(\bar{y}_{t}\right)$ and its cyclical component $\left(\tilde{y}_{t}\right)$ :

$$
y_{t}=\Lambda \bar{y}_{t}+\tilde{y}_{t} \quad(\mathrm{AV} .1)
$$

In DN17, $y_{t}$ is made up of inflation, inflation expectations, short-term nominal interest rates, expectations of the short rates and long-term nominal interest rates. The trends of these variables are assumed to be cointegrated as follows:

$$
\Lambda=\left(\begin{array}{lll}
1 & 0 & 0 \\
1 & 0 & 0 \\
1 & 1 & 0 \\
1 & 1 & 0 \\
1 & 1 & 1
\end{array}\right)
$$

This means that inflation and inflation expectations are cointegrated, but are independent of trend (short- and long-term) interest rates. Trend, actual and expected, short-term nominal interest rates are a function of trend inflation; while long rates are determined by trend inflation and trend short-term real rates. $\bar{y}_{t}$, therefore is a $(3 \times 1)$ vector of trend - inflation, real short rates, and the term premium. Trend real short rates is the estimate of $r^{*}$. The cyclical component, $\tilde{y}_{t}$, is a $5 \times 1$ vector, which is governed by VAR set-up. Each variable in $\tilde{y}_{t}$ is unconstrained in terms of the coefficents on its lags and those of the other components in $\tilde{y}_{t}$. This trend-cycle decomposition is estimated using a Bayesian Kalman Filter (see Table AV.1 and AV.2 for details). A time-series of the trend relative to the data for each country is shown in Figures AV.1-AV.9.

DN19 uses a similar set-up, but here expectation of inflation and the short-rate are not used. Instead, trends in the Euro Area countries are estimated jointly, with common factors for trend inflation, $\mathrm{r}^{*}$ and the trend term permium estimated together. Here, inflation, short-rates and long-rates for each country are stacked in $y_{t}$. There are seven countries and three variables, so $y_{t}$ is a $21 \mathrm{x} 1$ vector. The trend variables are cointegrated as follows: 


$$
\Lambda \bar{y}_{t}=\left(\begin{array}{ccccccccc}
1 & 0 & 0 & 1 & 0 & 0 & 0 & 0 & 0 \\
1 & 1 & 0 & 1 & 1 & 0 & 0 & 0 & 0 \\
1 & 1 & 1 & 1 & 1 & 1 & 0 & 0 & 0 \\
1 & 0 & 0 & 0 & 0 & 0 & 1 & 0 & 0 \\
1 & 1 & 0 & 0 & 0 & 0 & 1 & 1 & 0 \\
1 & 1 & 1 & 0 & 0 & 0 & 1 & 1 & 1
\end{array}\right)\left(\begin{array}{c}
C_{t} \\
i_{t}^{1} \\
i_{t}^{n}
\end{array}\right) \quad \mathrm{AV} .3
$$

Here, $C_{t}$ is a $3 \times 1$ vector representing the common Euro Area factor on trend inflation, shortrates and long-rates, which are cointegrated as in DN17. $i_{t}^{1}$ and $i_{t}^{n}$ are $3 \times 1$ vector of countryspecific trends, which are orthogonal to both the common trend and that of the other countries. For example, trend inflation in Germany is determined by the common inflation component plus the Germany-specific trend (first row in equation AV.3). Trend short rates are a function of both the (common and country-specific) inflation trend, and the common and country specific trend in real short rates (the $r^{*}$ estimate). Finally, trend long-rates are cointegrated with the factors just described plus a common and country-specific trend term premium. Again, this is estimated using a Kalman Filter with Bayesian techniques (see tables AV.3 and AV.4). The trend components for each county are shown in Figures AV.10-13.

Table 1. Prior and Posterior Means for the Variance of Trend and Cycle Components for DN17

\begin{tabular}{lcccccc}
\hline & \multicolumn{2}{c}{ Russia } & \multicolumn{2}{c}{ Czech Rep. } & \multicolumn{2}{c}{ Poland } \\
& Prior & Posterior & Prior & Posterior & Prior & Posterior \\
\hline Variance of cyclical component & & & & & & \\
Inflation & 5.00 & 10.13 & 3.00 & 0.23 & 3.00 & 10.13 \\
Short rate & 3.00 & 7.98 & 2.00 & 4.02 & 2.00 & 7.98 \\
Long-rate & 2.00 & 3.72 & 2.00 & 1.57 & 2.00 & 3.72 \\
Variance of trend component & & & & & & \\
Inflation & 0.08 & 0.51 & 0.08 & 1.26 & 0.40 & 1.10 \\
Short rate & 0.08 & 1.50 & 0.02 & 0.15 & 0.10 & 0.24 \\
Long-rate & 0.08 & 2.45 & 0.02 & 0.23 & 0.10 & 0.25 \\
Ratio of cycle to trend & & & & & & \\
Inflation & 63 & 20 & 38 & 0 & 8 & 9 \\
Short rate & 38 & 5 & 100 & 28 & 20 & 33 \\
Long-rate & 25 & 2 & 100 & 7 & 20 & 15 \\
\hline
\end{tabular}


Table 2. Data for DN17

\begin{tabular}{|c|c|c|}
\hline Variable & Description & Source \\
\hline \multicolumn{3}{|l|}{ Czech Republic } \\
\hline Inflation & Seaonally adjusted CPI & Czech Statistical Office/Haver Analytics \\
\hline Inflation Expectations & Inflation, $10 y$ rs ahead & Consensus Economics \\
\hline Short-term interest rate & 3 month T-bill yield & Bloomberg \\
\hline Expectaions of short rate & Forward rate, $3 \mathrm{~m}$ T-bill, $1 \mathrm{yr}$ ahead & Consensus Economics \\
\hline Long-term interest rate & 10-year bond yield & Haver Analytics \\
\hline \multicolumn{3}{|l|}{ Russia } \\
\hline Inflation & Seaonally adjusted CPI & Federal State Statistics Service/Haver \\
\hline Inflation Expectations & Inflation, $10 \mathrm{yrs}$ ahead & Consensus Economics \\
\hline Short-term interest rate & Central Bank Policy Rate & Haver Analytics \\
\hline Expectaions of short rate & Short rate, $5 \mathrm{yr}$ ahead forecast & IMF WEO database \\
\hline Long-term interest rate & 10 -year bond yield & FRED database \\
\hline \multicolumn{3}{|l|}{ Poland } \\
\hline Inflation & Seaonally adjusted CPI & Central Statistical Office/Haver Analytics \\
\hline Inflation Expectations & Inflation, $10 \mathrm{yrs}$ ahead & Consensus Economics \\
\hline Short-term interest rate & Inter-bank interest rate, weekly & Haver Analytics \\
\hline Expectaions of short rate & Forward rate, $3 \mathrm{~m}$ T-bill, $1 \mathrm{yr}$ ahead & Consensus Economics \\
\hline Long-term interest rate & 10-year bond yield & Bloomberg \\
\hline
\end{tabular}

Figure 1. Czech Rep., Inflation

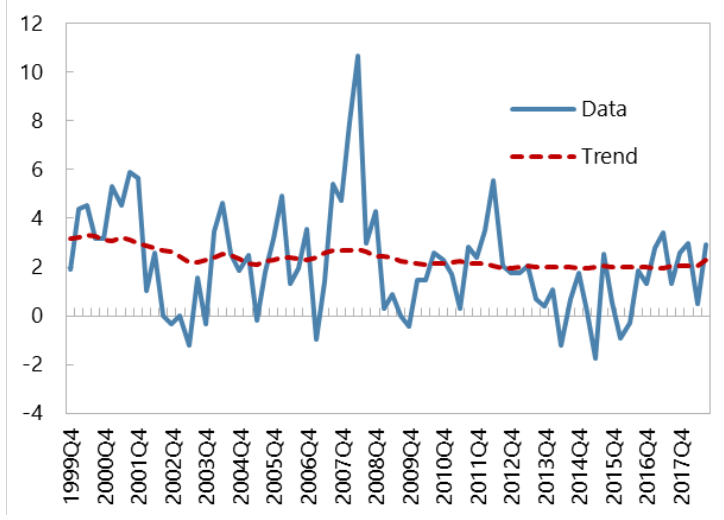

Figure 3. Czech Rep., Term Premium

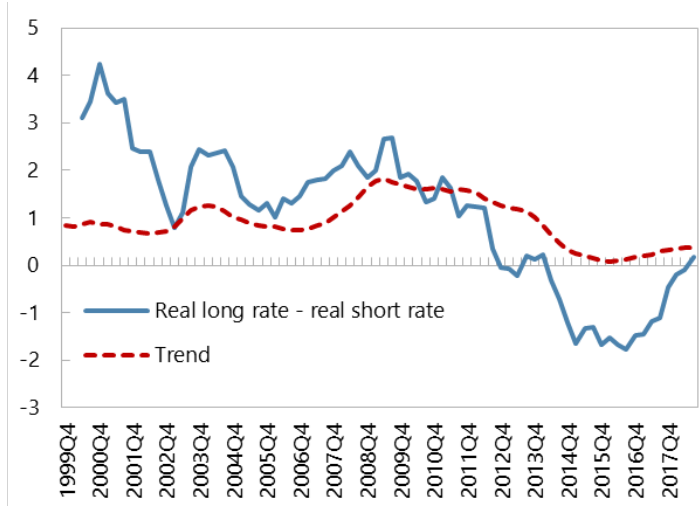

Figure 2. Czech Rep., Real Short Rate

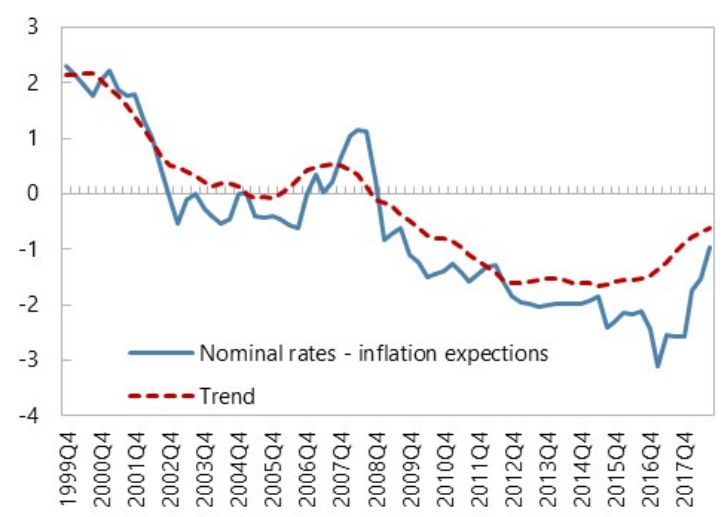

Figure 4. Poland, Inflation

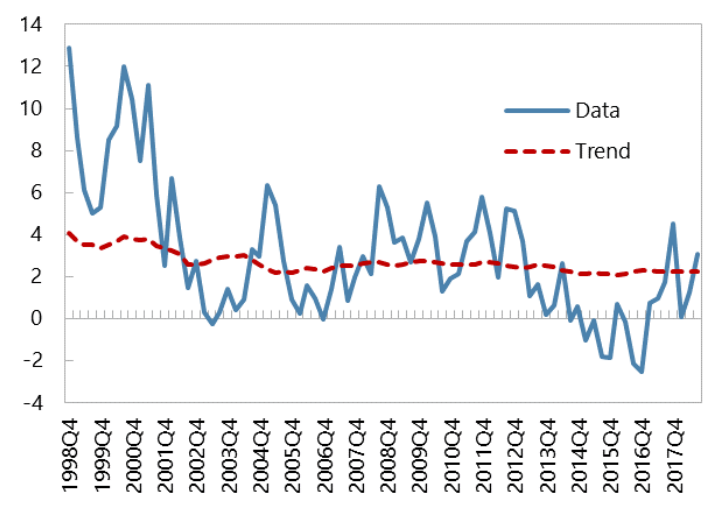




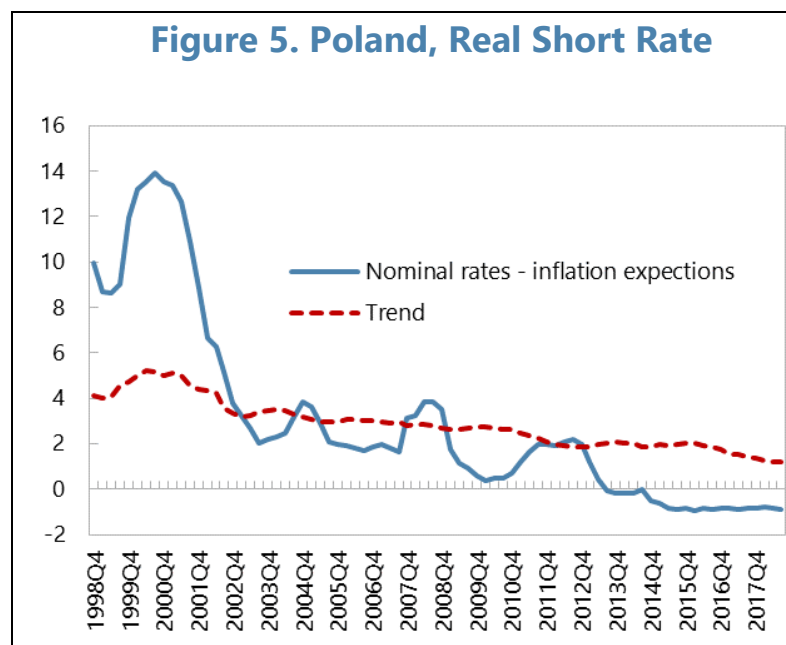

Figure 7. Russia, Inflation



Figure 9. Russia, Term Premium



Figure 6. Poland, Term Premium

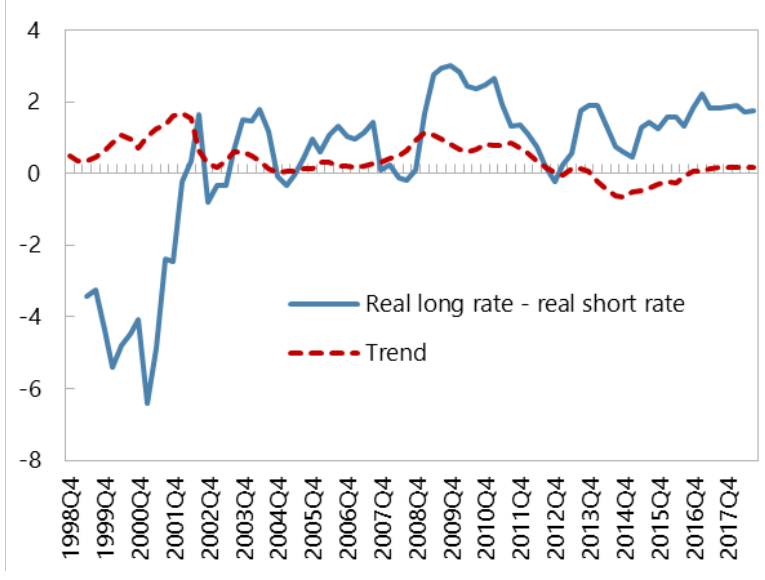

Figure 8. Russia, Real Short Rate

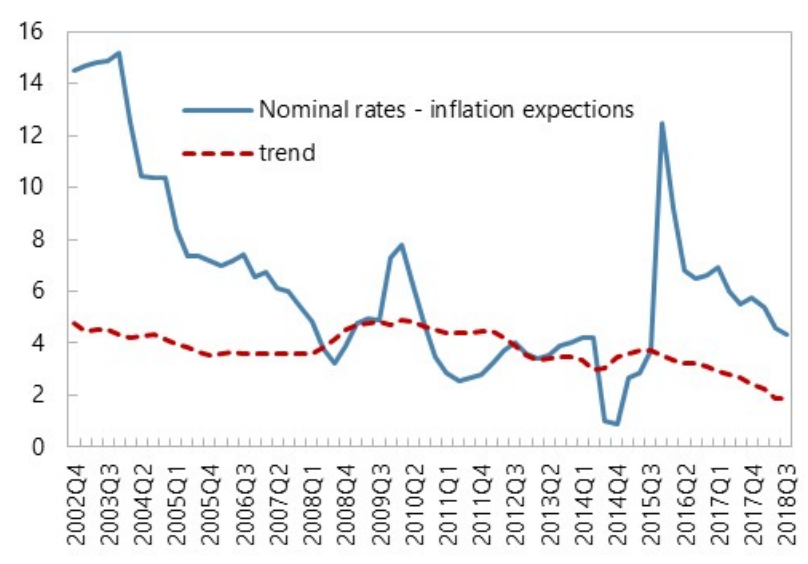

Figure 10. Euro Area, r*

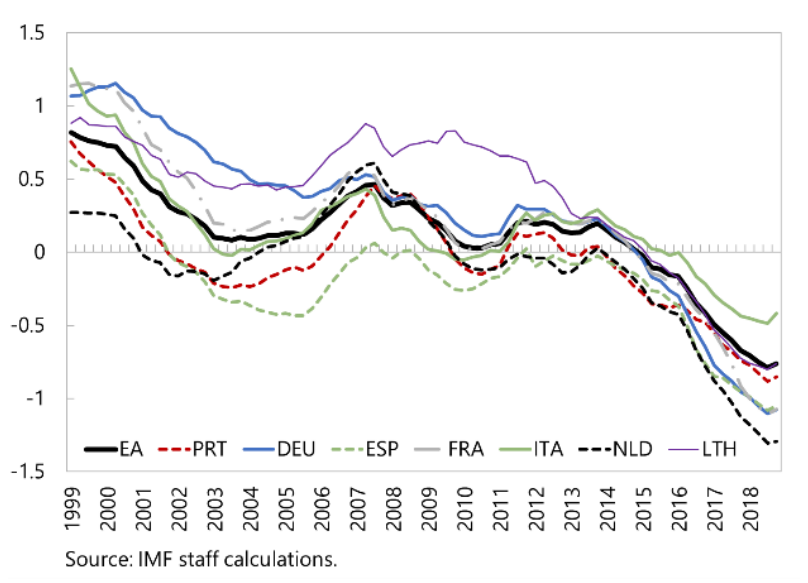




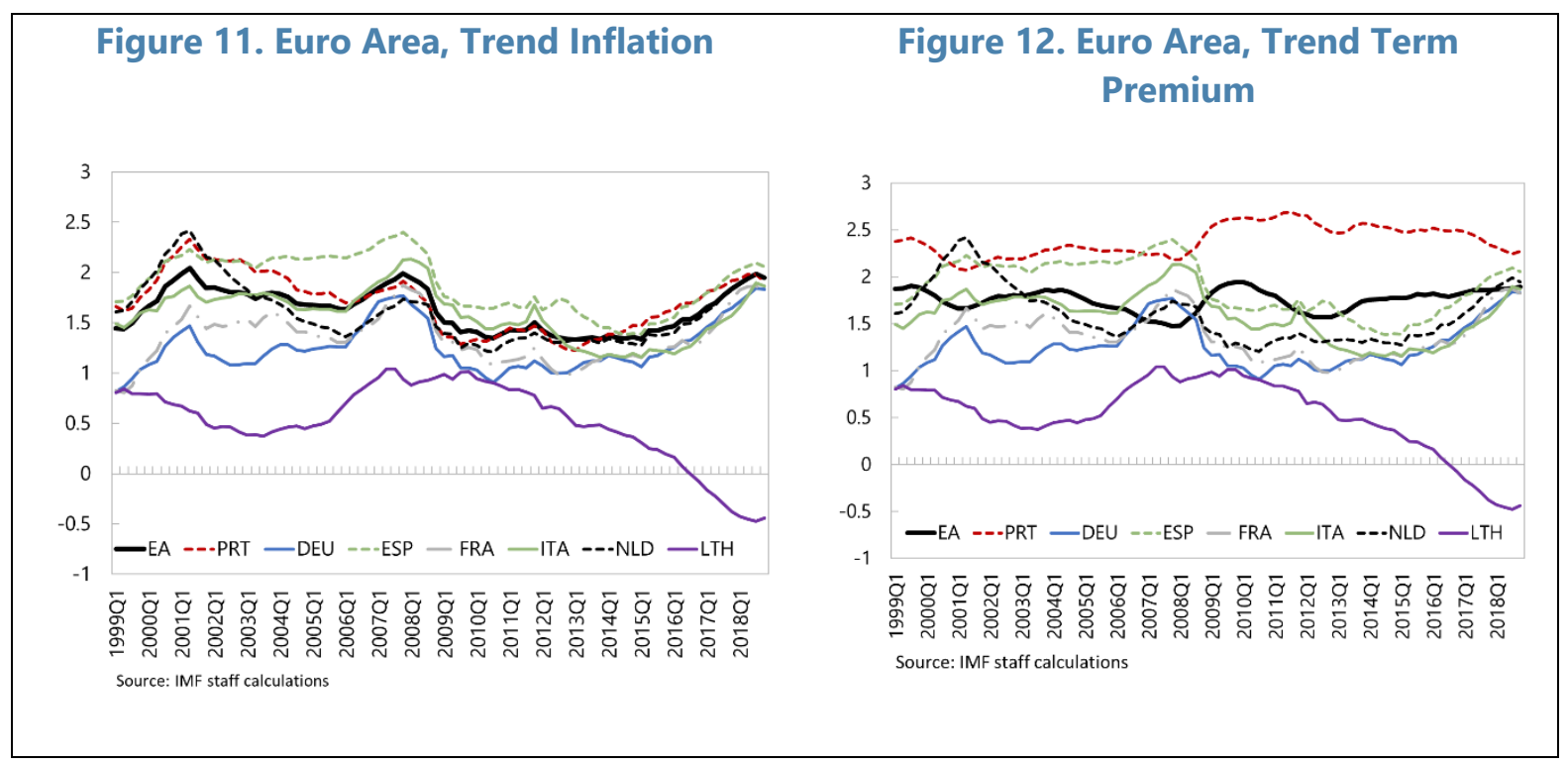

\begin{tabular}{|c|c|c|c|c|c|c|c|c|c|}
\hline \multirow[b]{2}{*}{ Variance of cyclical component } & \multirow{2}{*}{$\begin{array}{l}\text { Prior } \\
\text { All }\end{array}$} & \multicolumn{8}{|c|}{ Posterior } \\
\hline & & Euro & DEU & ESP & FRA & ITA & NLD & PRT & LTH \\
\hline Inflation & 8.0 & 1.7 & 1.69 & 1.26 & 1.44 & 0.87 & 0.87 & 4.15 & 7.40 \\
\hline Short rate & 2.0 & 0.7 & 2.98 & 2.41 & 2.85 & 2.79 & 2.79 & 2.77 & 5.74 \\
\hline Long-rate & 2.0 & $\mathrm{n} / \mathrm{a}$ & 0.41 & 1.38 & 0.59 & 1.35 & 1.35 & 6.79 & 6.22 \\
\hline \multicolumn{10}{|l|}{ Variance of trend component } \\
\hline Inflation & 0.01 & 0.16 & 0.30 & 0.25 & 0.27 & 0.30 & 0.18 & 0.23 & 0.22 \\
\hline Short rate & 0.01 & 0.06 & 0.07 & 0.09 & 0.07 & 0.09 & 0.09 & 0.11 & 0.15 \\
\hline Long-rate & 0.01 & 0.02 & 0.09 & 0.03 & 0.07 & 0.08 & 0.09 & 0.03 & 0.20 \\
\hline \multicolumn{10}{|l|}{ Ratio of cycle to trend } \\
\hline Inflation & 566 & 11 & 6 & 5 & 5 & 3 & 5 & 18 & 33 \\
\hline Short rate & 200 & 12 & 43 & 27 & 39 & 33 & 32 & 24 & 38 \\
\hline Long-rate & 200 & $\mathrm{n} / \mathrm{a}$ & 4 & 55 & 9 & 18 & 15 & 265 & 31 \\
\hline
\end{tabular}




\section{ANNEX VI. BACKGROUND FIgURES AND TABLES}

Figure 1. Natural Interest Rate Decomposition with Z Modelled as a Random Walk

Germany - Components of Natural Rate of Interest

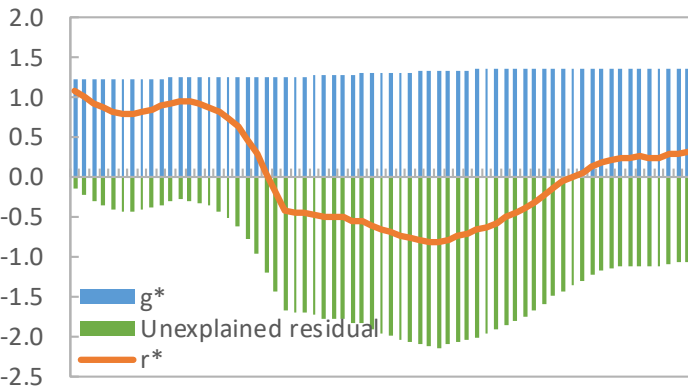



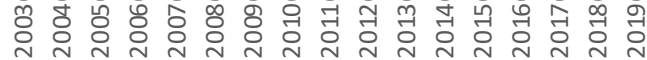

Portugal - Components of Natural Rate of Interest

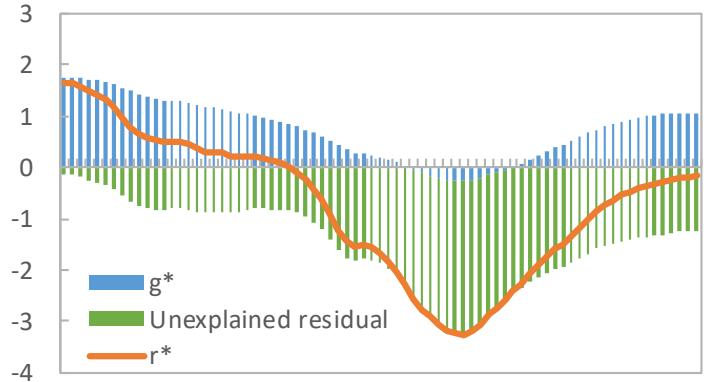

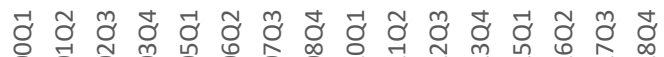



Italy - Components of Natural Rate of Interest

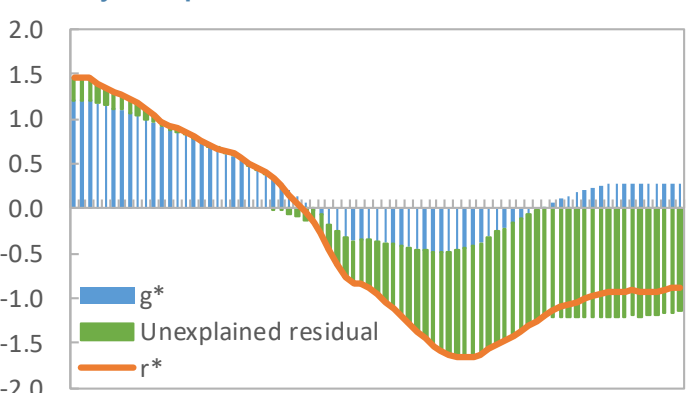

శี ชี ช్

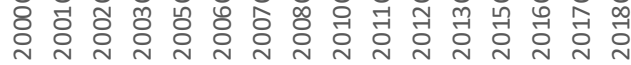

Netherlands - Components of Natural Rate of Interest

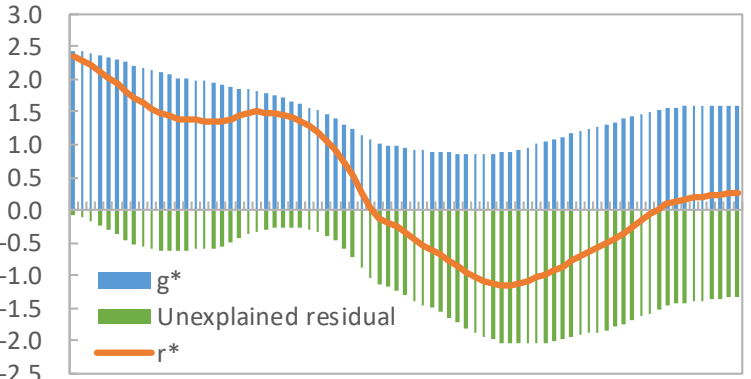

oี

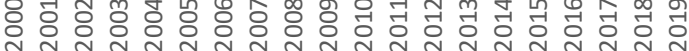

Spain - Components of Natural Rate of Interest



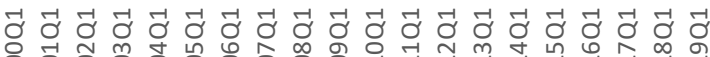

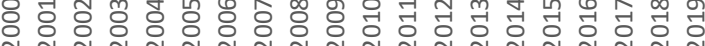

France - Components of Natural Rate of Interest

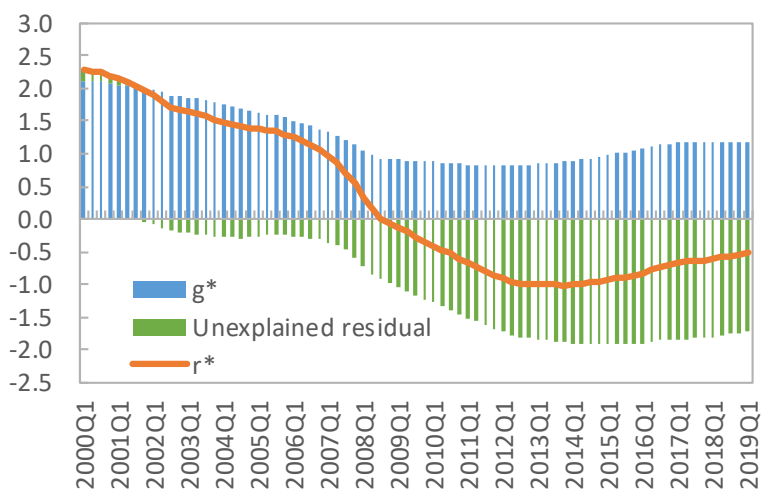

Sources: Authors' calculations. 


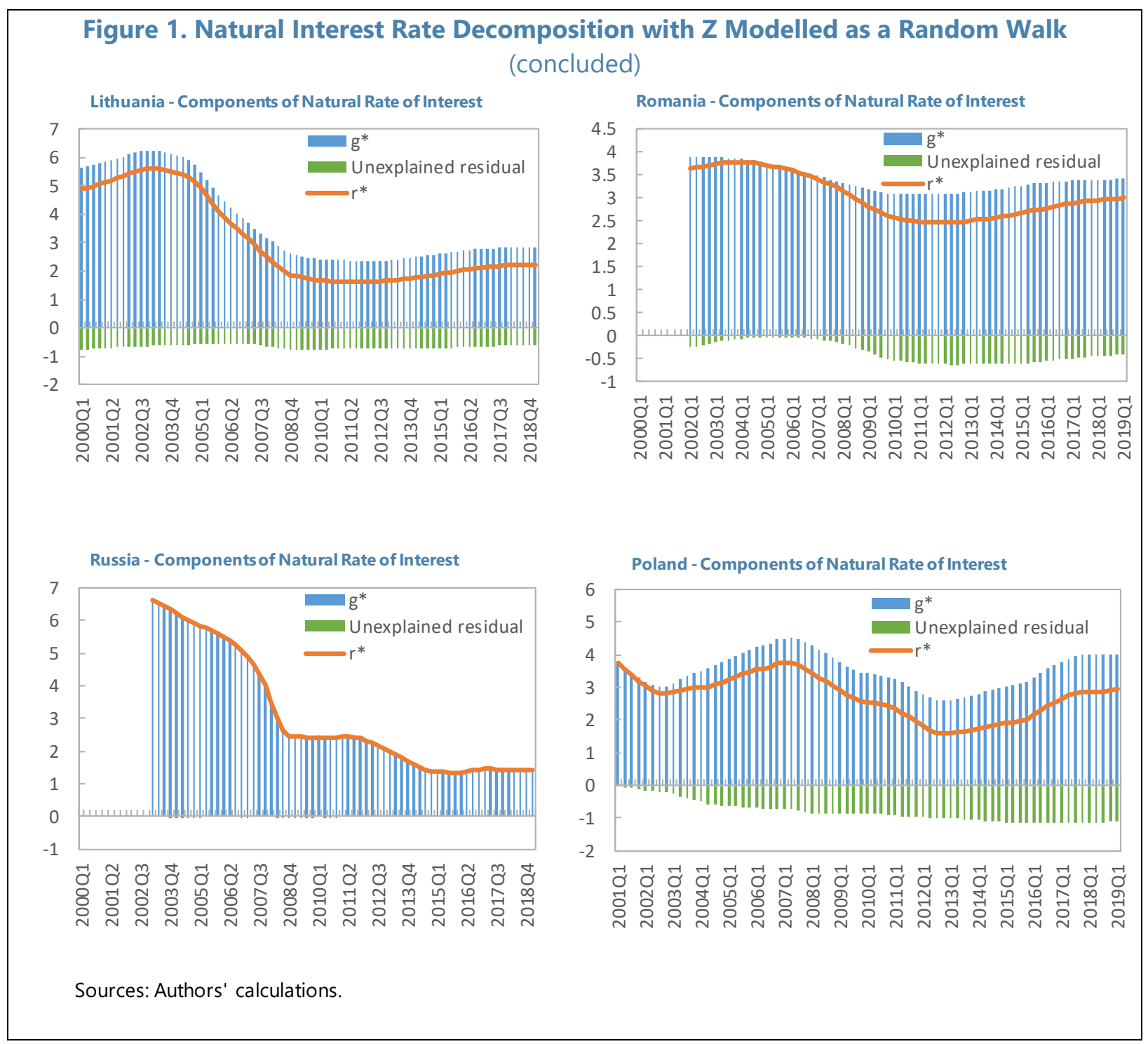


Figure 2. Decomposition of Natural Interest Rate Trend (z)

( $z$ Modelled as a Function of Other Variables: $z=r^{*}-g$ ) 1/

Germany: Decomposition of Z

(Percent; Z process modelled as a function of Spread, External demand, and REER)

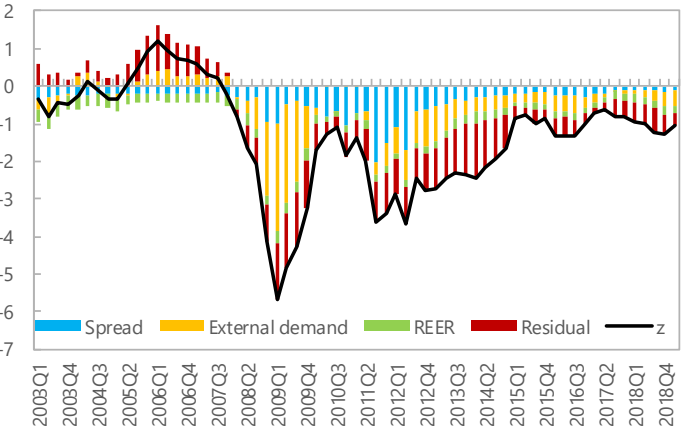

Portugal: Decomposition of $Z$

(Percent; Z process modelled as a function of Spread, External demand, and REER)

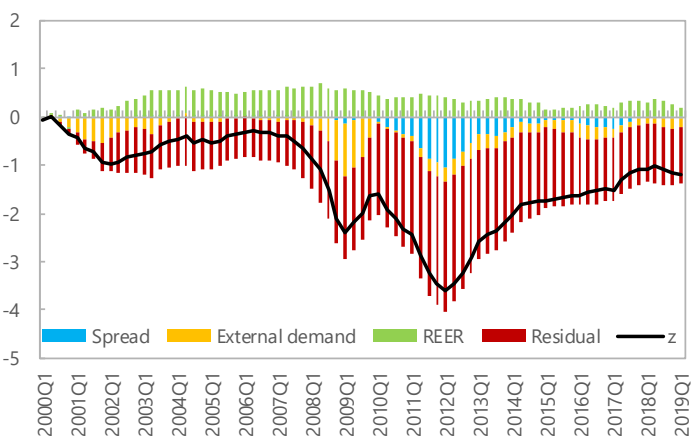

Italy: Decomposition of Z

(Percent; Z process modelled as a function of Spread, External demand, and REER

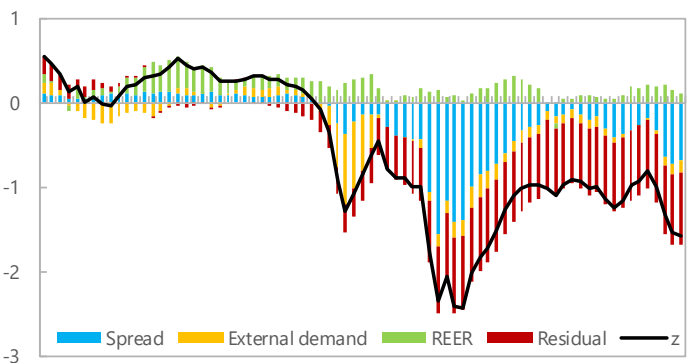



Netherlands: Decomposition of Z

(Percent; Z process modelled as a function of Spread, External demand, and REER)

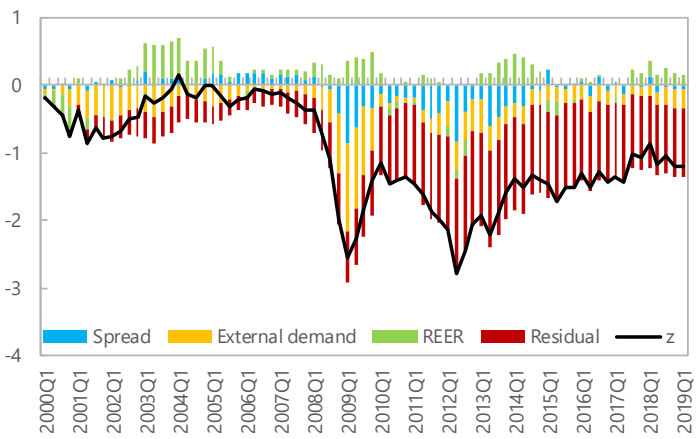

Spain: Decomposition of Z

(Percent; Z process modelled as a function of Spread, External demand and REER)

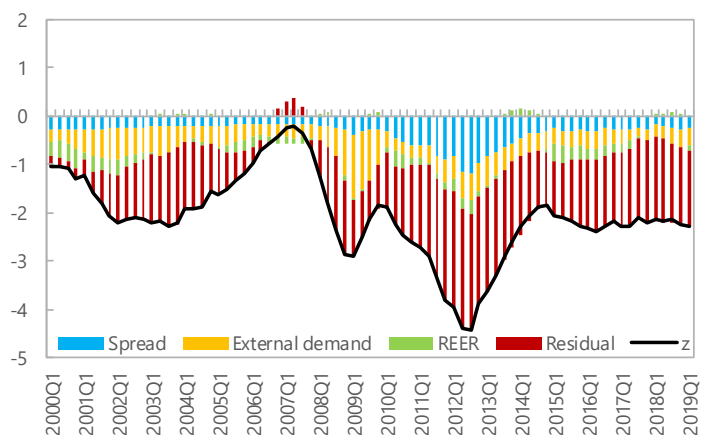

France: Decomposition of $Z$

(Percent; Z process modelled as a function of Spread, External demand and REER)

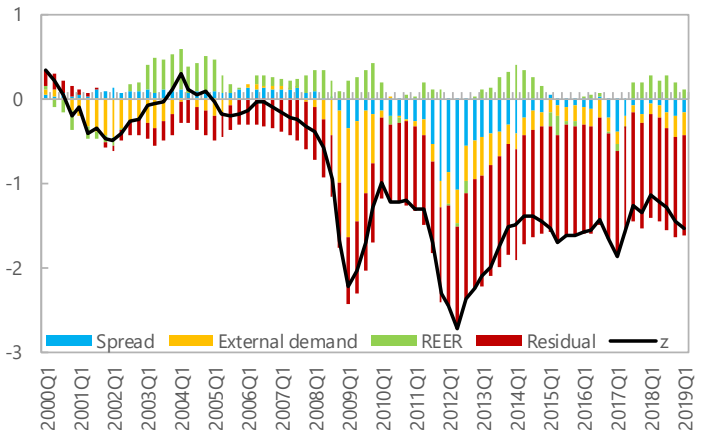

Sources: Authors' calculations.

$1 /$ The contribution of the explanatory variables shows the cumulative contribution over three quarters as each variable and the $z$ process are assumed to follow an AR(2) process. The residual includes the shock to $z$ this period and the lagged residual from the past two quarters. 
Figure 2. Decomposition of Natural Interest Rate Trend (z) (concluded)

( $z$ Modelled as a Function of Other Variables: $z=r^{*}-g$ ) 1/

Lithania: Decomposition of Z

(Percent; Z process modelled as a function of Spread, External demand, and REER)

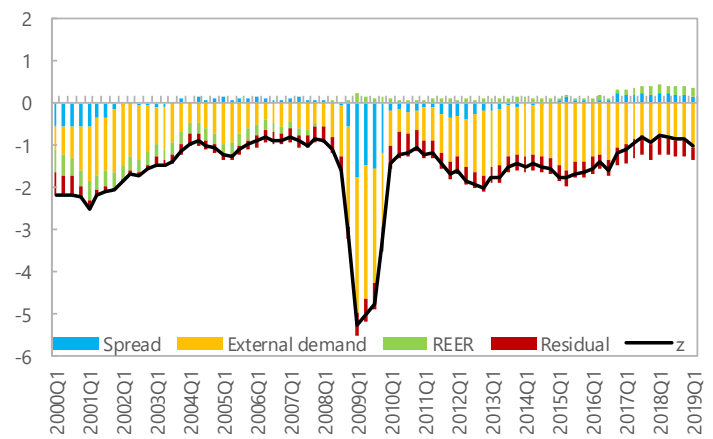

Romania: Decomposition of Z

(Percent; Z process modelled as a function of EMBI, US rate, and Policy uncertainty)



Russia: Decomposition of Z

(Percent; Z process modelled as a function of EMBI, US rate, and Policy uncertainty)



Poland: Decomposition of $Z$

(Percent; Z process modelled as a function of EMBI, US rate, and Policy uncertainty)



Sources: Authors' calculations.

$1 /$ The contribution of the explanatory variables shows the cumulative contribution over three quarters as each variable and the $z$ process are assumed to follow an $A R(2)$ process. The residual includes the shock to $z$ this period and the lagged residual from the past two quarters." 
Figure 3. Comparison of Natural Interest Rate Estimates

Germany - Three ${ }^{*}$ estimates

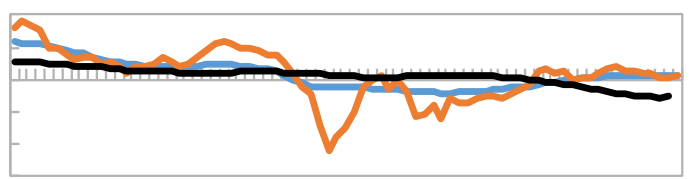

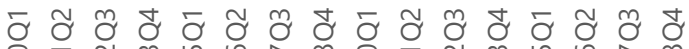
ஓ

$r^{*}$ - LW - z as a random walk

$r^{*}-\mathrm{LW}-\mathrm{z}$ as a function of relevant variables

$r^{*}-$ Del Negro

Portugal - Three $\mathbf{r}^{*}$ estimates

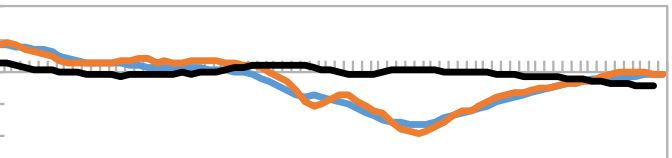

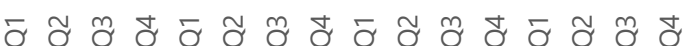



$r^{*}-\mathrm{LW}-\mathrm{z}$ as a random walk

$r^{*}-L W-z$ as a function of relevant variables

$r^{*}-$ Del Negro

Italy - Three $\mathbf{r}^{*}$ estimates

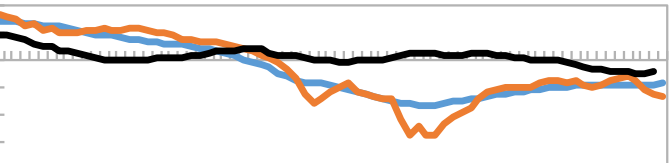

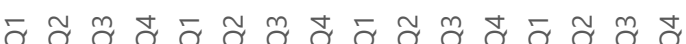

○

$r^{*}-\mathrm{LW}-\mathrm{z}$ as a random walk

$r^{*}-L W-z$ as a function of relevant variables

$r^{*}-$ Del Negro
Netherlands - Three $\mathbf{r}^{*}$ estimates

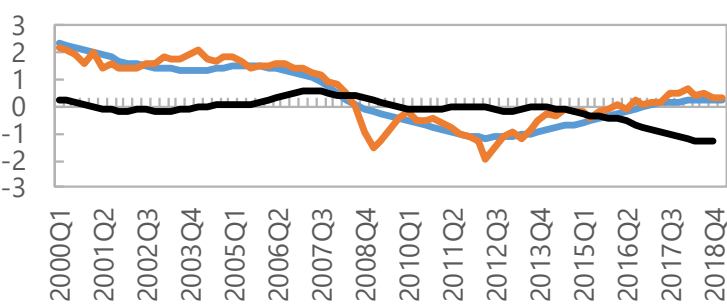

$r^{*}-L W-z$ as a random walk

$r^{*}-\mathrm{LW}-\mathrm{z}$ as a function of relevant variables

$r^{*}-$ Del Negro

Spain - Three $\mathbf{r}^{*}$ estimates



$\bar{\sigma} \approx \tilde{\sigma} \bar{\sigma} \tilde{\sigma} \tilde{\sigma} \bar{\sigma} \approx \tilde{\sigma} \bar{\sigma} \tilde{\sigma} \tilde{q}$

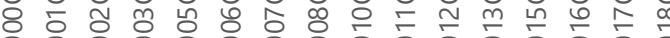

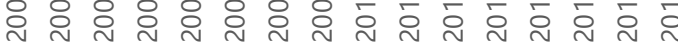

$r^{*}-L W-z$ as a random walk

$r^{*}-$ LW $-z$ as a function of relevant variables

* - Del Negro

France - Three $r^{*}$ estimates

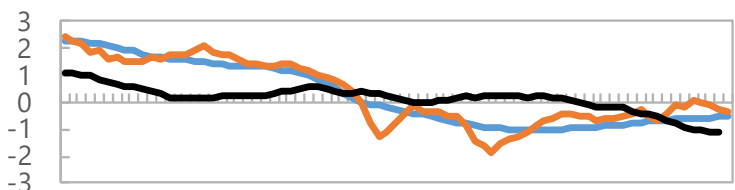

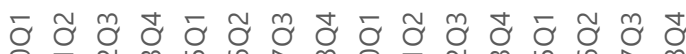
융

$r^{*}-L W-z$ as a rand om walk

$r^{*}-\mathrm{LW}-\mathrm{z}$ as a function of relevant variables

$r^{*}$ - Del Negro

Sources: Authors' calculations.

\section{CInternational Monetary Fund. Not for Redistribution}




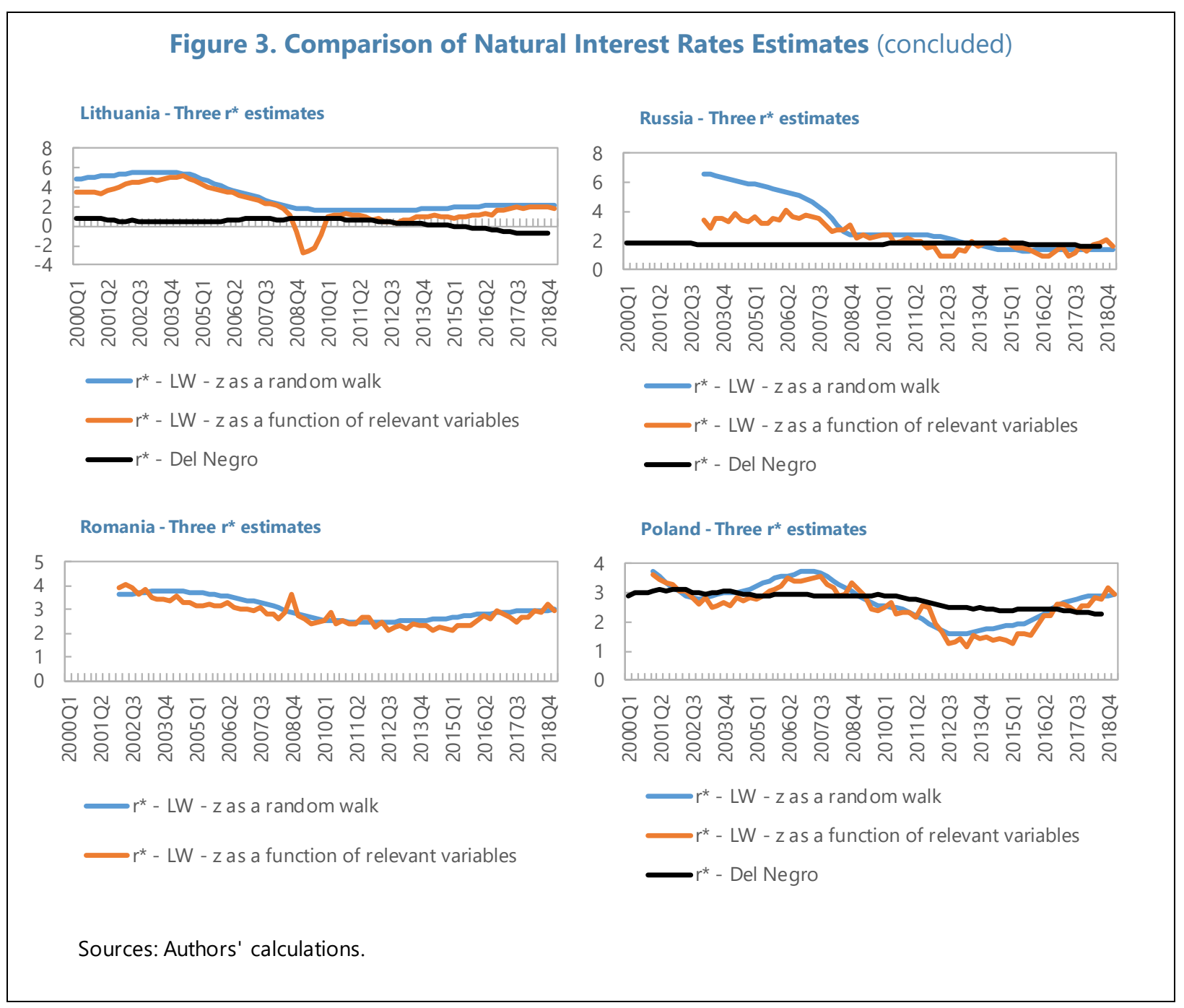

CInternational Monetary Fund. Not for Redistribution 
Figure 4. Monetary Conditions
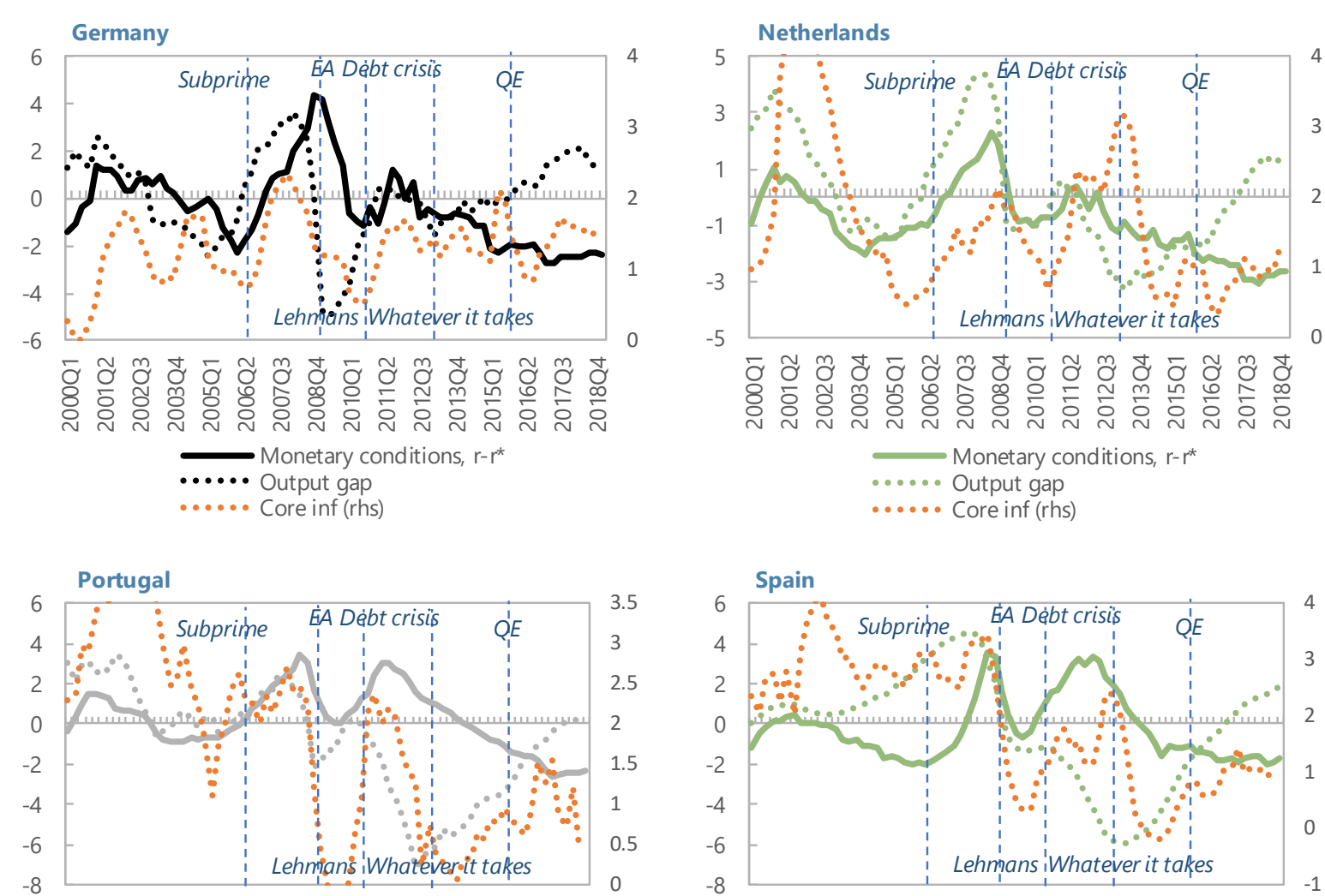

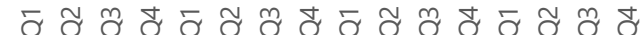

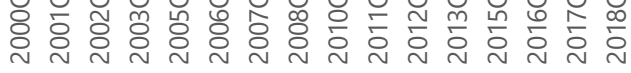
Monetary conditions, $r-r^{*}$ $\ldots$ Output gap ..... Core inf (rhs)

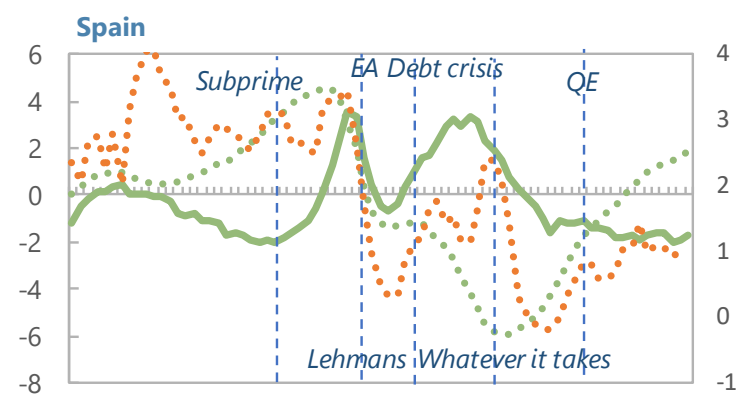

ธ $\widetilde{0}$ ชิ

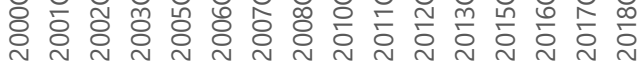
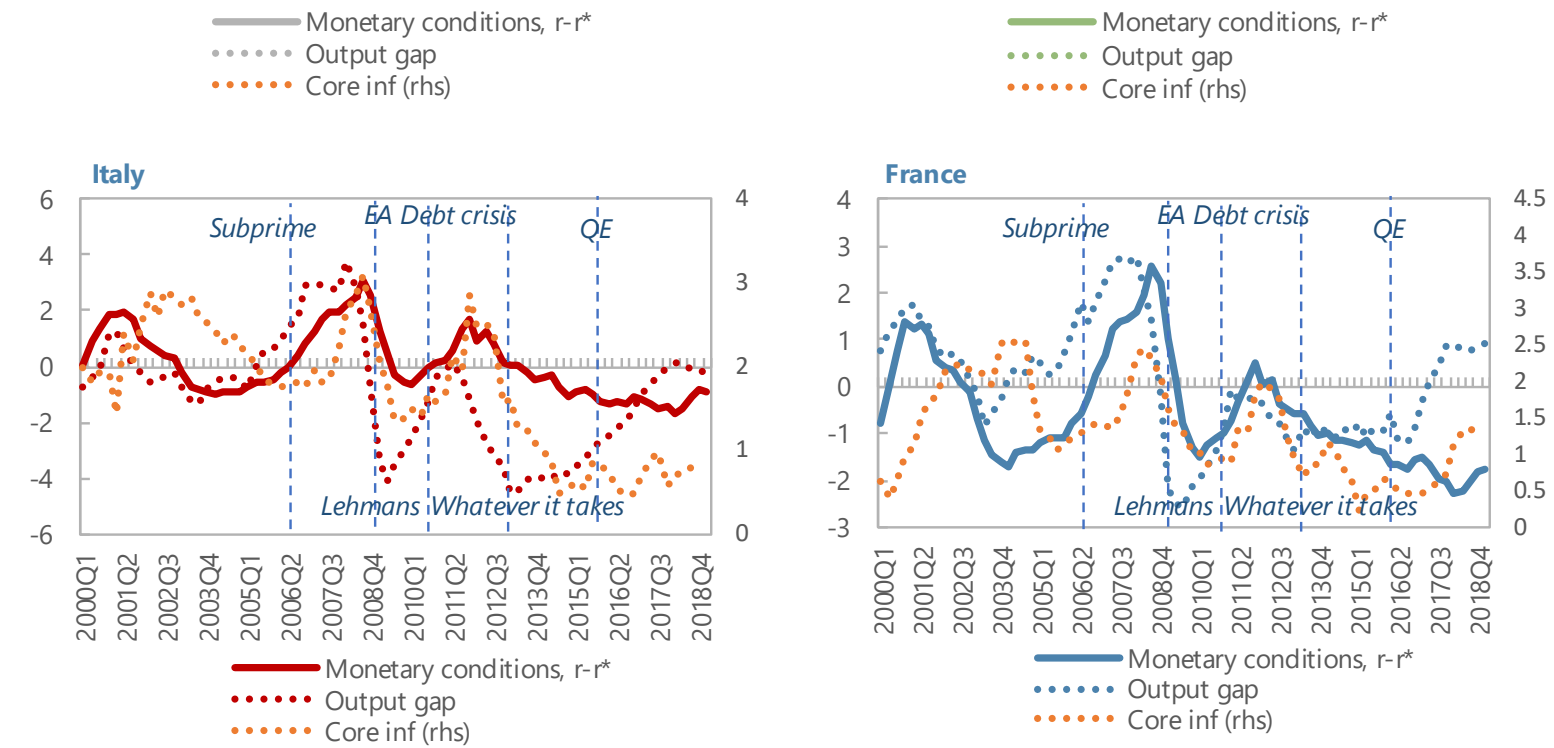

Sources: Authors' calculations. 
Figure 4. Monetary Conditions (concluded)



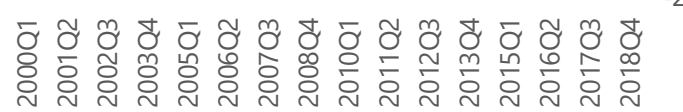

Monetary conditions, $r-r^{*}$

-.... Output gap

..... Core inf (rhs)
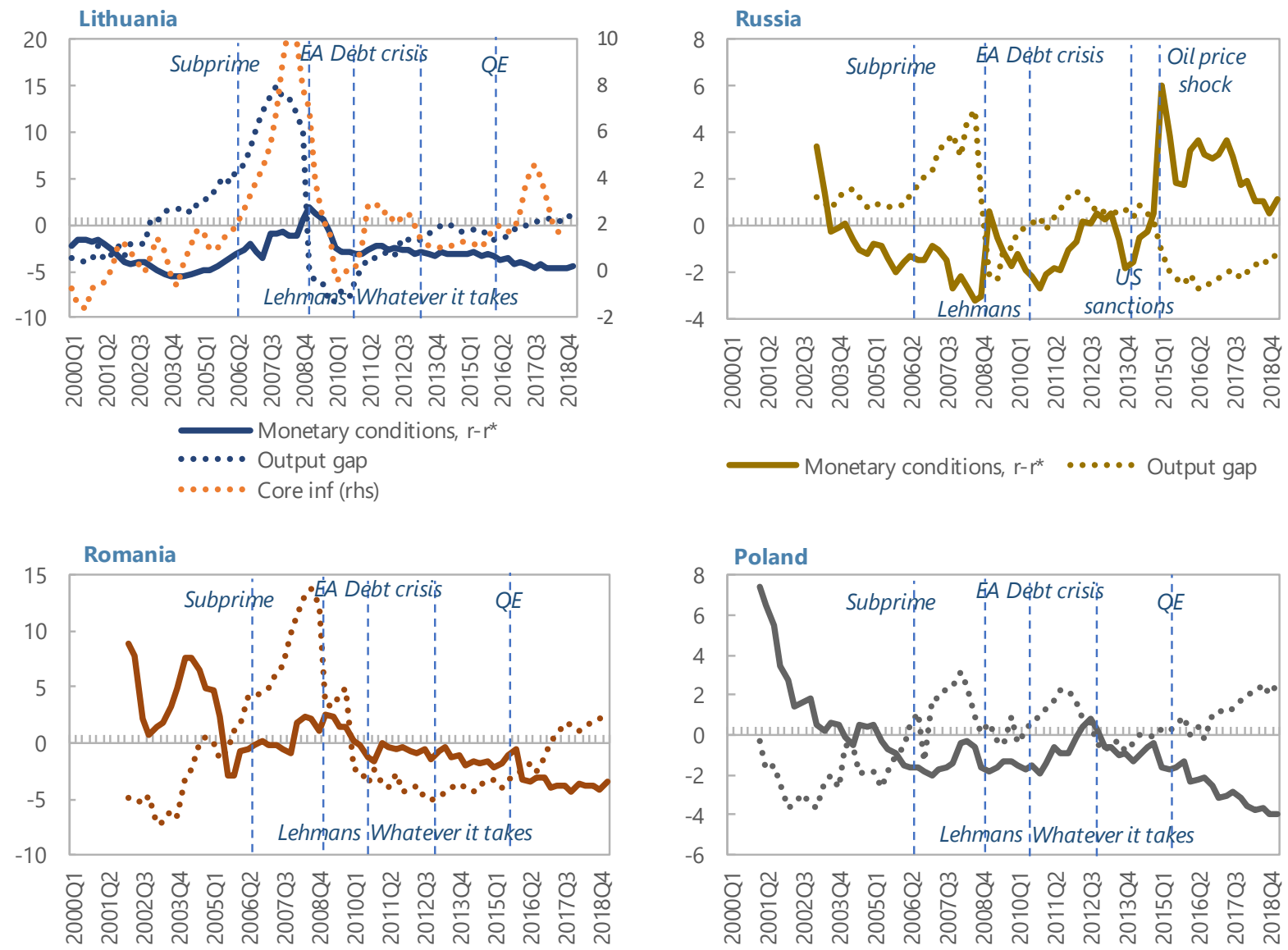

$\longrightarrow$ Monetary conditions, $r-r^{\star} \quad \cdots \cdots$ Output gap

Monetary conditions, $r-r^{*} \quad \cdots \cdots$ Output gap

Sources: Authors' calculations. 